\title{
From closed to open
}

Democratising medical devices using additive manufacture and open source development and distribution systems. 
A 90-point thesis submitted to the

Victoria University of Wellington in fulfillment of the

requirements for the degree of

Master of Design Innovation

By

\section{Callum Allen}

Supervised by

Simon Fraser \& Bernard Guy

Victoria University of Wellington,

School of Design

2019 


\section{Acknowledgments}

I would like to thank the following individuals for contributing their time and expertise to this project.

Project supervisors: Simon Fraser \& Bernard Guy. VUW Faculty of Architecture and Design Innovation.

Opthalmologist: Dr Jesse Gale. Capital Eye Specialists, Wellington, NZ.

Optics, electronics and software engineering: $\mathrm{Dr}$ J. Quilty, H. Colenso, M. Quinton. VUW Faculty of Engineering and Computer Science.

Proof of technical concept: Dr. E. Eldridge, Dr G. Gouws, Dr C. Moore, S. Pathmanathan, K. Polutea, M. Coop. VUW Faculty of Engineering and Computer Science.

This project was funded by the Medtech CoRE NZ. A special thank you to the Wellington free ambulance and the Wellington Rugby club for contributing thei time and resources to this project.

I'd also like to thank Jacob Marsh for continuously going out of his way to help me out, even when he

Finally, I would like to thank my friends and family . 
Table of Contents

Abstract.

Clinical background.

Medicines open source approach..

Methodology.....

Aims and objectives ............................................................ 23

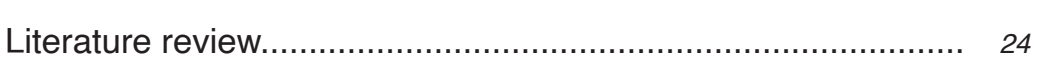

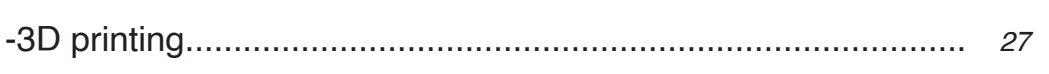

-Distributed manufacture................................................... 30

-Open source products...................................................... 33

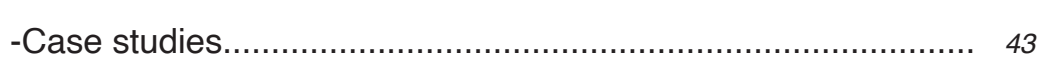

-Conclusion...................................................................... 45

Previous research................................................................ 51

Safety testing and validation............................................... 53

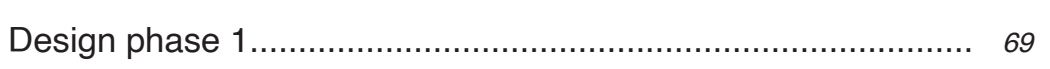

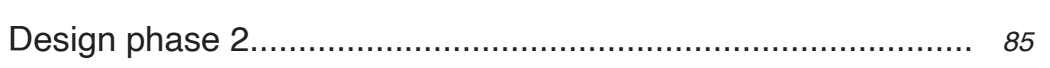

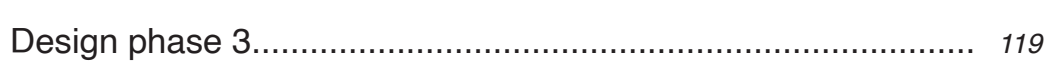

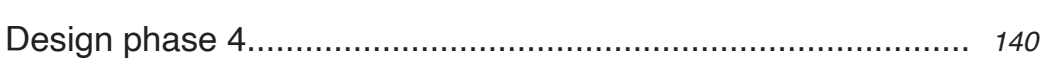

Contextualising the final design.............................................. 148

Navigating the regulatory environment..................................... 150

Discussion................................................................. 154

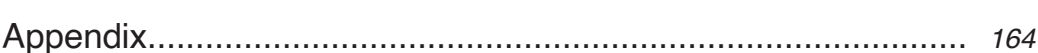

References... 


\section{Abstract}

Pupils can provide important neurological and tumors in the lung (Gale, et al). In a research context, there is increasing interest in studying the intrinsically photosensitive Retinal Ganglion cells (ipRGC), which respond to intense blue light thanks to a photo pigment called melanopsin. Studying sleep disorders and a range of optic nerve diseases.

Although commercially available pupil testing devices do exist, all cost upwards of $\$ 10,000$, and suffer from either poor portability or limitations in the tests they can perform. Specifically, the ipRGC require a specific intensity of blue light to
be activated and measured, which most devices cannot produce.

In recent years, the open source movement has enabled users from around the world to freely collaborate on the development and distribution of their own products. At first, only software could continued improvement of 3D printing technology has enabled the same model to be applied to physical products as well. From a medical perspective, this is particularly exciting.
The aim of this research was to produce an inexpensive, open source pupilometer that iuns on widely avalable components, can be distributed online and manufactured using $3 D$ printing technology. In doing so, this thesis asks the question; How can an open source development and distribution model be used in conjunction with online 3D printing services and widely available parts and components to produce an inexpensive and open source pupilometer?

To answer this, a range of practice based dologies, including research for design and resere through design were used to explore notential.

The resulting design proposal demonstrates how online file sharing platforms, in conjunction with distibuted 3D printing services and online supply chains can be combined to develop or

The ability to collect pupil data using an open source upilometer may lead to expanded data collection diagnostic capabilities from doctors in number of clinical settings, while a cloud based data cop will crem taking the form of a smartphone co will create a large biometric database and 


\section{Situating the research}

Clinical background

The function of the pupil is to regulate the amount light that enters the eye, acting similarly to a camera to describe the pupillary constriction that occurs in 2013).

The PLR may have first been described scientificall by Charles Henry in 1896, when he observed the pupils of fish would contract at the approach of a candle (Henry, 1896), but the constriction of pupils to light has been observed throughout human history. The neurological basis of the PLR is clearly understood, with a minority of the optic nerve fibres projectling to the midbrain, and activating neuro which lead back to the iris sphincter muscle.

The optic nerve fibres arise from cells in the inner retina called retinal ganglion cells. In recent years, there has been growing interest in a small group of intrinsically photosensitive retinal ganglion cells
(ipRGC) (Bailes \& Lucas, 2010). These ipRGC (ipRGC) (Bailes \& Lucas, 2010). These ipRGC receive input from retinal cells like other retinal ganglion cells, but they also have their own photo pigment called melanopsin, which allows them to respond to blue light in the absence of retinal photo

These ipRGC are interesting for numerous These ipRGC are interesting for numerous academic reasons, and they appear to serve the non-conscious visual funclions such as circadian nerve fibres which go to the midbrain and generate the PLR are largely these interesting ipRGC. Stimulating the melanopsin pigment using a blue light causes the ipRGC to remain active for several seconds, so the pupils may remain very small in the dark after a bright blue light has been turned off (the post-illumination pupil response, PIPR).

The PLR is an important signal in general practice, emergency medicine, neurology, ophthalmology, toxicology, anaesthesia and paramedical assessment. Most clinicians do not use any more advanced technology than a simple torch and ruler to measure pupils and test PLR. However, increasing academic interest in the pupils led to the development of the pupilometer in the early 1960 (Larson \& Singh, 2016). A pupilometer is a device used to measure pupil size under a variable light stimulation or in the dark, enabling clinicians to more-consistently stimulate and measure the PLR under standardised conditions.

modern research where the ipRGC are of particular inerest, the ability to produce intense as the PIPR (Post enables researchers to quantify (p)

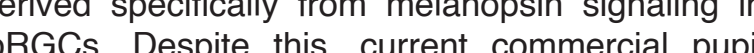
paCs. Despite this, current commercial pupil deve blue light required to genonse, making them unsultable tor researchers studying ipRGC. Electrophysiology equipment can produce the blue light required to by high costs and poor portability.

In a primary care setting, pupilometers could clinicians to diagnose pupil asymmetry when assessing neurological problems (which may whe brain aneurysms, impending strokes, lung

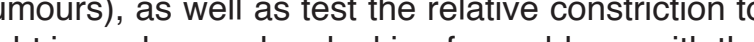
ight in each eye when looking for problems with the clic nerve. Whi more development, pupilometers could be used in research on circadian rhythms, and there is emerging interest in pupil signals trodegeneration such as Alzheimer disease.

Although pupilometers have improved dramatically since their inception, costs have remained high. Currently, portable pupilometers cost approximately Con times more than a pen torch, he most common it Fitzorald, 2018). A cha mald mey have application in a range of research

and in many primany care settings prach as mbulances, emergency departments and family practices (Gale et al, 2017).

The ability to collect pupil data using an open source pilometer may lead to expanded data collection and diagnostic capabilities from doctors in a a smartphone chill create a large biometric dabase and cooperative online research community. 


\section{Medicines open source approach}

The medical field has a strong culture of sharing mportant knowledge for the greater good of humanity. It is believed that this culture was established at some point in the 4th century BCE, when the Greek Physician Hippocrates and his students established a set of set of ethical standards for physicians that later became known as the Hippocratic Oath (Isaac history, the oath has been adapted and updated to better reflect the state of society at that particular point. On October 14, 2017, a newly revised version Assocument wat Association (Parsa-Parsi, 2017). Included in the newly revised

"I WILL SHARE my medical knowledge for the benefit of the patient and the advancement of healthcare"

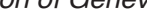
2017

Perhaps the best modern example of a clinician that embodied these values was the Late Fred Hollows. Hollows was a New Zealand Ophthalmologist who studied medicine at the University of Otago in the 1950 's. After finishing his studies, he moved to Australia in 1965, where he visited several indigenous communiles. Hollows was shocked by the pour stanimus particularly the incidence of infectious but easily fulfillod Profise Otago Magazino, University of Otago, New Zealand,"n.d.).
In 1968, Hollows began lobbying for funds, and between 1976 and 1979 the National Trachom and Eye Health Program was established, treating the eyes of 100732 people; 62116 of these were . The success of this program led to several more eye health programs in Eritrea, Nepal, and Vietnam, which have since restored the sight of thousands.

During the 1980s, Hollows worked with the World Health Organization in developing countries across Asia. Once again appalled at the lack medical resources and the prevalence of avoidable blindness that he winessed, Hollows developed a range of new techniques for performing basic cataract operations, better suited to low resource settings. To make the required equipment more accessible, he set up laboratoies in Nepal and Enirea to manufacture low cost plastic lenses, enabling local doctors to restore sight at a fraction of what it would cost in the developed world. Today, the same laboratories produce millions of lenses, with some of the proceeds reinvested in training local eye doctors and nurses ("Vision fulfilled, Profiles, Otago Magazine, University of Otago, Ne Zealand," n.d.)

Fred Hollows died on 10 February 1993 at the age of 63 years after a brave battle with kidney, lung, and 'brain cancer. Doctor Hollows was renowned for his 'boots on the ground approach to helping the most vulnerable members of society, and had a strong the last year of his life, Hollows began planning found year of his lie, Hollows began planning to come. That could con thue his legacy for years in more than 25 countries and has restored sight to over two million peope worldwide "“Fred's Story, Vision and Legacy I The Fred Hollows Foundation NZ," n.d.) 


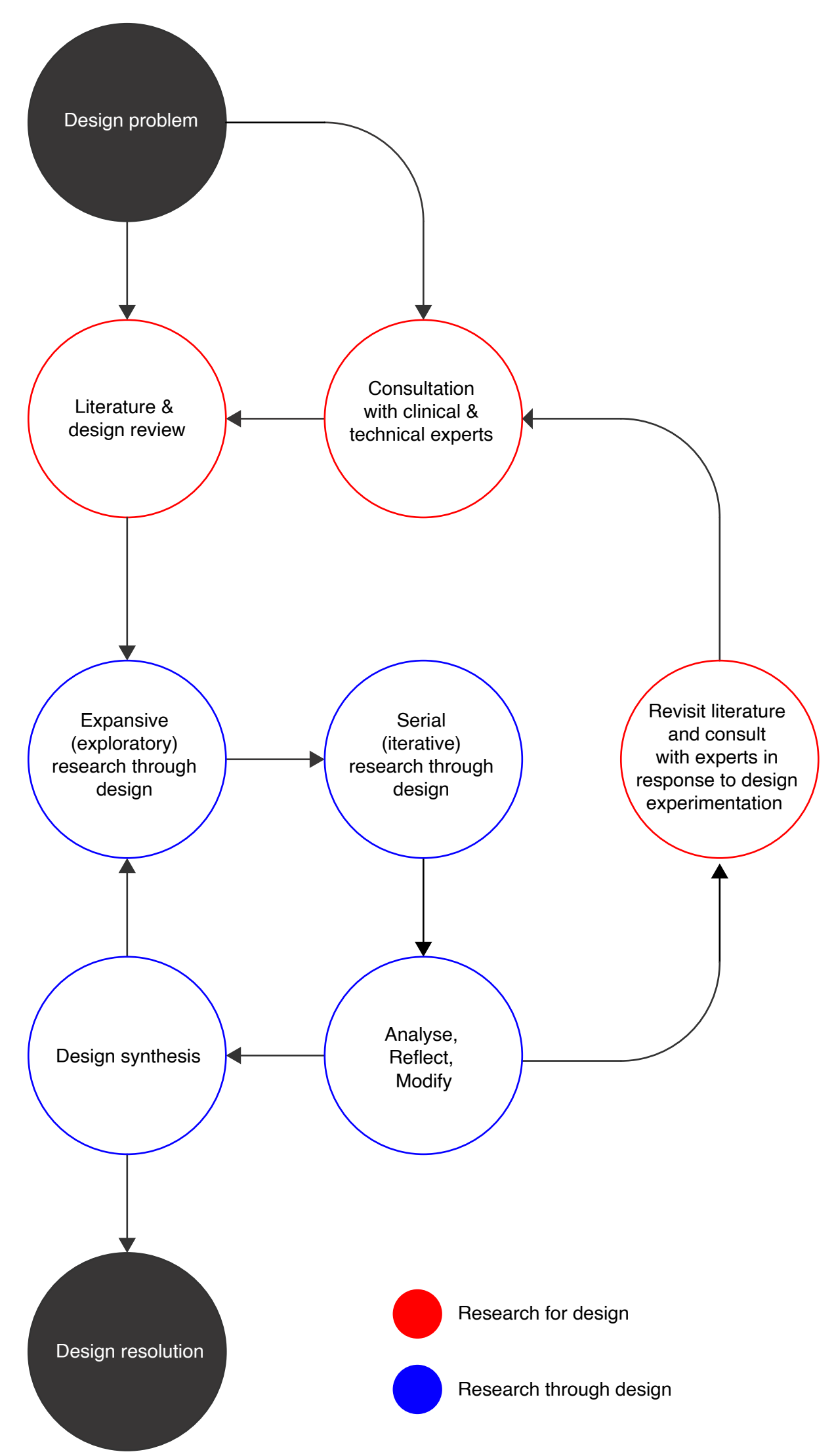

\section{Methodology} Frayling (1993) breaks design research down is produced based on the insights gained from into three main categories. Research into design, previous iterations, which in turn inform subsequent (esearch through design and research for design. generations of the design (Krogh, Markussen, \& This thesis employed research for design and Bang, 2015). In the context of this thesis, seria methodologies.

Research for design.

The first phase of this thesis involved research for design. Downton (2003) defines research for design as the research area that provides the information, mplications and the data that can be applied to achieve an end result in a design project. Downton refers to this process as 'research to enable design'

The research for design phase of this thesis involved conducting a literature and design review (Hanington \& Martin, 2012) to gain a contextual overview of additive manufacturing, distributed manufacturing, apen source development and distribution models and relevant design precedents. Another aspect of the research for design phase came in the form of input from the wider design team working on

the project. This included technical input
engineers, and clinical input from $\mathrm{Dr}$ Gale.

\section{Research through design}

The second phase of this thesis involved research through design. Hanington \& Martin (2012) define (esearin research method, where designers generate new knowledge through the design process itself. Expansive design research is an aspect of research hrough design used to reveal previously unknown knowledge to the designer, similar to how a \& Bang, 2015). Expansive reserch trough desin, configuration that can be easily $3 \mathrm{D}$ printed and

manufacluing sevice forproducing thepuplometer.

several methods, including sketching, CAD modelling, sketch modelling and 3D printing to iteratively produce pupilometer prototypes, where he findings from each new iteration informed the

\section{allel prototyping}

A long standing criticism of the iterative design ' A locess is that designers can become fixated on Pa a Mrev, 2012). One method that can be used to parall prom happening is parallel prototyping. Par protying is the act of producing a range bevaling the In the contoxt of this thack or an expert evaluation. conduct ater the inis, paralle protolyping was to expled alter the inital iterative design stage and configurange of different ergonomic forms comfortab for the user to pick up and hic chonds whilo the user to pick up and hold in their while at the same ticke ensund hold in their

The final stage of the design process involved ptimising the device based on the findings from e ergonomic and form studies carried out during e parallel prototyping stage. The goal of this stage whic wability and aesthetic refinement into a design sembled.

. 
Table 1. The aims, objectives, methods and design tools used within this thesis.

\section{Aims \& objectives}

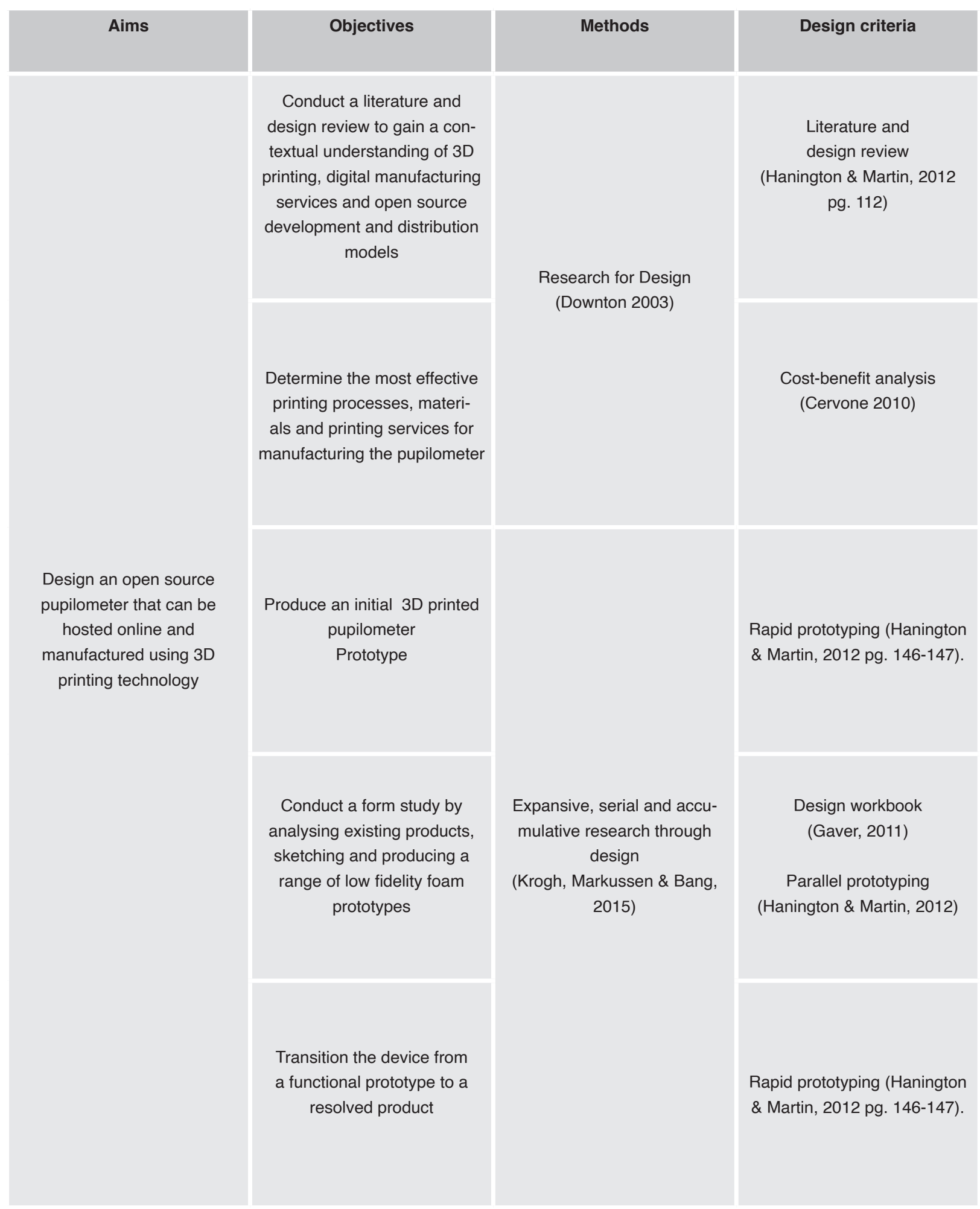




\section{Literature review}

Introduction

The purpose of this literature review is to understand the issues distribution of an open source pupilometer (and a wider context, medical devices in general) using distributed 3D printing services and widely available

This research will investigate $3 \mathrm{D}$ printing as a method of manufacture and identify any potential contexts where 3D printing may be more functionally suited or cost effective than traditional methods of manufacture. This research will also investigate the pupilometer digitally via an online file hosting platform, where users from around the world can download the files, manufacture the pupilometer services and assemble the device themselves.

Finally, this research wilinvestigate the advantages and disadvantages of developing open source products in comparison to products developed using traditional proprietary models. To achieve this, several open source case sudies wil be examine to identhy the advantages and disadvantages of implementing an open source development and distribution model in comparison to tradition proprietary development models.

This research aims to identify the most effective ays in which an open source development De used in conjunction with distributed printing services to design and manufacture to bust, inexpensive and accessible pupilometer the can be digitally distributed to clinicians around the Internet. 
continued technological improvements combined with lower associated costs have prompted an explosion of growth around the 3D printing industry 3D (3 Dimensional) printing is an additive in the 21st century. Today, 3D printers are used in a a digital model known as a CAD (computer-aided of producing complex structures using a variety of design) file (Berman, 2012). 3D printing differs from materials, other manufacturing processes because it bonds and even chocolate (Michalski MH \& Ross JS, materials together on a layer by layer basis. This is 2014).

in contrast to traditional manufacturing techniques,

which usually build structures by cutting, molding, There are several advantages to $3 \mathrm{D}$ printing when or otherwise manipulating raw materials (Michalski compared to other manufacturing methods. Firstly, MH \& Ross JS, 2014)

The first 3D printer was conceived by Charles Hull, manufacturing methods. Like the name suggests,

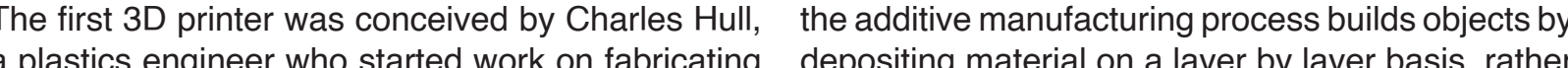
plastics engineer who started work on fabricating depositing material on a layer by layer basis, rather plastic devices from photopolymers in the early then cutting away excess material. This mean 1980s. Tired of the lengthy fabrication processes the additive manufacturing process uses only the available at the time (up to two months), combined required amount of material necessary to produce with the high probability of design imperfections the desired object (Prince, 2014). The additive which would then require several further iterations process also allows parts to be built with geometric to resolve, Hull started thinking of ways to improve complexities that could not be formed using othe the prototyping process. In 1984 he developed manufacturing processes (Prakash, Nancharaih, \& the SLA (Stereolithography) 3D printing process, Rao, 2018).

which he then patented in 1986 (U.S. patent No.

$5,174,931,1986)$. With Hull's work, in addition Secondly, there are no initial tooling requirements to the development and subsequent patenting of associated with additive manufacturing. Processes DM (Fused Depositon Modeling) by Scott Crump such as injection molding often requite inlial moulds 10 manut in manulacluring industry. Inilally, the 3D printing of dollars, and stil require the product to be mass process was used primarily to prototype designs
before they entered mass production. However,
In comparison, additive manufactured products require only a digital CAD file containing the dimensional data of the design. This data is split into layers by a computer, which can then be interpreted and constructed by the printer (Prakash, Nancharaih, \& Rao, 2018). The lack of tooling requirements associated with the additive process means that small or even one off production runs of highly customisable objects can be produced at affordable costs (Berman, 2012)

Despite these advantages, 3D printing still suffers from a range of limitations. For example, some additive manufacturing processes require support material to be produced around the object being manufactured. The support material acts like a
scaffolding, providing a platform for the nozzle scaffolding, providing a platform for the nozzle to build steep overhangs and complex internal
structures, and can be difficult to remove during post structures, and can be difficult to remove during post
processing. In some instances, support material can even distort the surface texture of the final object.

Another disadvantage is mass production costs. To $3 \mathrm{D}$ print an object, the cost per object is still high in comparison to items produced using mass
manufacturing methods such as injection moulding. manufacturing methods such as injection moulding. However, if only a small number of objects are
required, 3D printing is the cheaper option. Using a comparative analysis, Franchetti \& Kress (2017) is more cost effective for small or

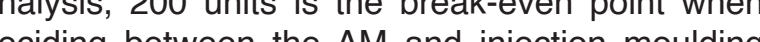
(Feen the AM and injection moulding (Franchetli \& Kress, 2017). This makes producing low numbers of an object.

or 3D printing to be competitive with traditional mass manufacturing methods such as injection moulding, expe applicalions that provide an advantage in either cost, quality or time must be identified. For xample, using 3D printing as a prototyping tool is the moulding, due to the lack of tooling requirements, the speed of the 3D printing process and the abilty to produce highly customisable one off objects.

By leveraging $3 \mathrm{D}$ printing technology in such a way lso enables seamless work flow integration from the folyping stage of the design process through to the final produclion inn As such forms this project.

(n)


Table 2. Services offered by Online $3 D$ printing plattorms.

\begin{tabular}{|c|c|}
\hline Service & \multicolumn{1}{|c|}{ Description } \\
\hline Design supply & $\begin{array}{c}\text { Designs files created by the plattorm } \\
\text { are offered (for free or for a fee) to } \\
\text { customers. }\end{array}$ \\
\hline Design hosting & $\begin{array}{c}\text { Plattorm hosts third-party designs } \\
\text { that are sold (marketplace) or of- } \\
\text { fered free of charge (repository) }\end{array}$ \\
\hline Design customisation & $\begin{array}{l}\text { Designs (own or third-party) can } \\
\text { be customised (e.g. shape, size, } \\
\text { layout) by users. }\end{array}$ \\
\hline Co-design service & $\begin{array}{l}\text { Assistance offered to consumers } \\
\text { when designing a 3D object, gen- } \\
\text { erally by transforming two-dimen- } \\
\text { sional sketches or pictures into a 3D } \\
\text { object. }\end{array}$ \\
\hline Design & $\begin{array}{l}\text { Users can crowd source a design } \\
\text { by posting a detailed project that } \\
\text { is then developed further by the } \\
\text { crowd. }\end{array}$ \\
\hline crowdsourcing
\end{tabular}

\section{Distributed manufacture}

In the industrial age, proprietary development models and mass production were relied on heavily to make products economically viable (Smith \& Mortati, 2017). In the 21st century the emergence of the Internet and 3D printing technologies have enabled users to begin designing and

manufacturing their own products independently.

New online manufacturing pathways that include To maximise efficiency and convenience, severa both distibuted networks of printers as well as services are often integrated into a single digita online 3D printing services are enabling users to platform. For example, Shapeways is an online 3D design, develop and then produce one off or small printing service that offers a combination of design production runs of their own products at affordable hosting, design customisation and 3D printing costs. In doing so, users can bypass the traditional services ("Shapeways - Create Your Product. Build mass manufacturing model that requires enormous Your Business," n.d.). Shapeways manufacturing amounts of equity to produce tooling molds, and facilities are located in the United States and the relies heavily on an 'economies of scale' approach Netherlands, however their website allows users o be profitable.

The first well known digital manufacturing platform Ponoko Ponoko, was established in 2007 and based in the size and scale of their design, troubleshoot printWrillington clity, New Zealand. Ponoko ofered 3D abilty issues and select which material they would printing and laser cutting services that could be like to print with. In 2011, Shapeways shipped nearly accessed thigh a browser based user inter ace 750,000 pans worldwe, in materials ranging from

Note. From Co-creation and user innovation: The role of online $3 D$ printing plattorms, by Rayna, Striukova, \& Darlington.

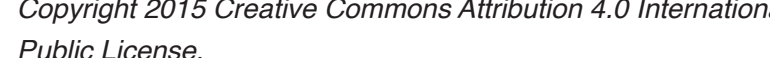
then, several dozen services following the same \& Simpson, 2013). 

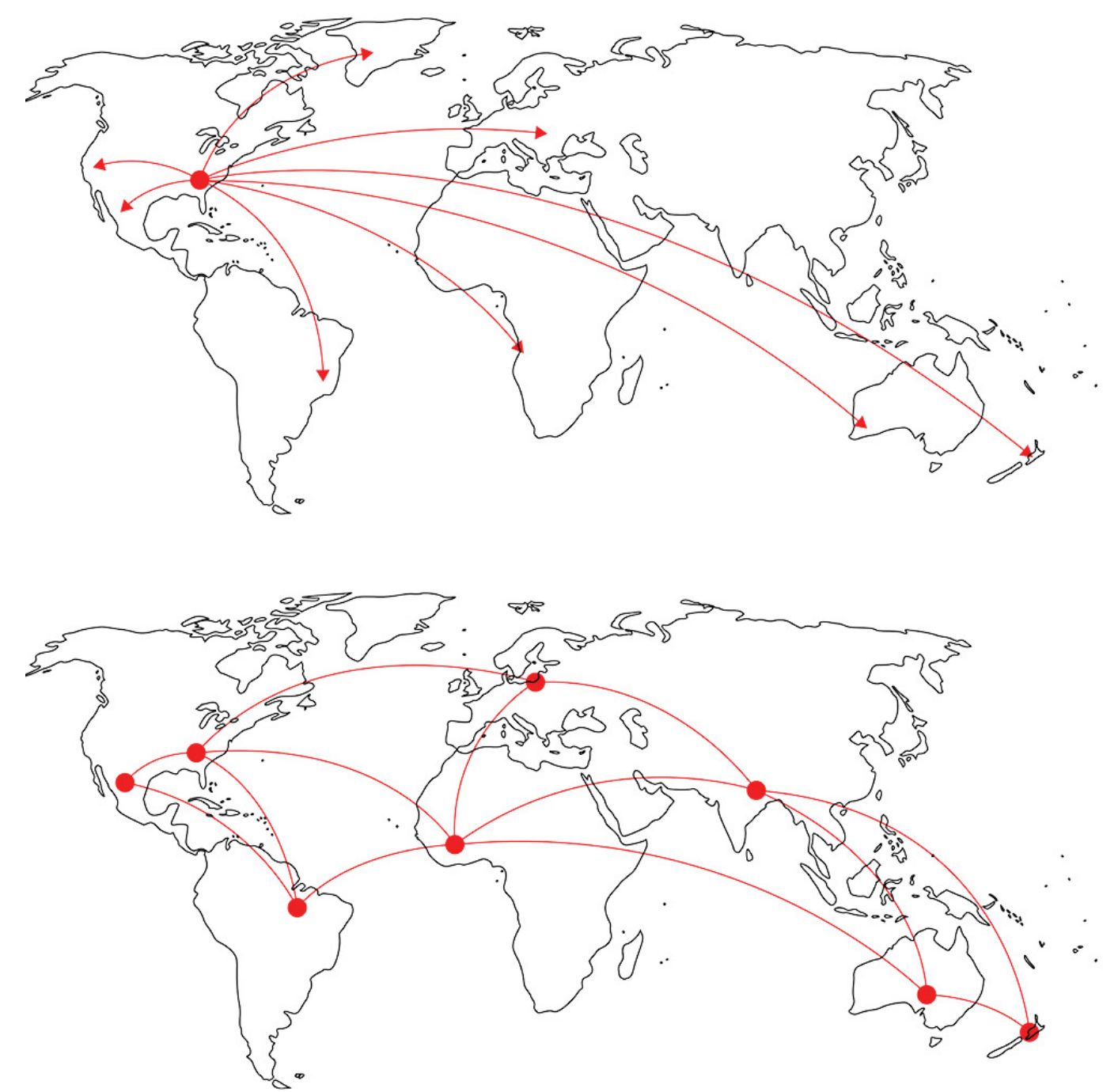

Figure 3. Diagrams showing the differences between a distributed manufacturing network and a centralised, online 3D printing service.
Another prominent online $3 D$ printing platform is engineers and designers as they have the strongest 3D hubs. Up until February 2018, 3D hubs was a need for on-demand parts, but we've learned tha global network of manufacturing hubs, with services part of this group is hestant to use our original peerconnected in over 140 counties (JD Hubs. Local to peer open marketplace as there's no guarante Manufacturing I 3D Printing \& CNC Machining," on the quality and timeliness of parts" "3D Hubs," n.d.). 3D hubs business model was an example of 2018). 3D hubs new system now relies on a select a distributed manufacturing network, described by few manufacturing partners that are required to Kühnle et al (2015) as "A manufacturing network, adhere to a set of strict quality standards, allowing whose functionality and performance is independent the company to support customers in even the mos of the physical distance between the involved regulated industies. 3D hubs change in business systems, units and elements". 3D hubs provided model suggests that 3D printing technology is not a crowdsourced 3D printing service, supplying the yet sophisticated enough to support a consistent digital infrastructure that faclitated transactions and reliable peer to peer system. Although the between 3D printer owners (Hubs) and customers distributed manufacturing model holds great that wanted to print their own designs (Rayna, potential, machines capable of producing high Striukova, \& Darlington, 2015)

There are several advantages to the distributed manufacturing model; one being lower logistics . costs. After decades; of decline, logistic costs are

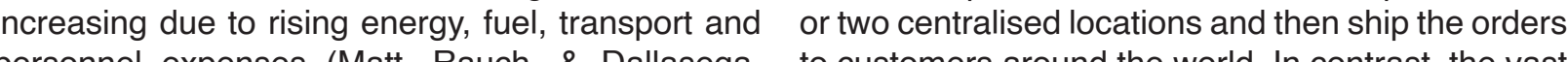
2015). Dxpenses (Matt, Rauch, \& Dallasega, to customers around the world. In contrast, the vast 2015). Distrbuted manufacture mitigates these majorty of printers avallable to individuals looking to issues by manufacturing products closer to their set up small distributed manufacturing hubs are only final destination. This in turn reduces the distance capable of producing low resolution parts, making it a product is required to travel, resulting in lower hard to compete with the quality and consistency overall costs and a reduced carbon footprint (Petrick of larger additive manufacturers. Despite its \& Simpson, 2013). Time from production to sale is current limitations, distributed manufacture holds also reduced, whilst providing local communities great potential in terms of affordable low volume with the means to manufacture and repair hheir own production. As industry competition continues $\begin{array}{ll}\text { products, which may one day lead to a more circular to increase and the technology itself continues } \\ \text { economy (Attaran, 2017). } & \text { to improve, Attaran (2017) predicts the price of }\end{array}$

(2017) predicts the price 3D printers will continue to decrease. This rise in

Although the peer to peer approach appeared to be qually at the core of 3D hubs business model, he service oblain 3D printers capable of producing industrial with a cloud based manuacturing service In a blog more reliable and robust distributed man macturing post, 3D hus founder Bam de Zwart explained noter. 
Facilitated by distributed additive manufacturing services and the increasing communicative powe of the Internet, networks of individuals now have the ability to design, manufacture and distribute the own open source products (Smith \& Mortati, 2017). model that exploits the distributed intelligence (Kont of participants in Internet communities (Kogu model originated with software development, where people would share pieces of code with each other across the Internet, and collectively collaborate to develop software further (Kogut \& Metiu, 2001). This development model is known as OSS (Open source software). The open source development software has been so successful that it now serves source hardware) (Pearce, 2017).

According to the Open source hardware associatio (2016) "Open source hardware is hardware whose design is made publicly available so that anyone can study, modify, distribute, make, and sell the desig or hardware based on that design. "In recent years, developing $\mathrm{OSH}$ has gained significant traction as an alternative to purchasing traditional equipment in a range of diterent contexis. One reason for this is cost. The implementation of an open development and distribution model can lead to technically of equipment developed privately (Pearce, 2017). This is because once the initial development of the product is complete, the digital CAD (Computer Aided Design) files of the device can be uploaded users using online file hosting services such as Github (The world's leading software development platform - GitHub," 2019). From here, the design files of the device can be downloaded for free and manufactured using online 3D printing services, distributed manufacturing networks or using personal 3D printer. This scaled replication saves 90-99\% on conventional costs, making equipmen cheaper and more accessible (Pearce, 2014).

A good example of open source hardware is the Arduino microcontroller ("Arduino - Home," n.d.) Arduino is a small, inexpensive microcomputer with an easy-to-use development environment that makes it an ideal starting point when developing more complex electronic products. It has a large online network of supporters, as well as community generated open software libraries available to simplify many tasks (Niezen, Eslambolchilar, \& Thimbleby, 2016). The low costs, strong support networks and wide availability of the Arduin microcontroller have all contributed to its success, pint open source Pi ("Teach Le most notably the Raspbery $\mathrm{Pi}$ ("Teach, Learn, and Make with Raspberry Pi - Raspberry Pi," n.d.). Because the Arduino and the Raspberry Pi micro processors both run on open source soltware, implementation can result in improved device longevity, as users can cren after the in even after the initial development phase has been with and Raspberry Pi instead of a lectronics can save considerable time and money during the development stage of a product, while improving product life expectancy.
Smartphones \& the Internet of things

The Internet of things describes the increasing interconnectivity between electronic products or 'things' that are able to interact and communicate with each other wirelessly to simplify tasks or achieve a common goal (lera, Floerkemeier, Mitsugi, \& Morabito, 2010). The touch point (ititerally) of the Internet of things is the smartphone, a device that can be used to control the other products via a wifi or bluetooth connection.

There are a number of advantages to designing open source products to be compatible with smartphones. In doing so, less built in components need to be included in the product isell. Instead, products can be designed to leverage the built in hardware of the smartphone via a bluetooth or wifi connection. For example, if an open source product requires a screen and a user interface, instead of integrating a screen into the hardware of the device and coding a user interface, it may be a better and user interface of the users smartphone. This and user interface of the users smartphone. This software perspective. much higher quality screens then what is available on the commercial open source marketplace
This, combined with the familiarity and widespread dopton or smartphones today make the device

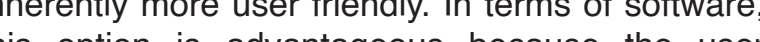
the option is advantageous because the user (n) . pocing so, the need for any complex installation proser in the device remotely from their smartphone. This strategy reduces the amount of required components, saves money on development costs,

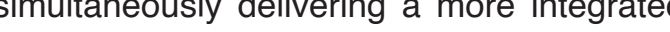
and user friendly product.

fering a companion app to be used in conjunction with a physical product also presents severa . One way this can be done is by giving away the CAD a the device for free so users can source and a smbl their own device at no cost, but charging a small fee to download the app. Variations of this a e able to run the app, providing addilonal app dverts from within the app (Pearce, 2017)

If users do not possess the time nor the technical abilities to source and assemble the device abe pre-assembled device for an additional fee. 


\section{Case studies}

Open source products are typically developed as an alternative to an existing product that is hard to obtain due to high costs or limited resources, and are becoming increasingly popular in a range

of different contexts. The following case studies leverage 3D printing technology, widely available components and/or smartphone integration to deliver an inexpensive and accessible alternative to an existing product. 
This content is unavailable. Please consult the figure list for further details.

Figure 4. oDocs visoscope. Retrieved November 5, 2018, from https://web.archive.org/web/20190713104307/http://www.odocstech com hisoscope/

\section{Case study 1: oDocs eyecare} oDocs (Smartphone Ophthalmosc Smartphone retinal camera," 2016) is a $\mathrm{Ne}$ Zealand based social enterprise established in 2014 by Dr. Hong Sheng Chiong and Dr. Benjamin O'Keeffe. ODocs main focus is the design and distribution of a range of cell phone attachments that transform any smartphone into an ophthalmologic tool capable of capturing high resolution images of the human retina (Smartphone Ophthalmoscope \& Smartphone retinal camera," 2016). One of oDocs products is the visoscope. The visoscope is a $3 \mathrm{D}$ printed Ophthalmoscope that can be purchased che oDocs webstle. Allonnatively, clinicians an download the design thes or the device for free and 3D pint their own visoscope using online 3D Service I Shapeways," 2019). By designing the visoscope to be compatible with most smartphones, visoscope to be compatible with most smartphones, oDocs mitigated the need for the device to include
any complex electronics of its own. Instead, oDocs created a free smartphone application called oDocs \& Smartphone Retinal Camera," 2019) The application acts as the interface of the device allowing users to access the phones camera and capture images of the patient's retina. Image data can then be examined from the phone, exported a computer or sent to a colleague for further analysis. oDocs open source approach enables

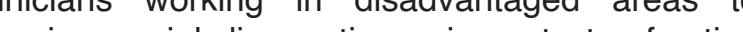
acquire cructal diagnostic equipment at a fraction of the cost of premium equipment. For example, expex (Hong, 2015), while the oDocs visoscope costs approximately $\$ 325.00$ USD to purchase pre assembled from the oDocs website (visoscope Smartphone Ophthalmoscope \& ( e visoscope can be 3D printed for approximately (100.00 USD using online 3D printing services such 政 evice themselves. 


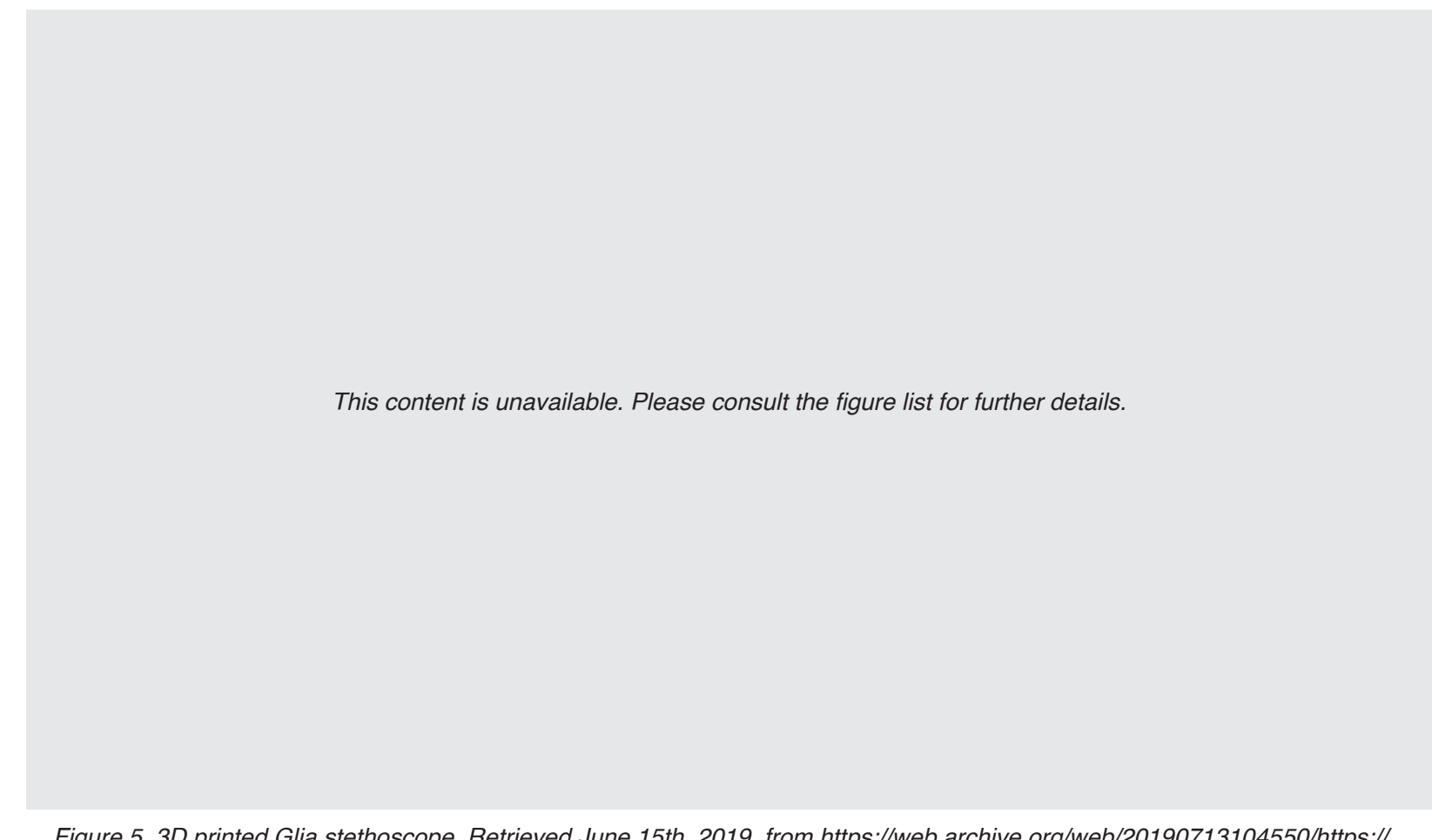

newatlas.com/glia-model-3d-printed-stethoscope/53811/
Case study 2: The Glia Project.

Another example of a project focused on producing open source medical equipment is the Glia Project. Glia is a social enterprise that focuses on the develops is of inexpensive, open source medica devices that can be manufactured in low-resource settings using 3D printing technology. According to the Glia project website ("Glia," 2019)

"If low-resource communities can access the equipment they need via an open source model, hey are empowered to troubleshoot problems, customize designs to meet their needs and share
their findings with others. The ability to share their findings with others. The ability to share successes in an open-access environment allows and avoid duplication of work and long feedback and avoid duplication of work and long feedback cycles. This model allows off-patent devices to exist exerts downward pressure on prices for high-quality premium brands."
Glia's most popular device is the Glia stethoscope. ordern stenoscopes can be an expensive part of the physician's required equipment, costing approximately several hundred US dollars. The Glia tethoscope is a low cost, 3D printed alternative premium stethoscopes that costs under three S dollars to produce (Pavlosky et al, 2018). The CAD files for the stethoscope are available through file hosting services such as Github (The world's leading software development plattorm, Gittub, 2019) and can be downloaded by anyone for free. components can then be $3 \mathrm{D}$ printed using Frinter and assembled by the user. The device does require add tional components such asearbuds and silcone when wasty online. When tested, the Glia stethoscope was found to perform at the same level as expensive premium devices and has been deemed a class 1 Felcal device according to Health Canada, and the Food and Drug Administration (FDA; Pavlosky et al, in the. Currently, the stethoscope is in clinical use in the London Health Sciences Centre in Canada as well as hospitals on the Gaza stip (Pavlosky al, 2018). 
This content is unavailable. Please consult the figure list for further details.

Figure 6. E-nable raptor prosthetic hand. Retrieved June 14th, 2019, from https://web.archive.org/web/20190713104807/ https://3dprint nih gov/sites/default/iles/models/additional images/arge_IMG 4824.JPG
E-nable ("Enabling The Future," 2019) is an online, with low cost 3D printed alternatives to tradition prosthetics, which ated alternatives to traditional consuming to produce. Enable began in 2013 when a South African carpenter reached out to lvan Owen after watching a video he posted online of a mechanical puppet hand he had built for a costume "Building an Online Community: Jennifer Owen," 2017). After receiving several more requests for prosthetic digits, Ivan posted his designs in an online forum, and asked others to help improve the design. Today the E-nable communty is made up of teachers, students, engineers, scientists, doctors, designers and antists who collaborate to develop and manufacture a range of open source prosthetics hands. The community also includes a
distributed network of $3 \mathrm{D}$ printer owners who $3 \mathrm{D}$ print prosthetics for amputees in their area, meaning users without access to a 3D printer can still receive a custom prosthetic. To ensure E-nable prosthetics are as accessible as possible, all designs are license. This allows all intellectual property to be shared freely, modified and adapted as users see fit ("Creative Commons - Attribution-ShareAlike 3.0 Unported - CC BY-SA 3.0," n.d.) The design files for each prosthetic can be downloaded for free from the E-nable website ("Enabling The Future," 2019) and printed using D printer (Ferreira et al, 2018), while the rest of the required components can be purchased through (Amazon. com," n.d.) and Albaba ("Alibaba.com," 2019). One E-nables most popular designs is the raptor loaded prosthetic hand. Designed collaboratively by members of the E-nable online community prosthetic works by mimicking the joints and tench of the human hand, and allows users to articulate the fingers by flexing their wrist and palm different directions. Unlike traditional prosthetics Which aim to disguise the missing limb by mimicking he color and shape of the human form, E-nable has embraced the 3D printed aesthetic. This encourages users (especially children) to have pride in their new limb, rather than trying to hide the-nable prosthetics are particularly applicable child amputees; especially those living in low cesource settings. This is because the design files can be scaled to fit the child using special CAD

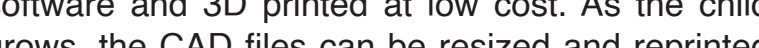
rows, the CAD piles can be resized and reprinted a matter of hours, at almost no cost. This is in comparison to traditional prosthetic manufacturing chols which can take weeks and cost housands of dollars to produce a single custom prosthetic. So far En pla hace a sricte cus ov proshellc. prosthelic limbs to indiv 
This content is unavailable. Please consult the figure list for further details.

Figure 7. Defense Distributed's 3D printed Liberator handgun. Retrieved July 1st, 2019, from https://web.archive.org/save/https:// Www dezeen com/2018/07/24/downloadable-files-3d-printed-guns-publicly-accessible-cody-wilson-defense-distributed

\section{Case study 4: The Liberator}

Defense Distributed is a nonprofit organization based in the United States, com Second Amendment rights by taclltating globa access to information related to the 3D printing of arms" and publishing this information online for free Harvard Law Review, 2017). The organisation rose the world's first called the libertor 3 p pined, single shot handgun website, where they could be downloaded for free.

Although ethically questionable, the liberator is great example of an open source, 3D printed product that relies on a distributed manufacturing model. In just two days, the digital CAD thes for the users from around the world (Harvard Law Review, users from around the world (Harvard Law Review, received in such a short space of time prompted the American State department to take action, ordering
Defence Distributed to take the CAD files

down, citing national security concerns (Harvard

Law Review, 2017). Despite the forced removal of

the files from Defense Distributed's website, the digital nature of CAD files meant that the blueprints for the liberator have remained avaliable online to this day, reuploaded by users and made freely avallable through third party websites and torrenting services. If these siles are taken down, new one emerge soon after, making il almost inpossible to regulate the distribution of the files. The success of the liberator has also prompled several online communities of 21st century gunsmiths to begin developing, printing, testing and distributing the own 3D printed gun designs, many of which now ence and urability.

Despite politically charged debate that surrounds the topic of 3D printed guns, the liberator serves as an excellent example of an open source produc designed to be distributed via the Internet and 
Online 3D printing services, widely available conjunction with widely available, inexpensive components and global distribution networks have components, medical devices can be designed, enabled small scale development, production and manyactured and distributed at a fraction of distribution models to become a viable allernalive to the cost of premium equipment. These findings the traditional mass manufacture model. The ability support Doctor Gales proposition of an open source produce CAD (computer aided design) files pupilometer that can be sourced and assembled by that can be replicated and shared via the internet, clinicians around the world. It is hoped that he data combined with online 3D printing services have collected using the Openpupil device can then be

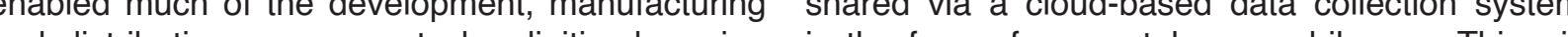
and distribution processes to be digitised, saving in the form of a smartphone mobile app. This will ime, money and improving efficiency. These new enable researchers to collaborate and share their digital pathways present new, novel opportunities findings with their colleagues, and forms the basis for the development and distibution of a range of for a global Online research community where the open source products. In a medical context, this is data generated represents the real value of the particularly exciting. The literature suggests that by project, rather than the device itself.
Based on the findings from the literature and design review, this thesis will focus on answering the question:

How can an open source development and distribution model be used in conjunction with online $3 D$ printing services and widely available parts and components to produce an inexpensive and open source pupilometer? 




Figure 8. Poster showing work completed on the pupillometer during the first summer research scholarship. Retrieved from: https:/ web.archive.org/web/20190713164133/https://github.com/kaiwhata/OpenPupil

\section{Previous research}

Research stage no. 1

The first goal of the project was to produce the $\mathrm{Pi}$, an infrared camera, a NeoPixel ring and a handfu of other widely available components, a functional prototype was successfully produced.

Before the start of this thesis, the pupilometer The second goal was to develop the software had already undergone two separate stages of necessary to successfully test the melanopsin development. The first stage was carted out in funclion of the eye. To achieve this, frame by frame 2017, anter Dr Jesse Gale approached the Victorla image processing soltware was witten using the University of Wellington's Faculty of Engineering c++ programing language that could successfully department with a research project proposal. quantify the image data recorded by the infrared

The project was to develop a device capable of stimulating the melanopsin pigment in the eye Overall, the project achieved both of it's goals by using an intense blue light and then recording the producing a functional 'proof of concept' prototype PIPR (Post llumination Pupil Response). To fulfill that could stimulate the melanopsin response the open source requirements of the project, the and record the PIPR. However, a number of device needed to be constructed using only widely recommended improvements were outlined at the available technology. The proposal was approved, end of the project. These included: Refining the and a summer research scholarship was setup eyecup design and component housings to improve comfort and hygiene, as well as refining the software mp inprove the acciracy of the device. 


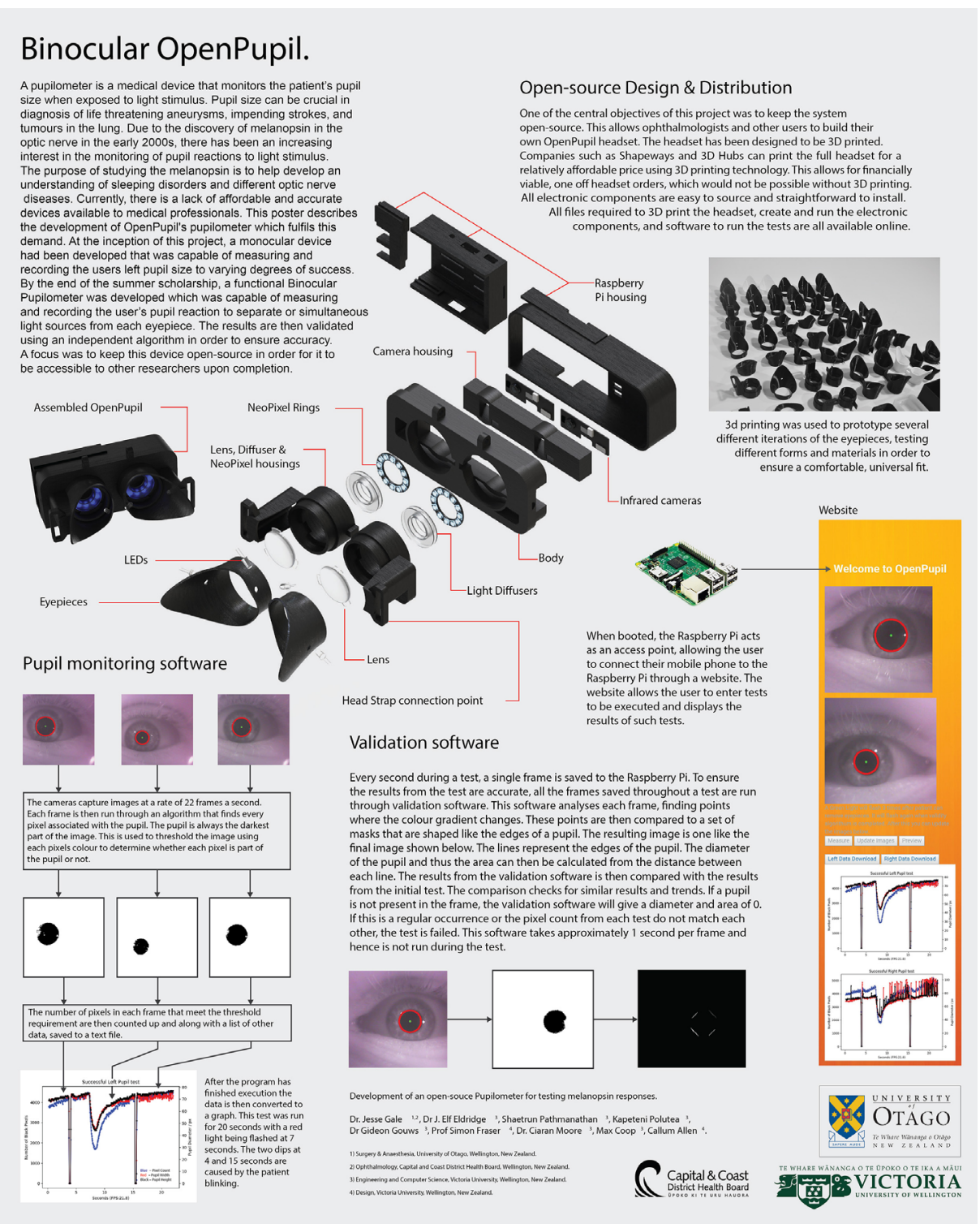

Figure 9. Poster showing work completed on the pupillometer during the second summer research scholarship.

\section{Research stage no. 2}

The second phase of the project was carried out in conjunction with the Victoria University Faculty of Engineering department, as well as the Victoria University Faculty of Design through another summer scholarship.

The design goals of this project were to transition the device from a monocular to binocular format so that both eyes could be tested independently or simultaneously, while also ensuring the device was easy to assemble, and could be consistently manufactured using a standard FDM (fused Deposition Modeling) 3D printer.

The engineering goals tor this project included adapting the device's software so that it could successfully record both pupils independently or simultaneously, as well as oplimising the hardware

Although a number of issues hindering the functionality and usability of the device remained at the end of this stage, the overall concept of an open . 


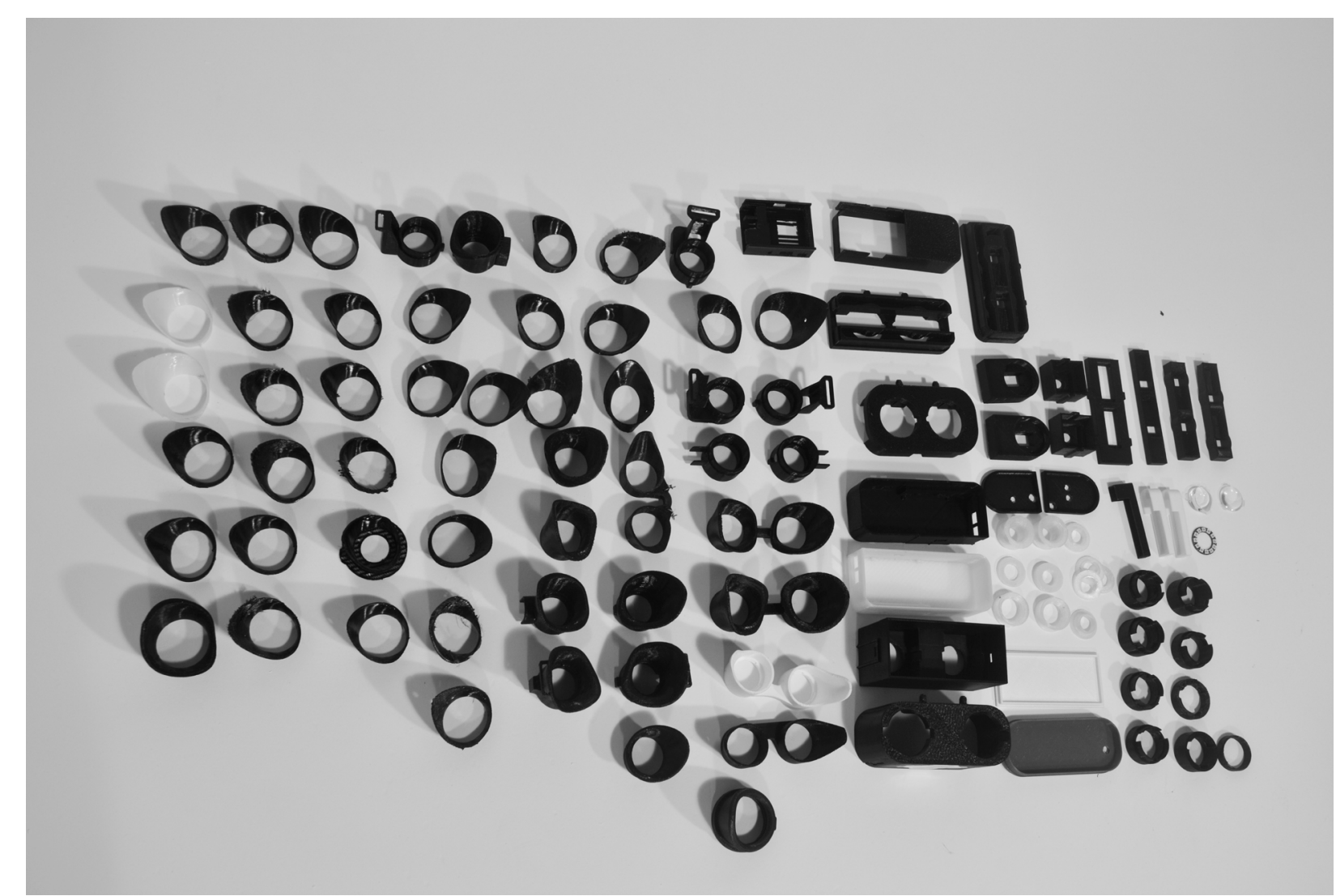

Figure 10. Iterative prototypes produced during the second summer research scholarship.

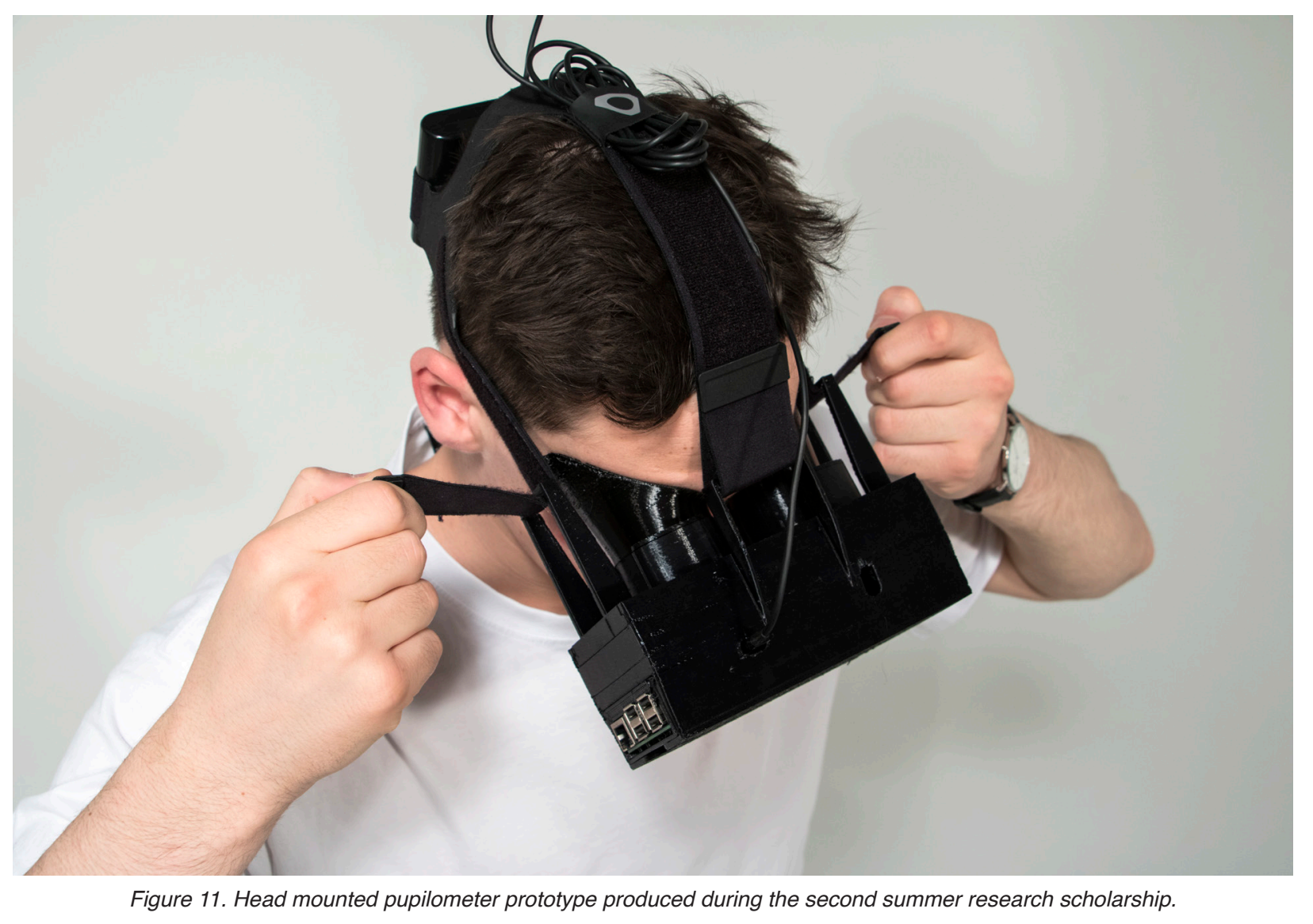

Figure 11. Head mounted pupilometer prototype produced during the second summer research scholarship. 


\section{Safety testing and validation}

At the end of the summer scholarship, a function 3D printed pupilometer prototype had been produced. However, the prototype was still clunky, had a variety of usability issues (ranging from handling to assembly) and suffered from a range of device.

Because the device is designed to interact with human eyes, safety testing of the inter human eyes, safety testing of the LEDs was
necessary to ensure the device was safe for use on necessary to ensure the device was safe for use on patients in a clinical research setting. Specifically, pe device was required to pass the safety standard sed Maximum permissible exposures for ocular devices (Delori, Webb, \& Sliney, 2007). The testing devices (Delori, Webb, \& Sliney, 2007). The testing was carried out by the Measurement Standards measuring the outputs of the LEDs used within the device to ensure they were safe for use on humans.

The testing found that the LEDs do not produce stable light output until they have been on for roughly an hour. The testing also found the LEDs mit a very high frequency flickering light when the brightness is reduced. Overall MSL found applying the standard to diffuse annular light sources such as the ones produced by the LEDs winh the device was difficult. Soon after this point, the prototype stopped functioning completely, preventing any rther testing from being conducted.

However the testing was sufficiently comprehensive confirm that the device was safe in principle and on that basis it was decided that MSL would (n) once a core robust device in terms of boh hardware and fftware had been produced. 


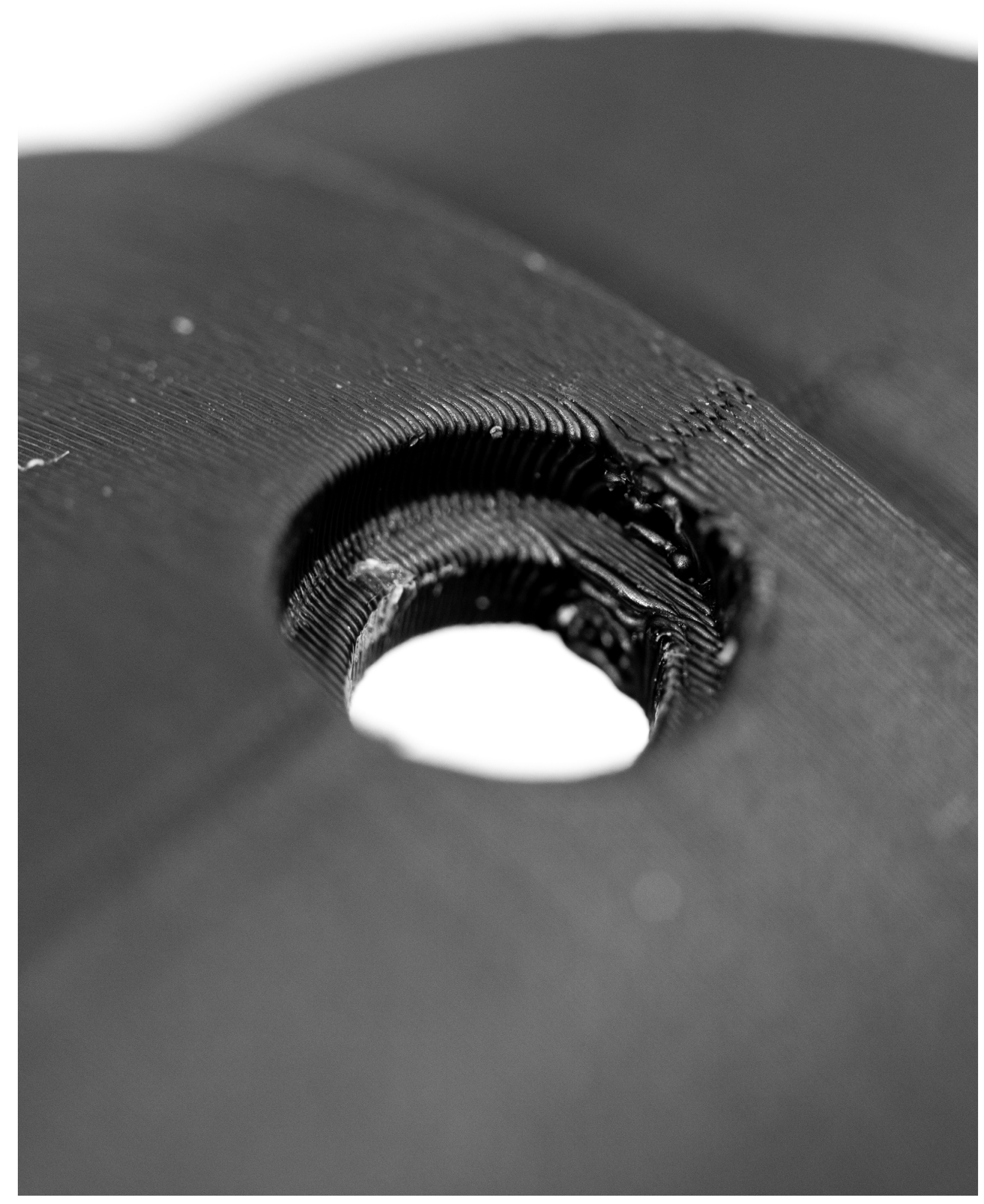

\section{Design phase 1.}

Part optimisation

The continued improvement of $3 \mathrm{D}$ printing technology combined with faster and more integrated IT (information technology) in the last two decades has prompted the establishment of several online additive manufacturing services around the world.

As the online $3 \mathrm{D}$ printing market has become more and more competitive, an increasing number of $3 \mathrm{D}$ printing technologies, capable of manufacturing objects from a wide range or materials have become accessible to a global audience. Not only this, but a range of online senices (depicted in table 1, page 24) provide users with access to a wide variety of
online CAD (computer aided design) files which online CAD (computer aided design) files which based on the users requirements.
These continued innovations have resulted in a diverse online 3D printing market, where CAD files can be sourced for almostany application imaginable and manufactured via online printing services with only a few clicks of a mouse. Although incredibly powertul, this newound freedom can make the task of selecting the right printing processes, materials and manufacturing services a daunting task.

To simplify this process, the International Organization for Standardization (IOS)/American Society for Testing and Materials (ASTM) ASTM52910 - 2018 classily standard, AM (penteries, displayed in table

Based on the information displayed in table 2 Selective Laser Sintering), FDM (fused deposition modelling), SLA (Stereolithography) and materia jetting printing were all identified as potentia printing the pupilometer. 


\section{Expansive research through desig}

To test which of the processes identified in table 2 would be most suitable to manufacture the pupilometer, expansive research through design was conducted. This process involved testing the ability of several online $3 D$ printing services to manufacture a range of test objects, each adapted from the existing pupilometer design.

Each object file contained geometry that is traditionally difficult to $3 \mathrm{D}$ print, and tested the printing services' ability to manufacture each of the designs using the printing processes and materials
identified in table 2 .

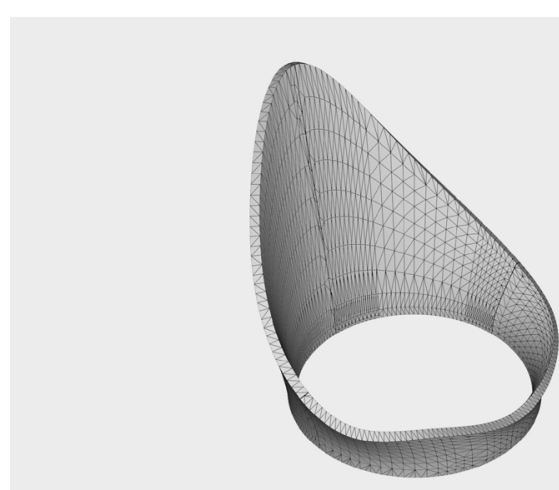

Figure 12 (a). Digital representation of the eyecup.

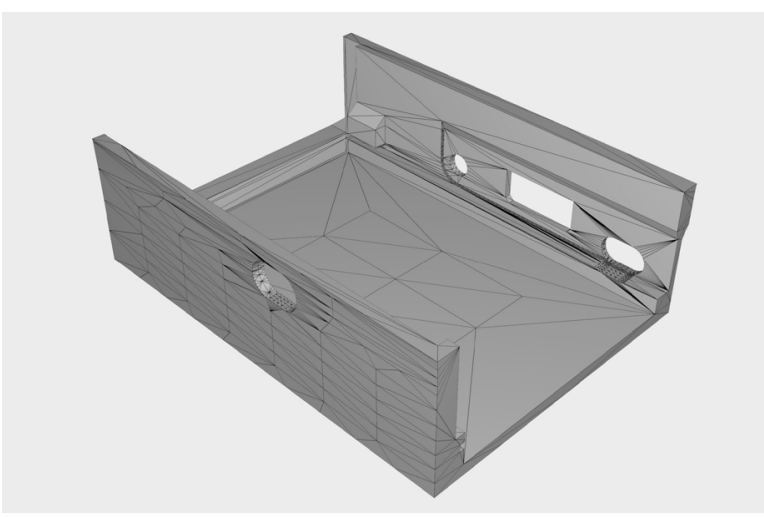

Figure 12 (b). Digital representation of the Raspberry Pi

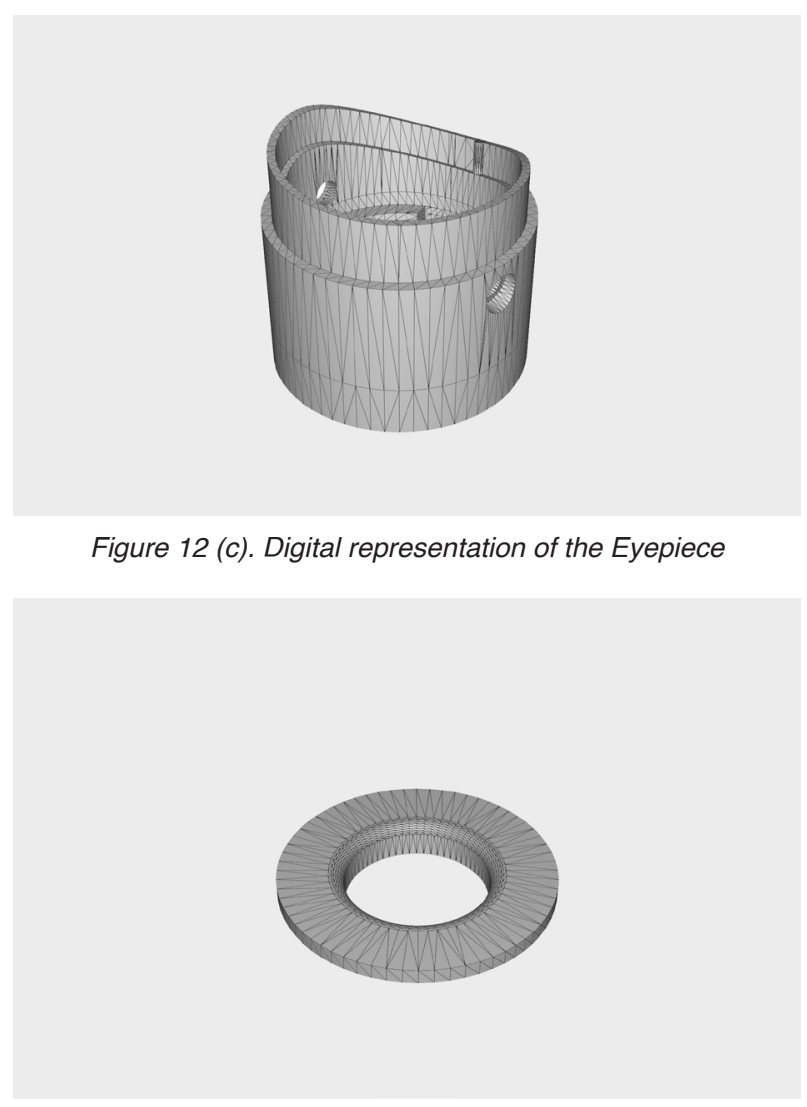

Figure 12 (d). Digital representation of the Diffuser
The eye cups are an important component of the design,as they come in contact with the users face. Because of this, the eye cups must be strong and durable, yet also soft and malleable in order to accommodate a wide variety of facial structures. Because the skin surrounding the eyes is a sensitive area, the printing material must have a smooth surface finish to minimise discomfort. The eyepieces also need to maintain a light seal around the users eyes, as any ambient light that enters the eyepiece may affect the pupilometers measurements.

The raspberry $\mathrm{pi}$ is a popular open source motherboard, and is a key component of the pupillometer. A common problem with many $3 D$ printing processesis that they are prone to producing warped parts when printing lat geometries with large surface area. The raspberry pi housing will test the 3D printers ability to print thin, flat geometry accurately without any warping.

The eyepiece housing is a critical part of the pupillometer as it contains several internal housings, each of which accomodate its own component. These components include the Lenses, the neopixe rings, the infrared LEDs as well as the LED diffusers. The internal housings need to be printed at a high resolution for the components to fit correctly. To achieve this, the eyepiece housing must be printed as accurately as possible, as even small distortions in the geometry may prevent hio components from achieving a tight fit.

The diffusers clip over the Neo pixel rings, and light impring the as to provide an even spread of aqeduete levels of diffusion, the diffusers need to be printed using a clear opque plastic, so as to effectively spread the light from the LED's. 
Table 3. Table comparing the range of $3 D$ printing services, processes, and materials used to manufacture the eyecups.

\begin{tabular}{|c|c|c|c|c|c|}
\hline $\begin{array}{l}\text { Printing } \\
\text { process }\end{array}$ & Material & $\begin{array}{l}\text { Manufacturing } \\
\text { service }\end{array}$ & $\begin{array}{l}\text { Cost } \\
\text { (NZD) }\end{array}$ & Advantages & Disadvantages \\
\hline $\begin{array}{l}\text { Fused deposition } \\
\text { modelling (FDM) }\end{array}$ & $\begin{array}{l}\text { Polylactic } \\
\text { acid (PLA) }\end{array}$ & Treatstock & $\$ 17.09$ & $\begin{array}{l}\text { Cheap and localised } \\
\text { manufacturing option }\end{array}$ & $\begin{array}{l}\text { The FDM printing process } \\
\text { builds objects by stacking } \\
\text { layers of material on top of } \\
\text { each along the } z \text { axis. This } \\
\text { limits the levels of flexibility } \\
\text { that can be achieved } \\
\text { Low resolution, layered } \\
\text { surface quality }\end{array}$ \\
\hline $\begin{array}{l}\text { Selective laser } \\
\text { sintering (SLS) }\end{array}$ & $\begin{array}{l}\text { Thermo- } \\
\text { plastic poly- } \\
\text { urethane } \\
\text { (TPU) }\end{array}$ & i.materialise & $\$ 55.16$ & $\begin{array}{l}\text { The eye cup was printed } \\
\text { using a strong and } \\
\text { durable TPU material that } \\
\text { had an attractive, grainy } \\
\text { surface finish }\end{array}$ & $\begin{array}{l}\text { Porous, Grainy surface } \\
\text { texture } \\
\text { Although the material is } \\
\text { somewhat flexible, it is still } \\
\text { quite hard. This can cause } \\
\text { discomfort when pressed } \\
\text { against the users face }\end{array}$ \\
\hline $\begin{array}{l}\text { Stereolithography } \\
\text { (SLA) }\end{array}$ & Resin & 3D hubs & $\$ 88.77$ & $\begin{array}{l}\text { The eyecup was printed } \\
\text { using a Soft, flexible resin } \\
\text { material that was very } \\
\text { malleable and provided } \\
\text { good levels of comfort }\end{array}$ & $\begin{array}{l}\text { Most expensive printing } \\
\text { process } \\
\text { Limited to an opaque white } \\
\text { color } \\
\text { The eyecup became discol- } \\
\text { ored over time }\end{array}$ \\
\hline
\end{tabular}

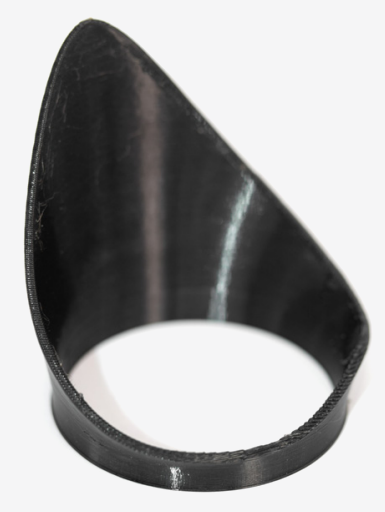

Figure 13 (a). Eyecup printed via Treatstock using the FDM printing proces
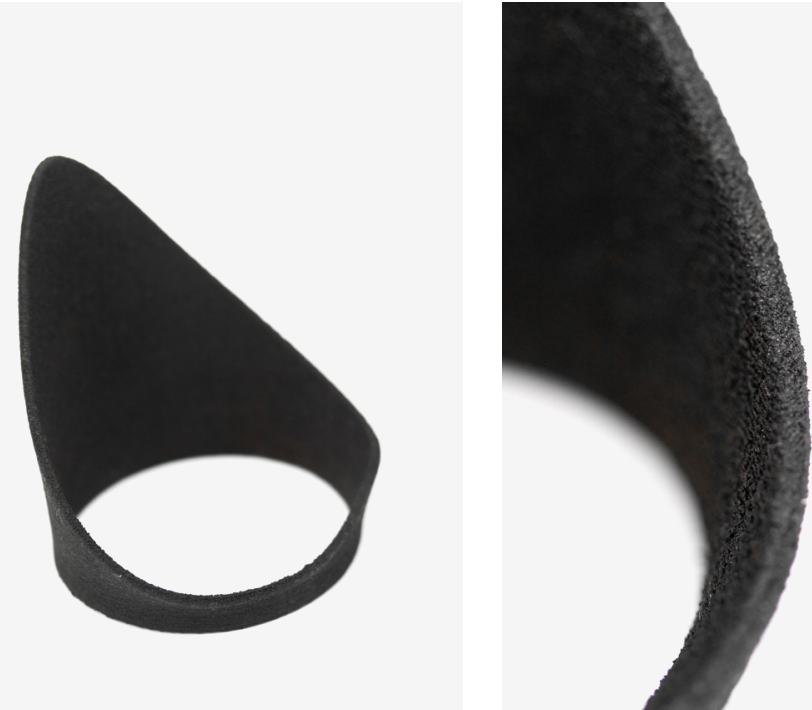

Figure 13 (b). Eyecup printed via Shapeways using the SLS printing process

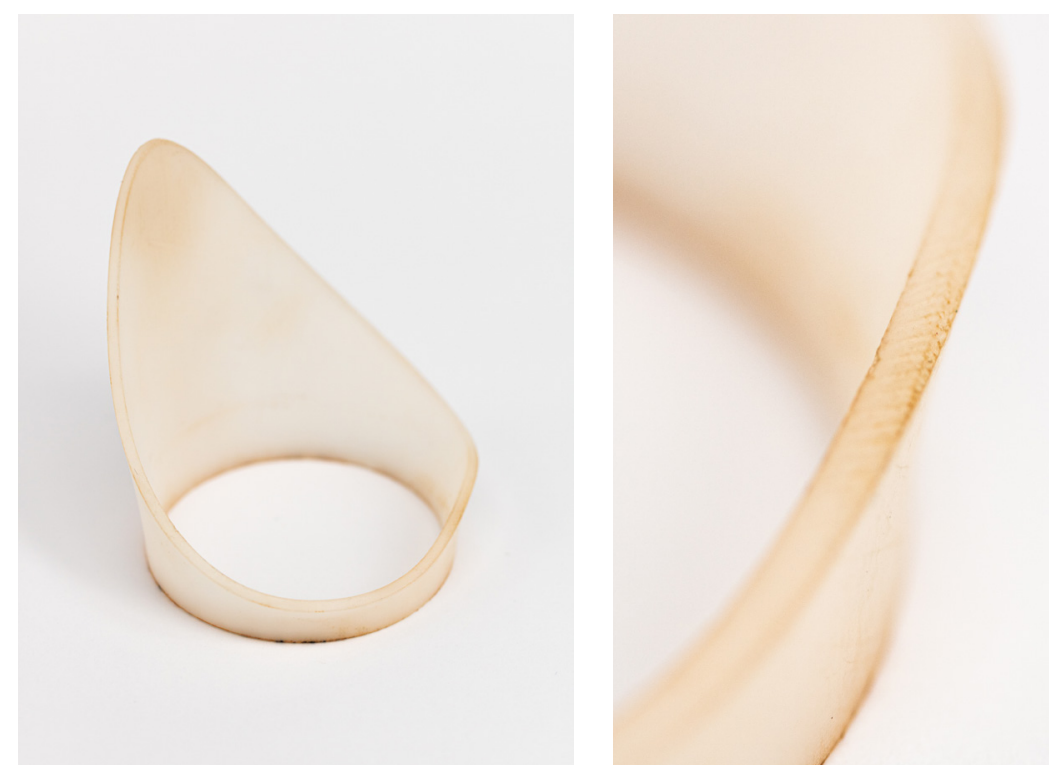

Figure 13 (c). Eyecup printed via 3Dhubs using the SLA printing process 

Table 4. Table comparing the range of $3 D$ printing services, processes, and materials used to manufacture the Raspberry Pi housing

\begin{tabular}{|c|c|c|c|c|c|}
\hline $\begin{array}{l}\text { Printing } \\
\text { process }\end{array}$ & Material & $\begin{array}{l}\text { Manufacturing } \\
\text { service }\end{array}$ & Cost (NZD) & Advantages & Disadvantages \\
\hline $\begin{array}{l}\text { Fused deposition } \\
\text { modelling (FDM) }\end{array}$ & $\begin{array}{l}\text { Polylactic acid } \\
\text { (PLA) }\end{array}$ & Treatstock & $\$ 14.40$ & $\begin{array}{l}\text { Cheapest printing } \\
\text { option tested } \\
\text { The print was strong } \\
\text { and durable }\end{array}$ & $\begin{array}{l}\text { The Treatstock FDM print was } \\
\text { warped in multiple directions, } \\
\text { seriously affecting the parts } \\
\text { functionality and making it very } \\
\text { difficult to insert the Pi }\end{array}$ \\
\hline $\begin{array}{l}\text { Fused deposition } \\
\text { modelling (FDM) }\end{array}$ & $\begin{array}{l}\text { Polylactic acid } \\
\text { (PLA) }\end{array}$ & 3D Hubs & $\$ 27.77$ & $\begin{array}{l}\text { The pi housing was } \\
\text { printed at a satisfactory } \\
\text { resolution } \\
\text { No signs of warping } \\
\text { The Raspberry Pi fit } \\
\text { into the housing with } \\
\text { little resistance }\end{array}$ & $\begin{array}{l}\text { The 3D hubs FDM print was } \\
\text { visibly lower resolution then the } \\
\text { SLS printing options } \\
\text { Minor surface defects }\end{array}$ \\
\hline $\begin{array}{l}\text { Selective laser } \\
\text { sintering (SLS) }\end{array}$ & Nylon (PA12) & Shapeways & $\$ 45.41$ & $\begin{array}{l}\text { The Pi housing was } \\
\text { printed at a high } \\
\text { resolution } \\
\text { The print was very } \\
\text { durable and showed } \\
\text { no signs of warping } \\
\text { The Raspberry Pi fit } \\
\text { into the housing with } \\
\text { little resistance }\end{array}$ & $\begin{array}{l}\text { The Shapeways SLS print had a } \\
\text { slightly porous surface texture. } \\
\text { This could potentially be difficult } \\
\text { to clean } \\
\text { When scratched, the textured } \\
\text { surface finish wore away, leaving } \\
\text { a shiny surface underneath }\end{array}$ \\
\hline $\begin{array}{l}\text { Selective laser } \\
\text { sintering (SLS) }\end{array}$ & Nylon (PA12) & 3D Hubs & $\$ 119.00$ & $\begin{array}{l}\text { The Pi housing was } \\
\text { printed at an extremely } \\
\text { high resolution and } \\
\text { showed no signs of } \\
\text { warping } \\
\text { The Raspberry Pi fit } \\
\text { perfectly into the hous- } \\
\text { ing with little resistance }\end{array}$ & $\begin{array}{l}\text { The 3D Hubs SLS print was over } \\
\text { double the cost of the Shapeways } \\
\text { SLS print } \\
\text { By far the most expensive } \\
\text { printing option tested }\end{array}$ \\
\hline
\end{tabular}

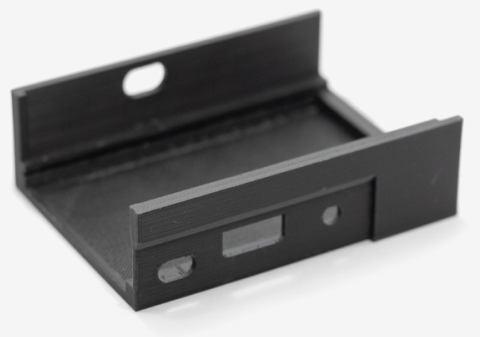

Figure 15 (a). Raspberry Pi housing printed via Treatstock using the FDM printing process

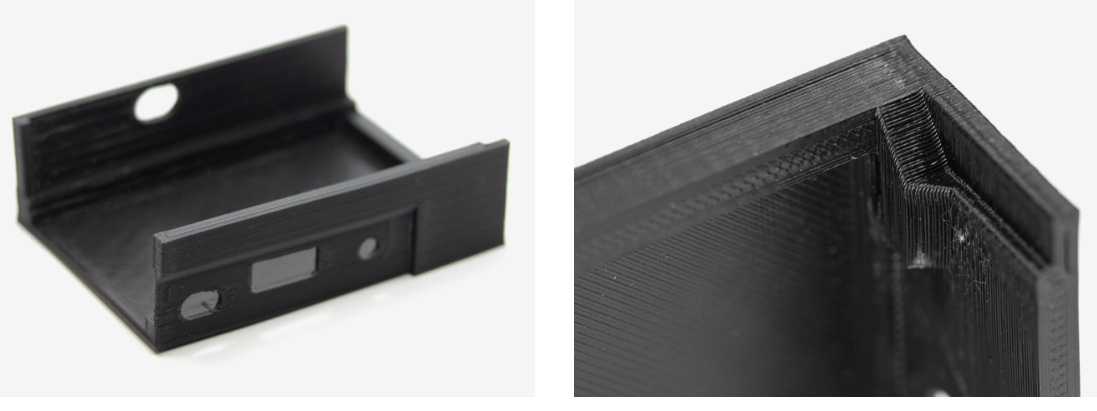

Figure 15 (b). Raspberry Pi housing printed via 3Dhubs using the FDM printing process

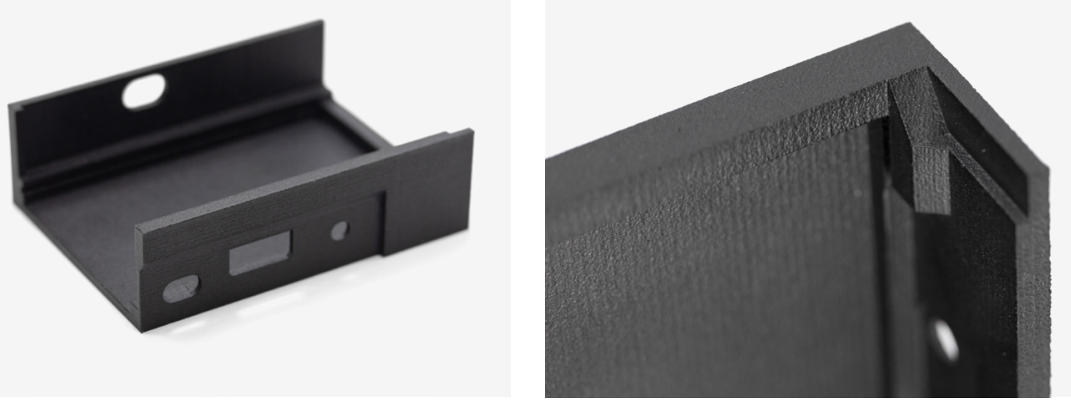

Figure 15(c). Raspberry Pi housing printed via 3D3Dhubs using the SLS printing process
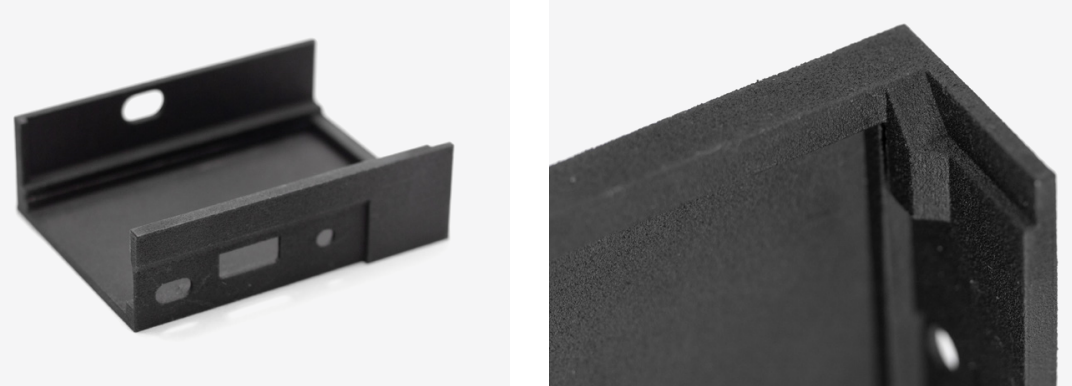

Figure 15 (d). Raspberry Pi housing printed via Shapeways using the SLS printing process 
Table 5. Table comparing the range of $3 D$ printing services, processes, and materials ability to manufacture the eyepiece.

\begin{tabular}{|c|c|c|c|c|c|}
\hline $\begin{array}{l}\text { Printing } \\
\text { process }\end{array}$ & Material & $\begin{array}{l}\text { Manufacturing } \\
\text { service }\end{array}$ & Cost (NZD) & Advantages & Disadvantages \\
\hline $\begin{array}{l}\text { Fused deposition } \\
\text { modelling (FDM) }\end{array}$ & $\begin{array}{l}\text { Polylactic acid } \\
\text { (PLA) }\end{array}$ & Treatstock & $\$ 14.40$ & $\begin{array}{l}\text { Cheapest printing } \\
\text { option tested } \\
\text { The print was strong } \\
\text { and durable }\end{array}$ & $\begin{array}{l}\text { The Treatstock FDM print was of } \\
\text { a low resolution, and contained } \\
\text { several small defects } \\
\text { The internal geometry was not } \\
\text { printed accurately, resulting in } \\
\text { several components not fitting } \\
\text { into their housing, making the part } \\
\text { Non-functional }\end{array}$ \\
\hline $\begin{array}{l}\text { Fused deposition } \\
\text { modelling (FDM) }\end{array}$ & $\begin{array}{l}\text { Polylactic acid } \\
\text { (PLA) }\end{array}$ & 3D Hubs & $\$ 27.77$ & $\begin{array}{l}\text { Cheap manufacturing } \\
\text { option } \\
\text { The eyepiece was } \\
\text { printed at a satisfactory } \\
\text { resolution } \\
\text { The internal geometry } \\
\text { was printed relatively } \\
\text { accurately }\end{array}$ & $\begin{array}{l}\text { The 3D hubs FDM print had some } \\
\text { Small surface defects, however } \\
\text { they did not affect the functionality } \\
\text { of the part }\end{array}$ \\
\hline $\begin{array}{l}\text { Selective laser } \\
\text { sintering (SLS) }\end{array}$ & Nylon (PA12) & Shapeways & $\$ 45.41$ & 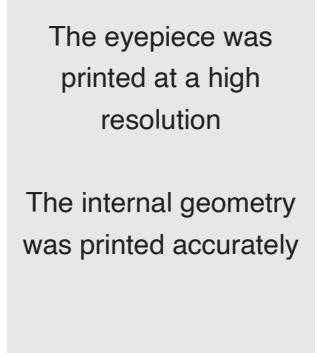 & $\begin{array}{l}\text { The Shapeways SLS print had a } \\
\text { textured surface finish that was } \\
\text { slightly porous. This could poten- } \\
\text { tially be difficult to clean } \\
\text { When scratched, the textured } \\
\text { surface finish wore away, leaving } \\
\text { a shiny surface underneath }\end{array}$ \\
\hline $\begin{array}{l}\text { Selective laser } \\
\text { sintering (SLS) }\end{array}$ & Nylon (PA12) & 3D Hubs & $\$ 88.90$ & $\begin{array}{l}\text { The eyepiece was } \\
\text { printed at an extremely } \\
\text { high resolution and } \\
\text { showed no signs of } \\
\text { warping } \\
\text { The internal geometry } \\
\text { was printed accurately }\end{array}$ & $\begin{array}{l}\text { The 3D Hubs SLS print was } \\
\text { almost double the cost of the } \\
\text { Shapeways SLS print } \\
\text { By far the most expensive } \\
\text { printing option tested }\end{array}$ \\
\hline
\end{tabular}

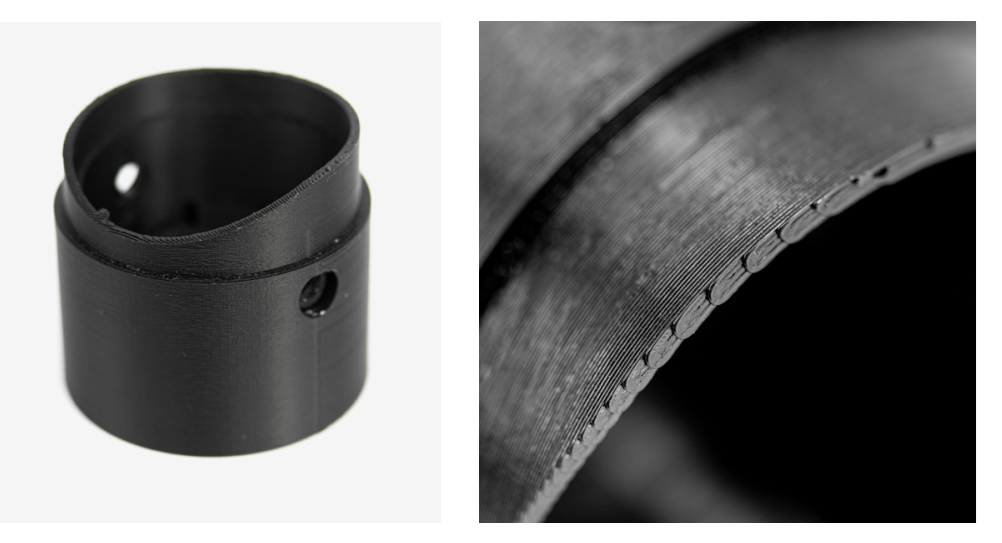

Figure 16 (a). Eyepiece printed via 3Dhubs using the FDM printing process
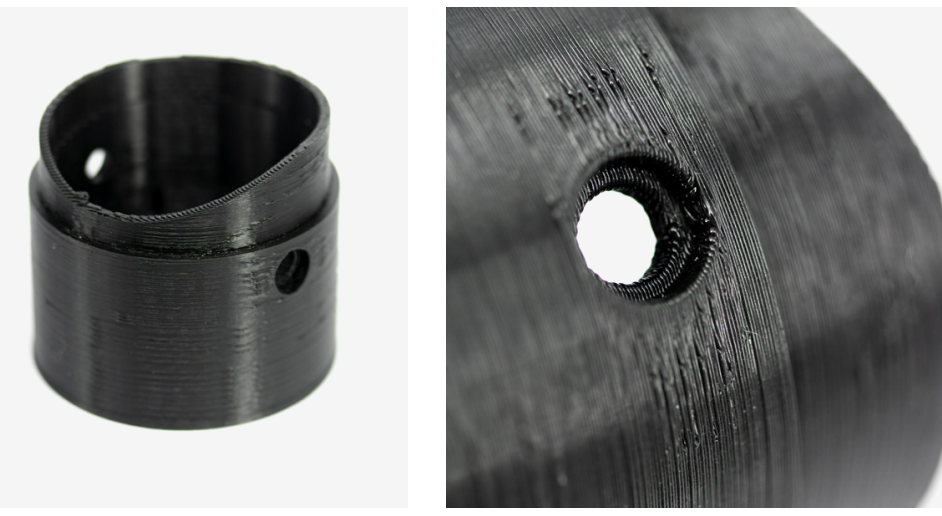

Figure 16 (b). Eyepiece printed via 3Dhubs using the FDM printing process
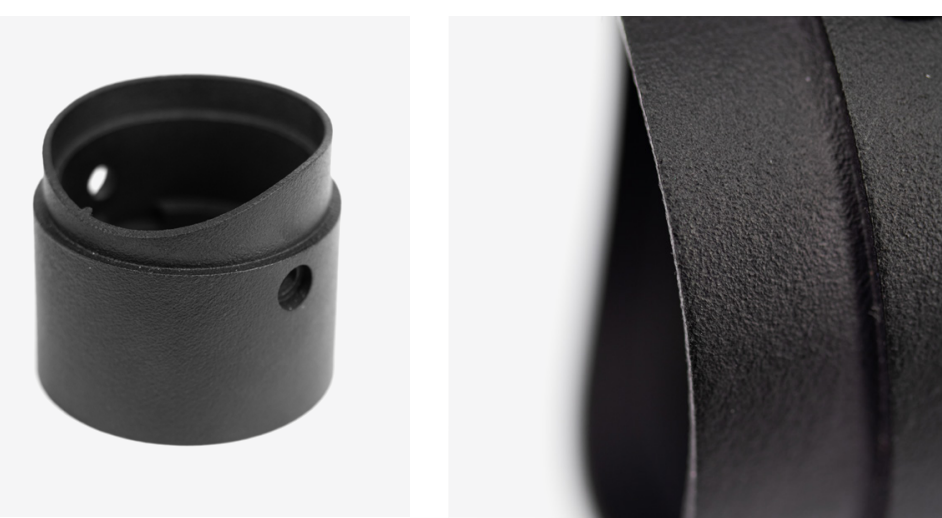

Figure 16 (c). Eyepiece printed via $3 D$ Hubs using the SLS printing process
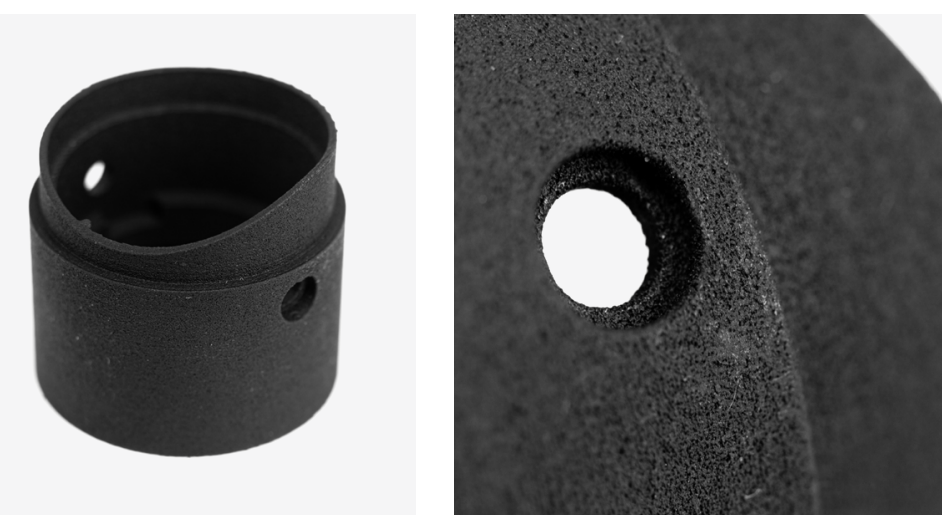

Figure 16 (d). Eyepiece printed via Shapeways using the SLS printing process 
Table 6. Table comparing the range of $3 D$ printing services, processes, and materials used to manufacture the diffuser

\begin{tabular}{|c|c|c|c|c|c|}
\hline $\begin{array}{l}\text { Printing } \\
\text { process }\end{array}$ & Material & $\begin{array}{l}\text { Printing } \\
\text { service }\end{array}$ & $\begin{array}{l}\text { Cost } \\
\text { (NZD) }\end{array}$ & Advantages & Disadvantages \\
\hline $\begin{array}{l}\text { Fused deposition } \\
\text { modelling (FDM) }\end{array}$ & $\begin{array}{l}\text { Polylactic acid } \\
\text { (PLA) }\end{array}$ & Treatstock & $\$ 2.15$ & None & $\begin{array}{l}\text { The manufacturer } \\
\text { cancelled the order due to } \\
\text { lack of opaque material, } \\
\text { despite it being available } \\
\text { on their website }\end{array}$ \\
\hline $\begin{array}{l}\text { Fused Deposition } \\
\text { Modelling (FDM) }\end{array}$ & $\begin{array}{l}\text { Polyethylene } \\
\text { Terephthalate } \\
\text { Glycol (PETG) }\end{array}$ & 3D Hubs & $\$ 12.00$ & None & $\begin{array}{l}\text { The manufacturer } \\
\text { cancelled the order due to } \\
\text { lack of opaque material, } \\
\text { despite it being available } \\
\text { on their website }\end{array}$ \\
\hline Material jetting & $\begin{array}{l}\text { Resin based } \\
\text { plastic (Photo- } \\
\text { polymer) }\end{array}$ & Shapeways & $\$ 7.50$ & $\begin{array}{l}\text { High resolution print } \\
\text { The photopolymer is } \\
\text { opaque, and provides } \\
\text { adequate levels of } \\
\text { diffusion }\end{array}$ & $\begin{array}{l}\text { According to the literature, } \\
\text { photo polymer plastics } \\
\text { degrade over time } \\
\text { However no degrada- } \\
\text { tion was observed in the } \\
\text { diffusers }\end{array}$ \\
\hline
\end{tabular}

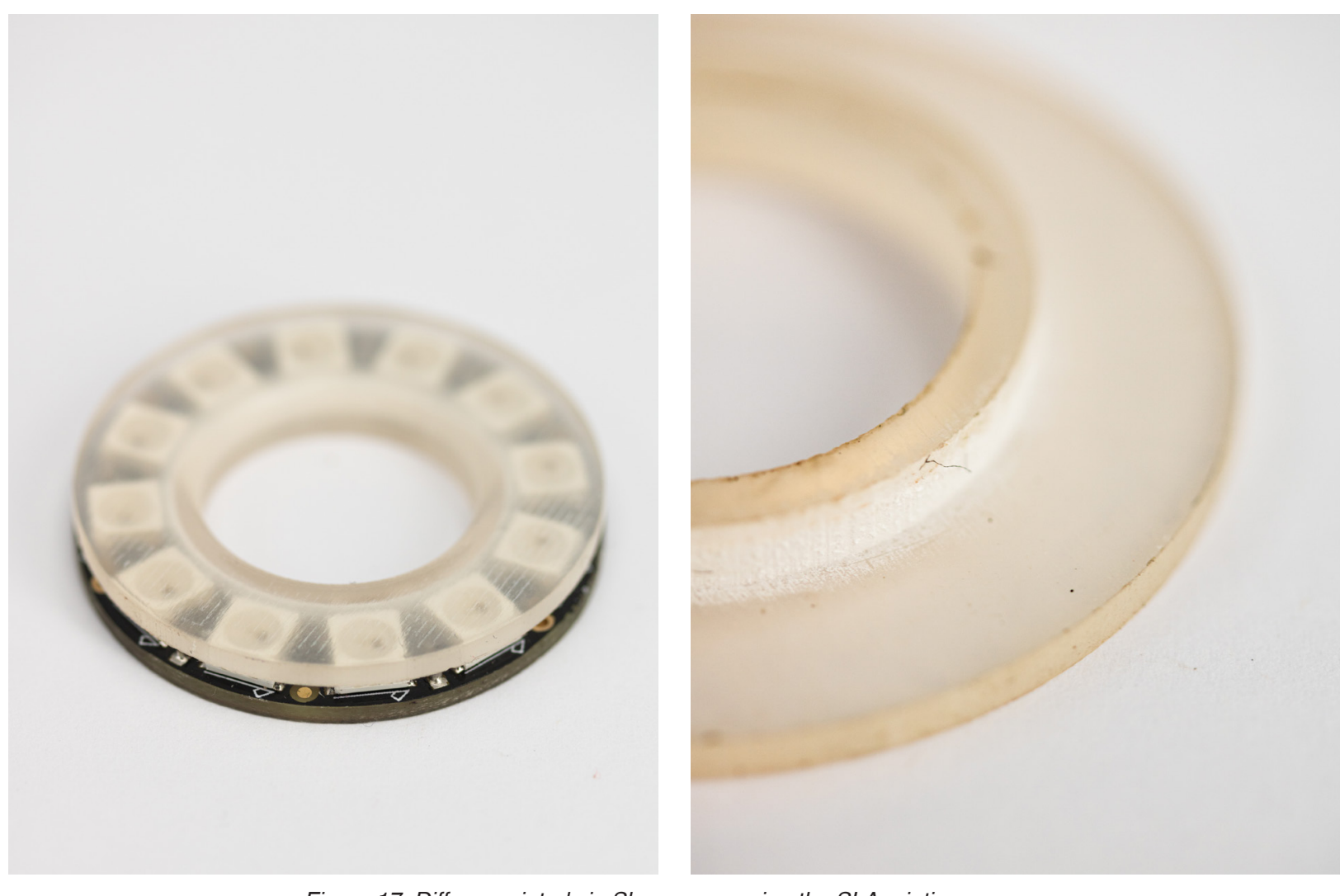

Figure 17. Diffuser printed via Shapeways using the SLA printing process 
Stereolithography print from 3D hubs was very soft and malleable, however that material is only offered an opaque color, meaning it will not create an Based on the experiments conducted in design effective light seal around the eye. Not only this, but phase 1, the SLS (selective laser sintering) process the print has shown signs of degradation over time, printed using nylon (PA12) was decided upon as the making it unsuitable for real world application.

optimal manufacturing method for the eyepieces

and the pi housing. Although the SLS prints from 3D The diffusers proved hard to obtain, as three orders hubs provided a smoother surface finish and slightly were placed in a range of clear/opaque materials, higher levels of detail, they were approximately but only one arrived. Both Treatstock and 3D hubs twice as expensive as the shapeways prints, cancelled their orders due to lack of material, making them unsuitable for use in an open source despite each respective material being displayed as medical device. The shapeways prints provided a available on each site. This eliminates each service high quality, textured surface finish with satisfactory from selection, as having materials available at al levels of detail at a much more affordable price, times is imperative for the manufacture of open making it the optimal choice for manufacturing the source medical devices.

pupilometer.

The diffuser that did arrive was a material jetted In terms of the eye cups, no ideal solution was photopolymer from shapeways. The print was found. Although the SLS print from i.materialise was of high resolution and displayed a good leve of a superb quality, it's grainy surface texture and of opaqueness, making it a satisfactory choice limited flexibility proved to be uncomfortable when for the diffusers. The diffusers are made from a pressed against the users face. The same can be photopolymer which can degrade when exposed said about the FDM (fused deposition modelling) to sunlight, however no signs of difusion were print from treatstock, as the low resolution print observed thus far

quality and extremely limited levels of flex also made 


\section{Design phase 2.}

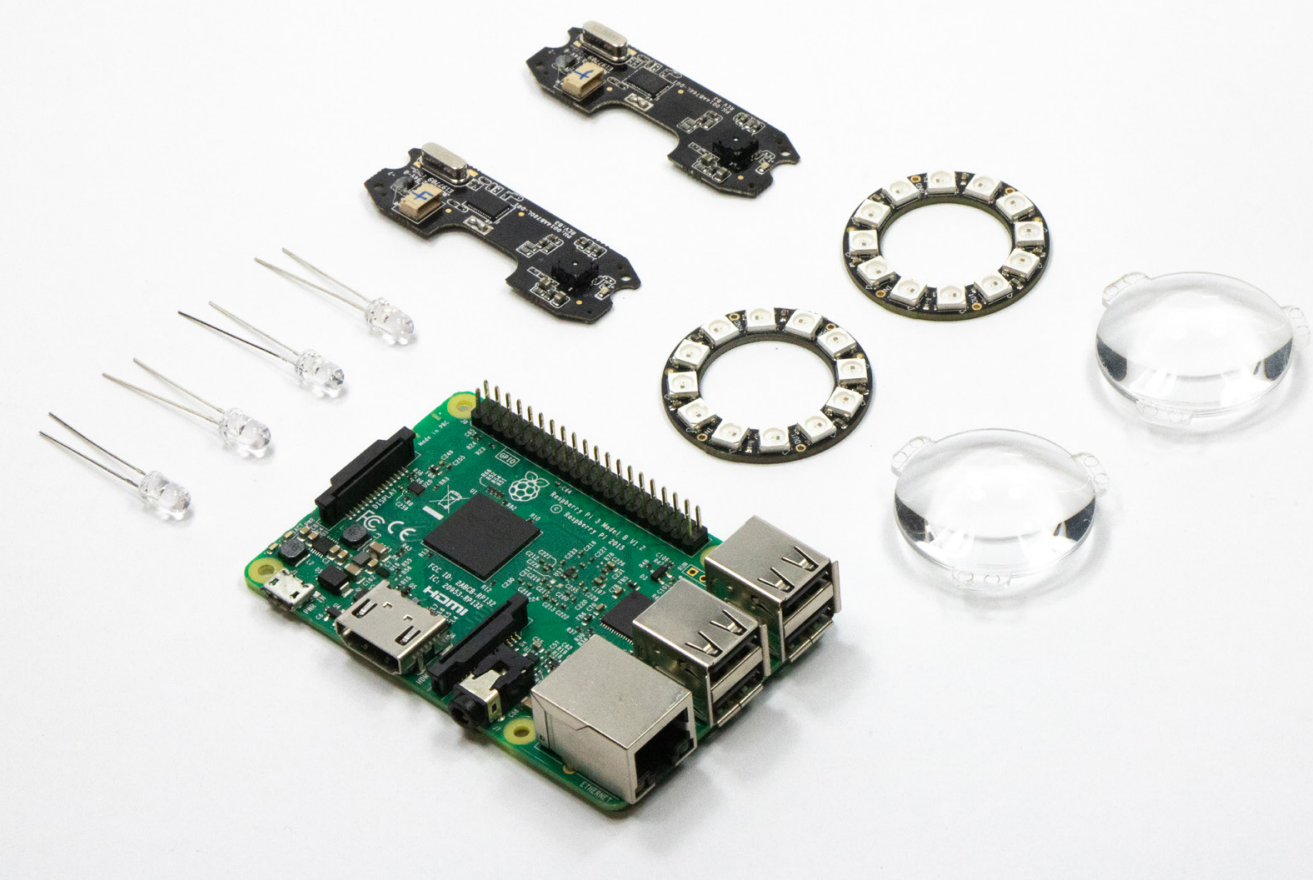

Figure 18. Non 3D printed Components housed within the pupilometer
Accomodating the technical package

The first step in producing the pupilometer was to develop housings for each of the devices internal components. To achieve this, sevial research through design was conducted using an FDM (Fused Deposition Modelling) 3D printer to iteratively prototype each housing to a salisfactory level of refinement. From here, the parts were manufactured using Shapeways' SLS nylon 3D printing service to ensure each of the components fit correctly.

The initial components within the device included:

4x IR (infrared) LED's

$2 x$ Infrared Webcams

2x NeoPixel rings

2xGoogle cardboard lenses

1x Raspberry Pi 3 


\section{SLS tolerance tests}

To better understand Shapeways' SLS (selective laser sintering) nylon material, a set of slot fit test objects were designed and Shapeways' online 3D printing service. Starting a a tolerance of $0.04 \mathrm{~mm}$ and ascending incrementally by a scale of $0.02 \mathrm{~mm}$ up to $1.0 \mathrm{~mm}$, these objects tested the consistency of Shapeways' SLS nylon material and determined which tolerance would provide the optimal push fit between two SLS nylon parts.

Based on these tests, it was determined that a $0.04 \mathrm{~mm}$ tolerance provided the optimal push fit tolerance for parts printed using SLS nylon.

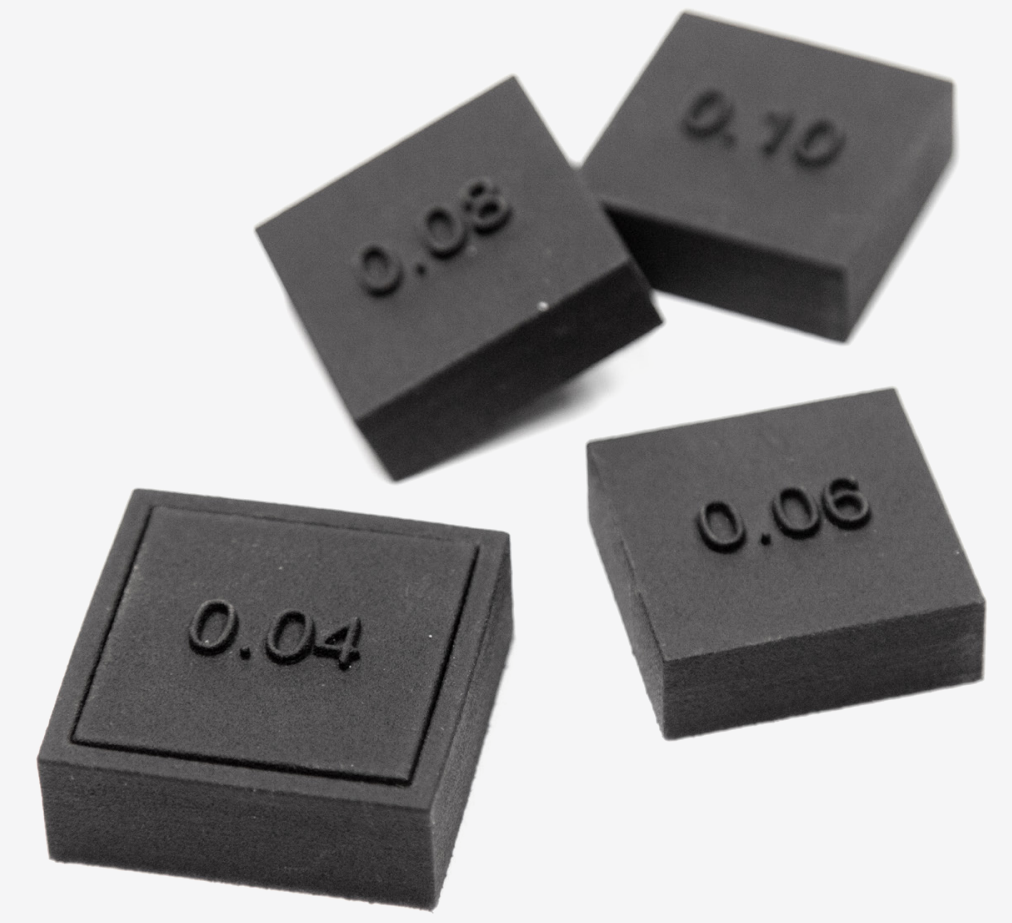

Figure 19. The $0.04 \mathrm{~mm}$ tolerance test provided the best slot fit 
To accommodate the infrared LEDs, a $2.5 \mathrm{~mm}$

ring with 10 holes extruded through its walls was

designed and printed using Shapeways SLS nylon

material. The smallest of these holes had a diameter

of $5 \mathrm{~mm}$, (the diameter of the LED) with each hole

getting incrementally larger by $0.02 \mathrm{~mm}$; the bigges

hole being $5.2 \mathrm{~mm}$.

When tested, the $5.02 \mathrm{~mm}$ hole provided a firm push

fit that kept the LEDs secure, yet did not require a

massive amount of pressure to install/remove the

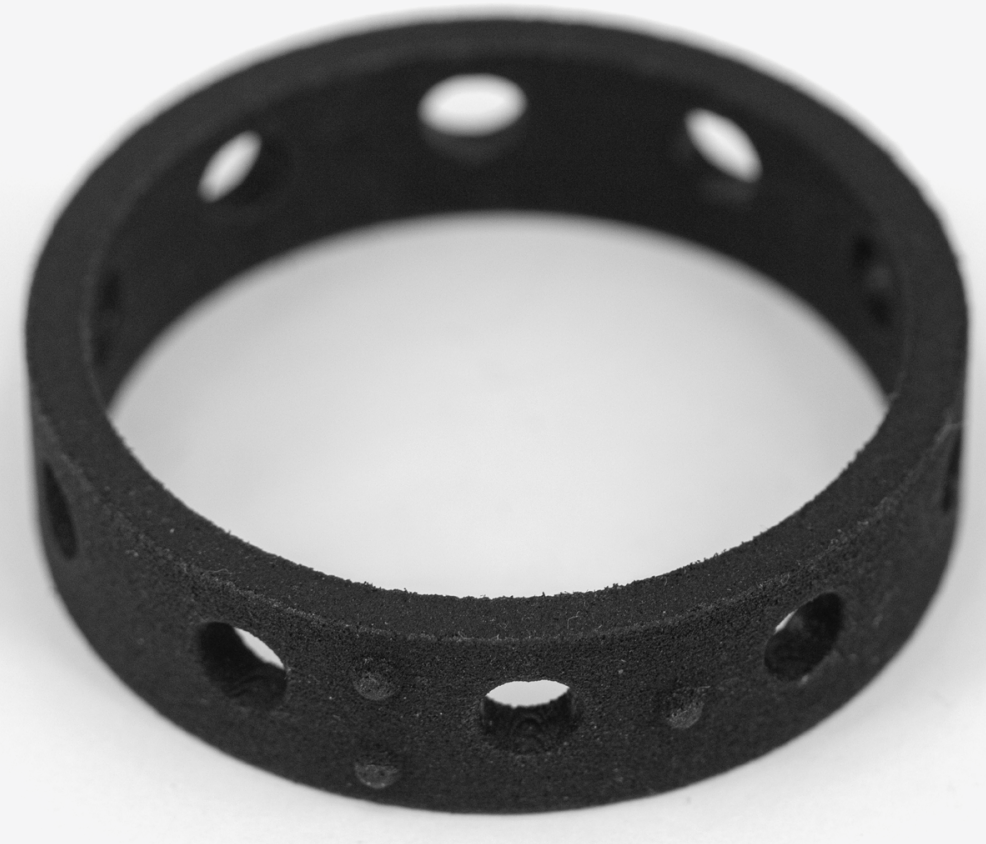

Figure 20 (a)

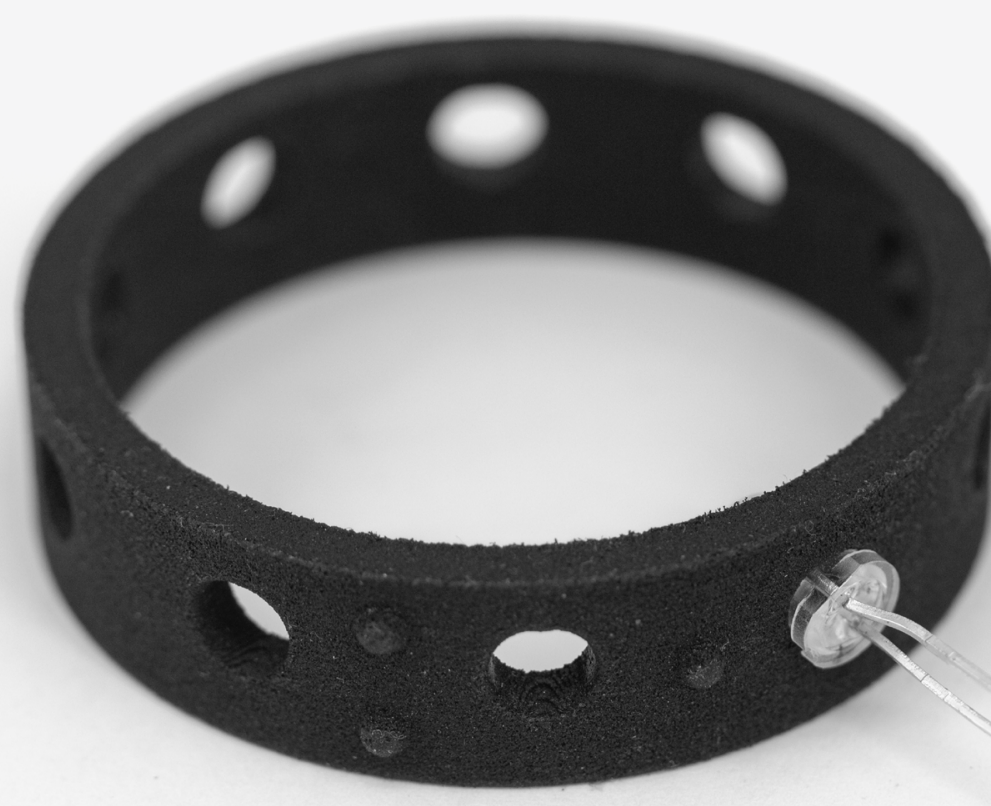


To accommodate the lens, a push fit housing was designed using the circumference of the lens as a reference point. Tolerance optimisation was

then conducted by producing a range of housing

prototypes using an FDM 3D printer until a

satisfactory push fit was achieved. The housing was

then printed via Shapeways to ensure the tolerance

also applied to SLS nylon.

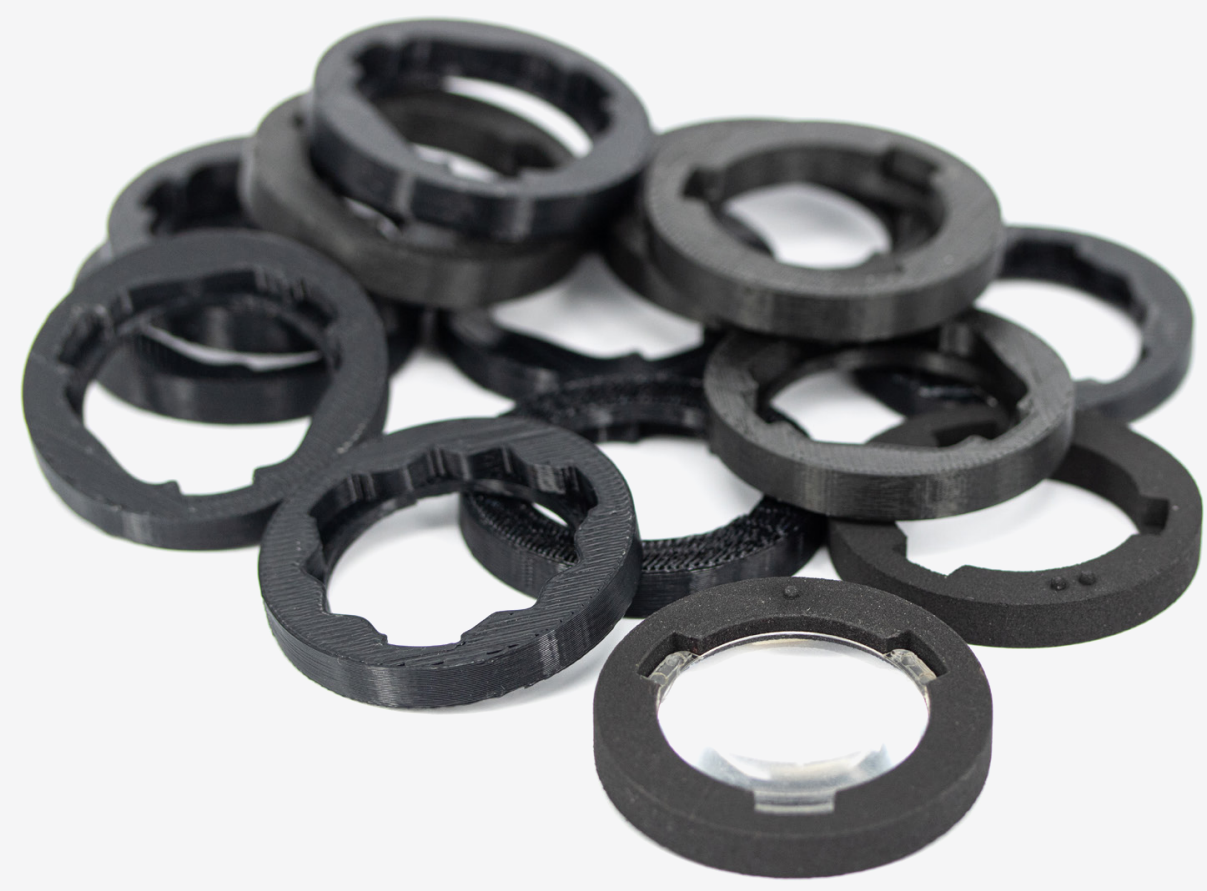

Figure 21 (a). Prototypes created during the tolerance optimisation process of the lens housing.
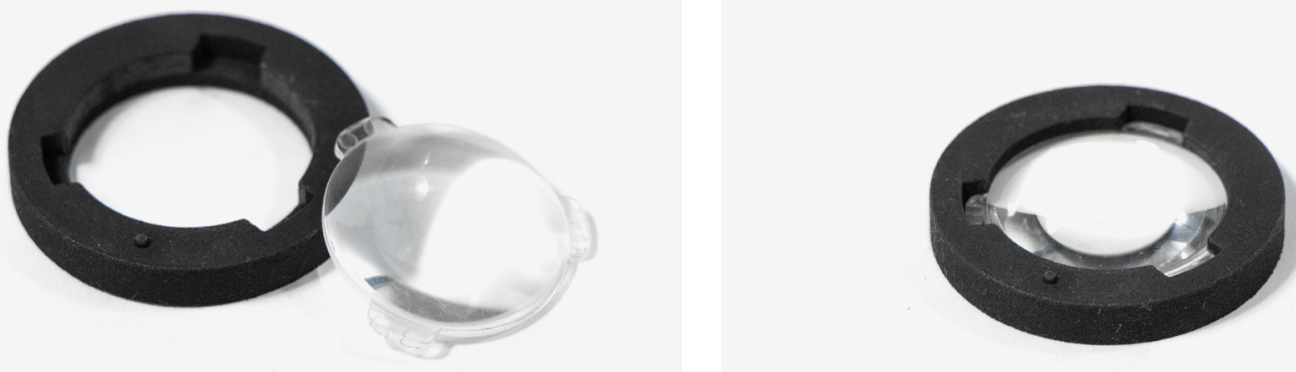

Figure $21(b)$.

Figure 21 (c) 


\section{NeoPixel Ring housing}

To accommodate the NeoPixel Rings, an initial push

fit housing was designed using the circumference of

the ring as a reference point. Tolerance optimisation

was then conducted by producing a range of

housing prototypes using an FDM 3 D printer until

satisfactory push fit was achieved. The housing was

then printed via Shapeways to ensure the tolerance

also applied to SLS nylon.

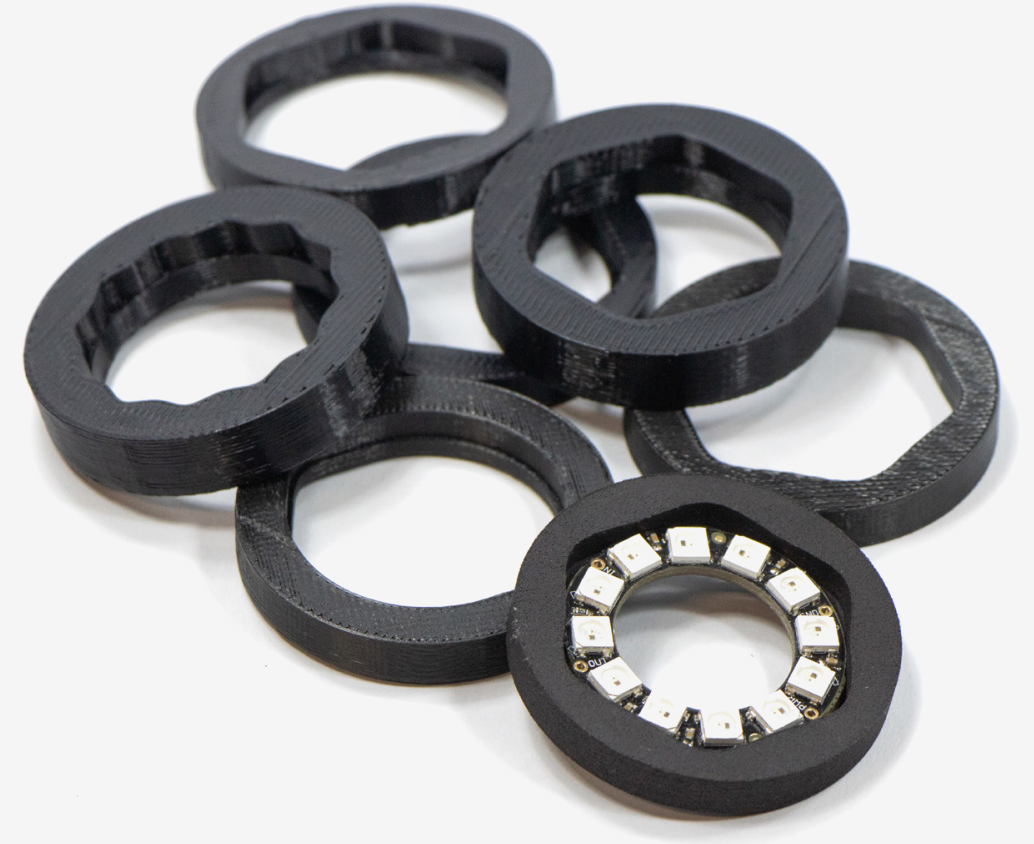

Figure 22 (a). Prototypes created during the tolerance optimisation process of the Neopixel Ring housing.

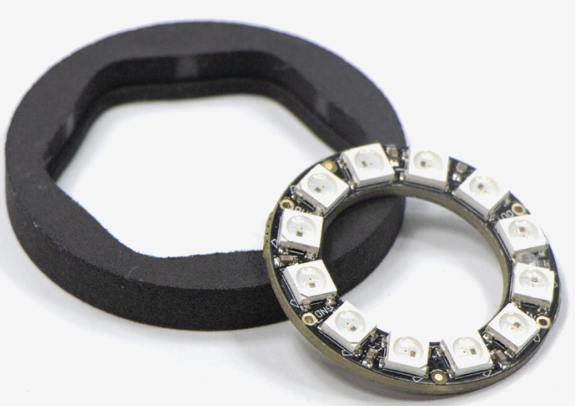

Figure $22(b)$.

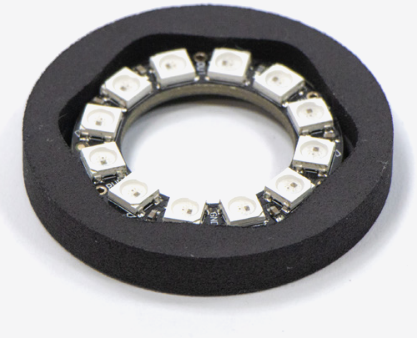

Figure $22(c)$ 


\section{Infrared camera housing}

To accommodate the infrared cameras, a push fit housing was designed using the outline of the meras as a reference point Tolerance optimisation

was then conducted by producing a range of

housing prototypes using an FDM 3D printer until

satisfactory push fit was achieved. The housing was

then printed via Shapeways to ensure the tolerance

also applied to SLS nylon.

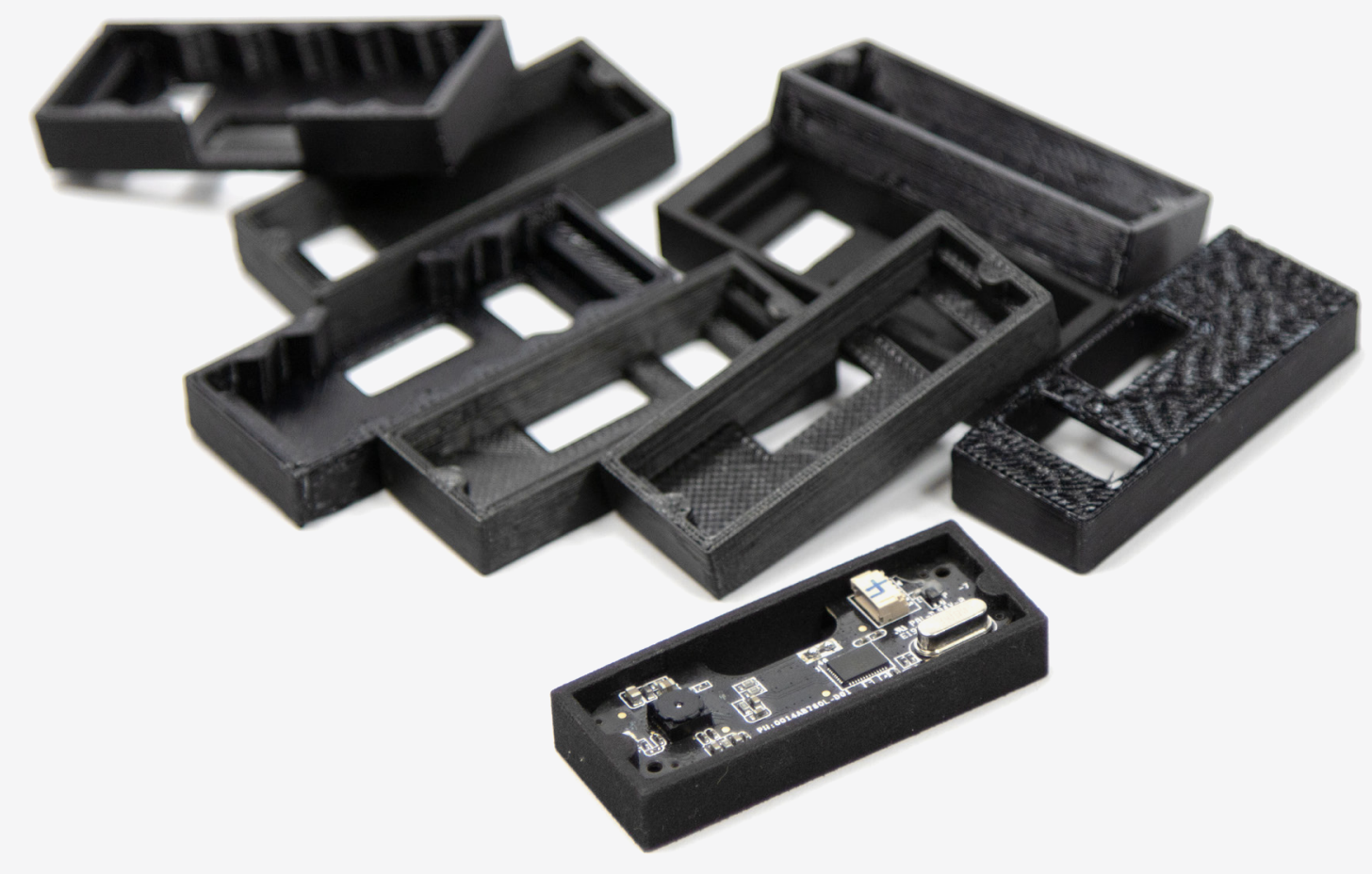

Figure 23 (a). Prototypes created during the tolerance optimisation process of the camera housing.

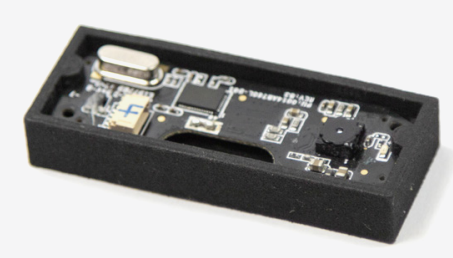

Figure 23(b).

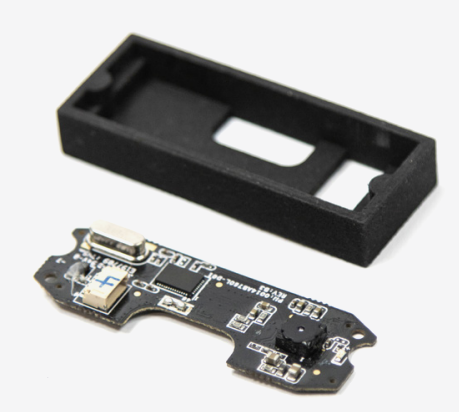

Figure 23 (c). 
Raspberry Pi housing

To accommodate the Raspberry $\mathrm{Pi}$, a push fit housing was designed using the outline of the $\mathrm{P}$ as a reference point. Tolerance optimisation was then conducted by producing a range of housing prototypes using an FDM 3D printer until a satisfactory push fit was achieved.

Unlike the other components however, the push fit approach did not house the $\mathrm{Pi}$ securely. In response, several different housing configurations were developed and tested. Eventually, a housing configuration that relied on four small clips to securely hold the PI in place was produced. The housing was then printed via Shapeways to ensure the tolerance also applied to SLS nylon.

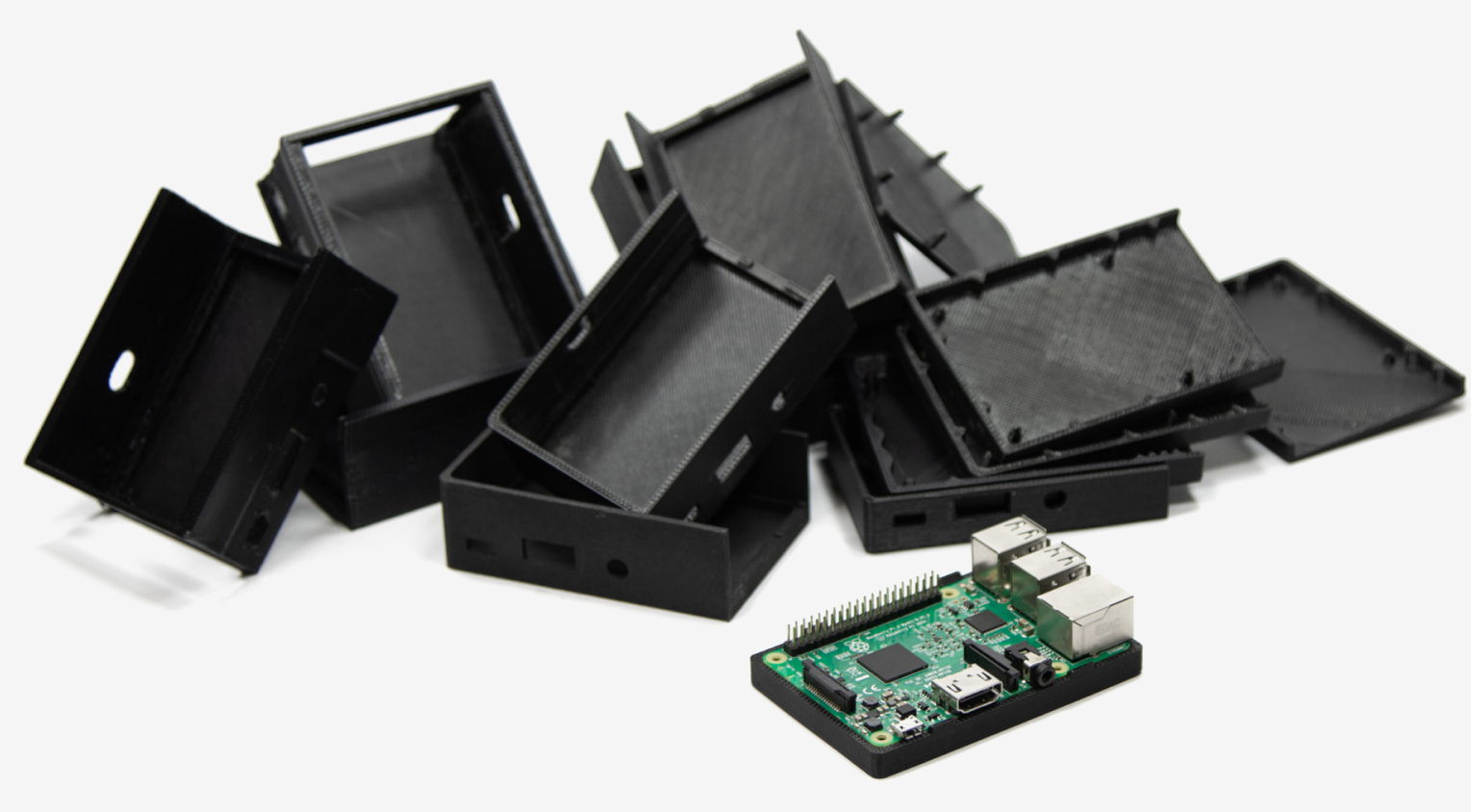

Figure 24(a). Prototypes created during the tolerance optimisation process of the Raspberry Pi.

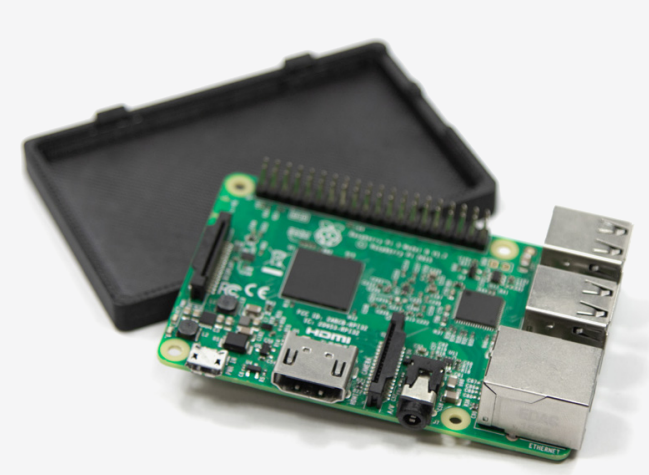

Figure 24 (b).

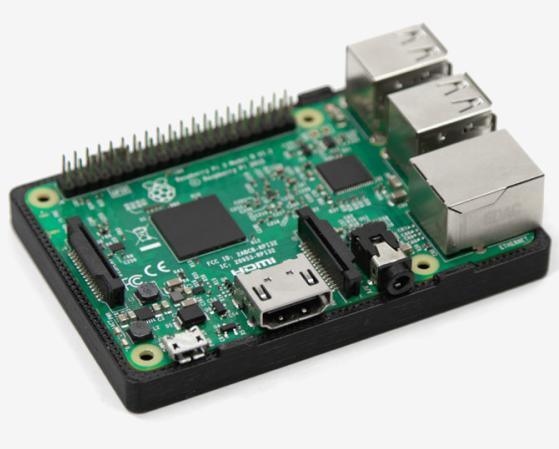

Figure 24 (c). 
Once all of the component housings had been successfully developed, they needed to be synthesised into an initial prototype.

The primary goal of this prototype was to provide the engineers something with which they could tes and trouble shoot their software.

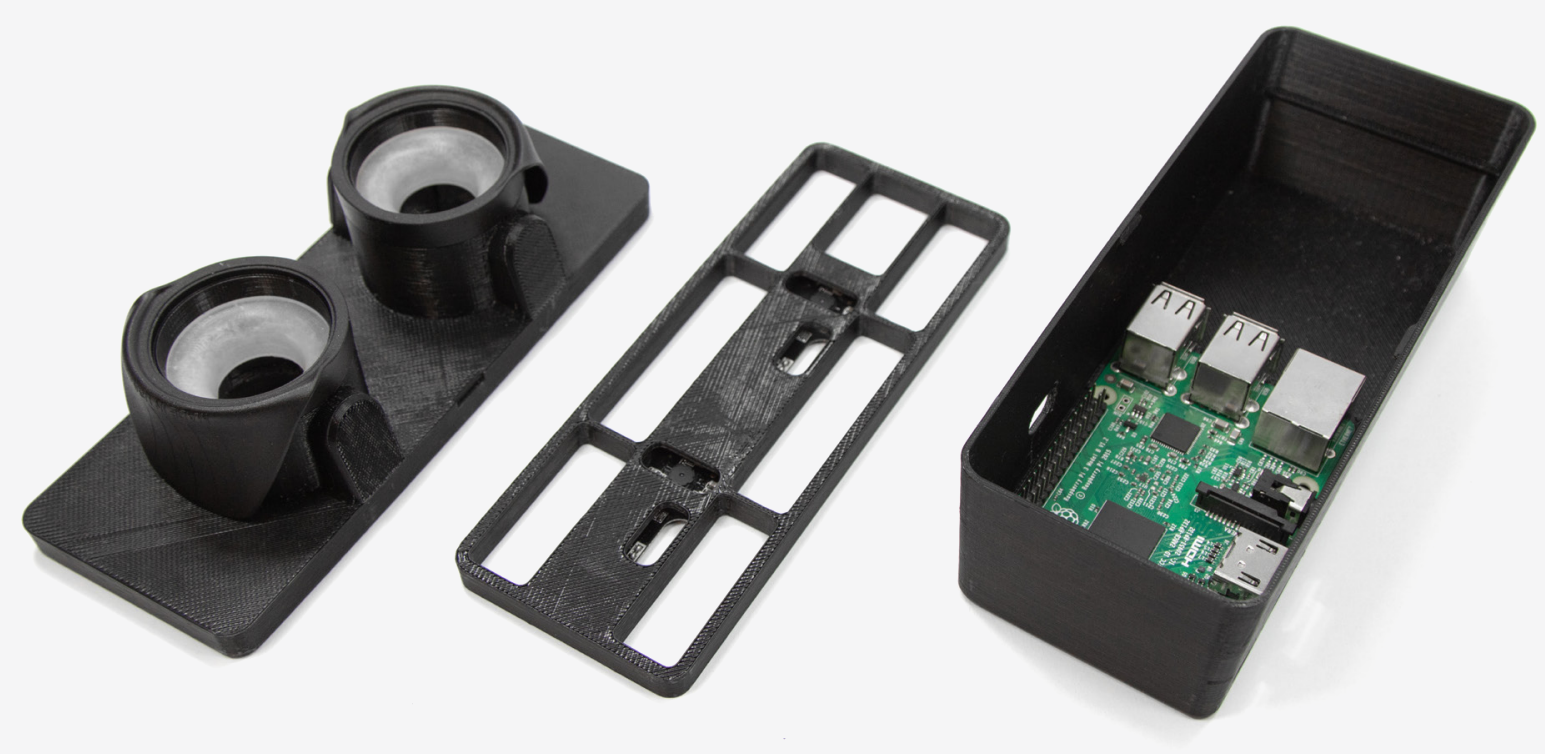

The development of this prototype also enabled each component to be optimised in terms of how much material it used, so that the prototype would be cheaper to print using Shapeways SLS nylon material.

Because this prototype contains the dimensional

data necessary to house each of the internal components of the device, it also acted as the structural skeleton for the rest of the design process.

Figure 25 (a). Exploded view of the initial prototype configuration.

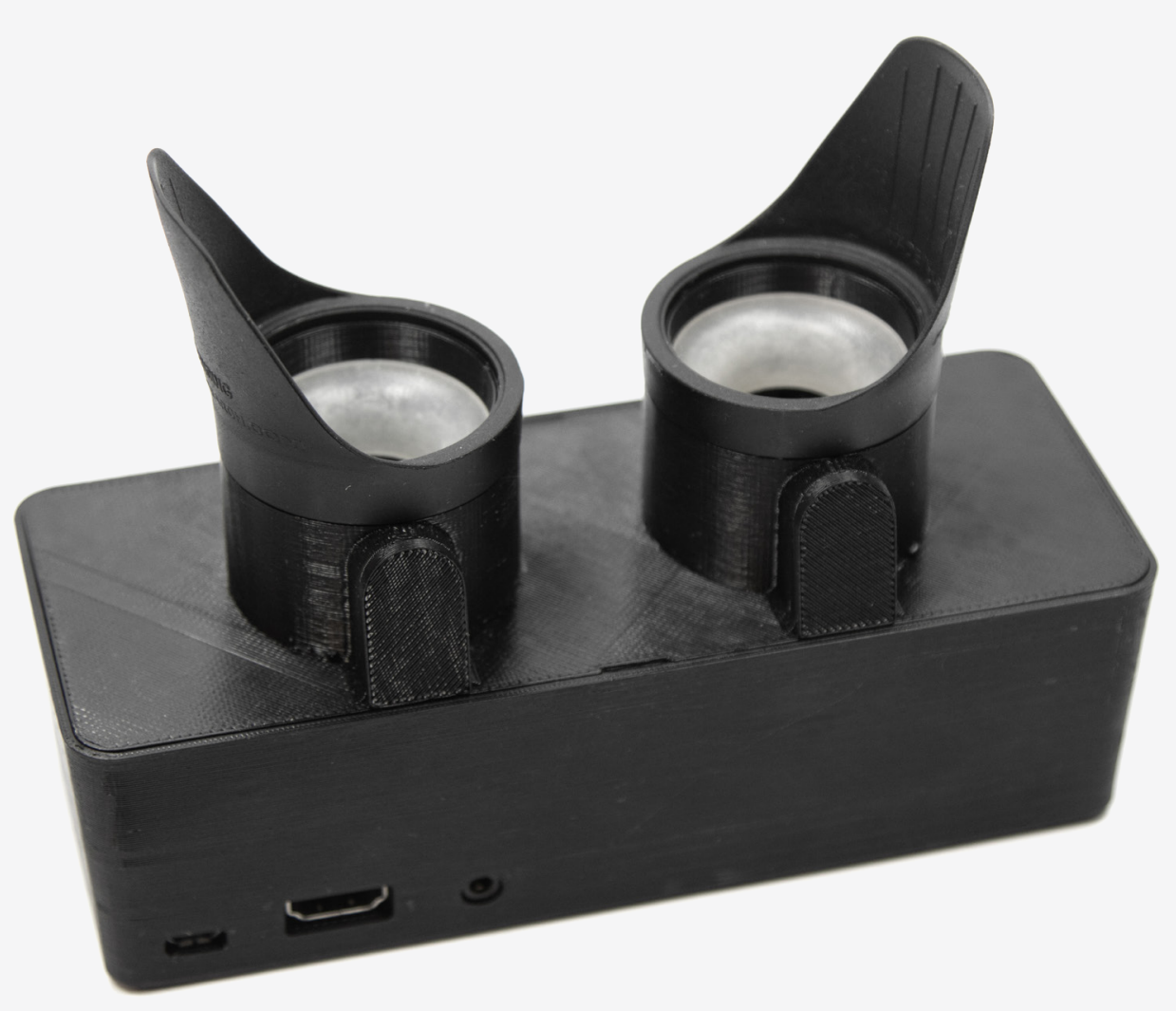




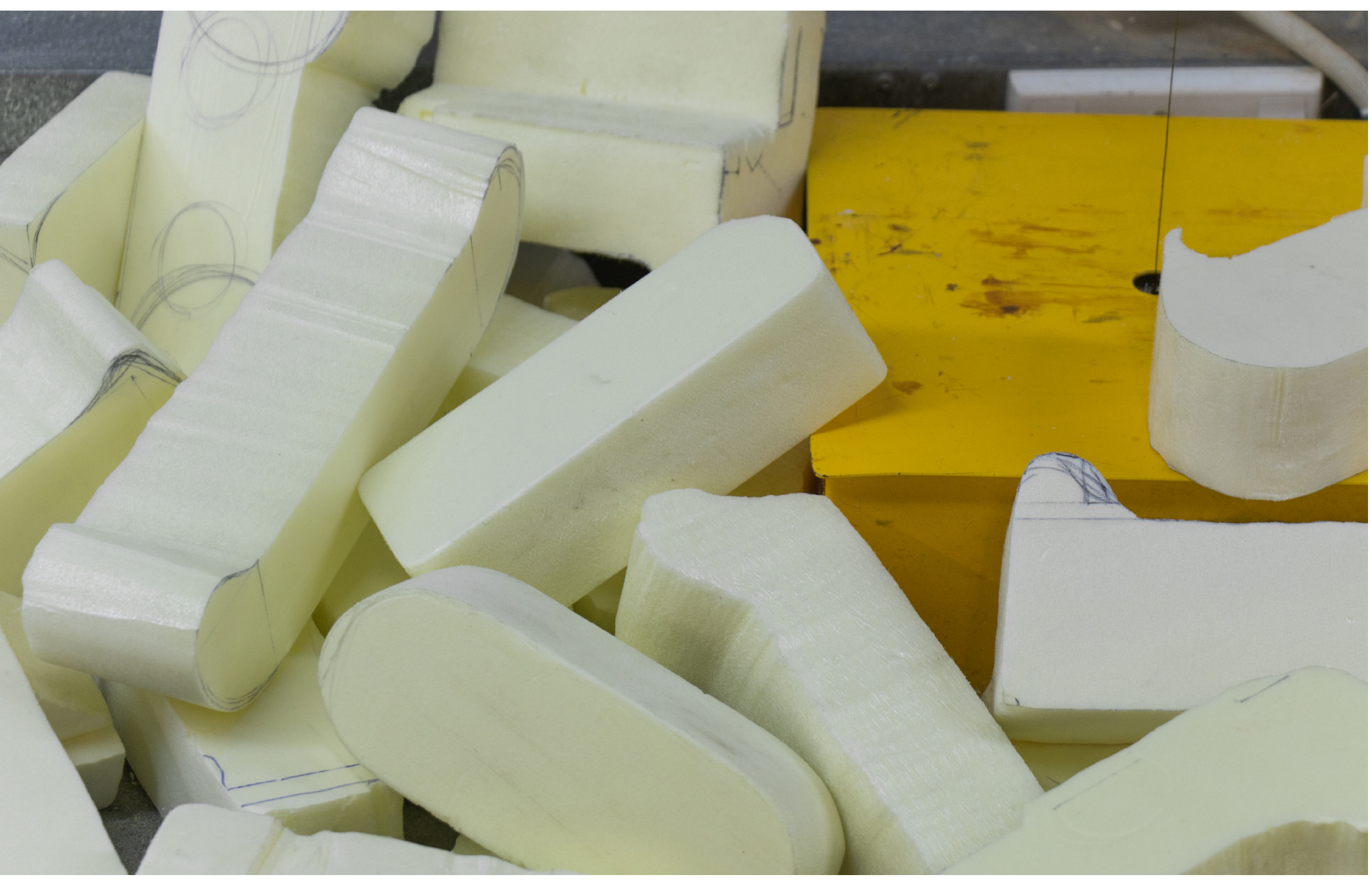

\section{Design phase 3}

Ergonomic analysis

a range of low fidelity gold foam models. Paralle The goal of the third design phase was to take a step prototyping is the act of producing a range of back from the more technically oriented research prototypes simultaneously, and then selecting the through design conducted in the previous design best based on user feedback (Hanington \& Martin, phases to address the ergonomic and usability 2012). This process prevents 'hill climbing' to a less aspects of the device.

To achieve this, existing optical devices designed

to interact with the users eyes in some way were By producing a range of different prototypes collated and analysed to identify any design simultaneously and testing them with users, features that may be applicable to the design of the valuable ergonomic and usability feedback was Openpupil device. optimal design resolution, which can occur when conducting linear iterative design research.

Following this, a range of sketches were produced to help solidify the ideas generated throughout this gathered and applied to the overall design of the pupilometer. 


\section{Precedent analysis}

\section{Virtual reality headse}

A virtual reality (VR) headset is a head mounted device that sits over the users face and projects

moving images into the users eyes. Virtual reality

headsets are required to sit comfortably over the

users eyes and face for long periods of time, and because of this the ergonomics of the device must be carefully considered.

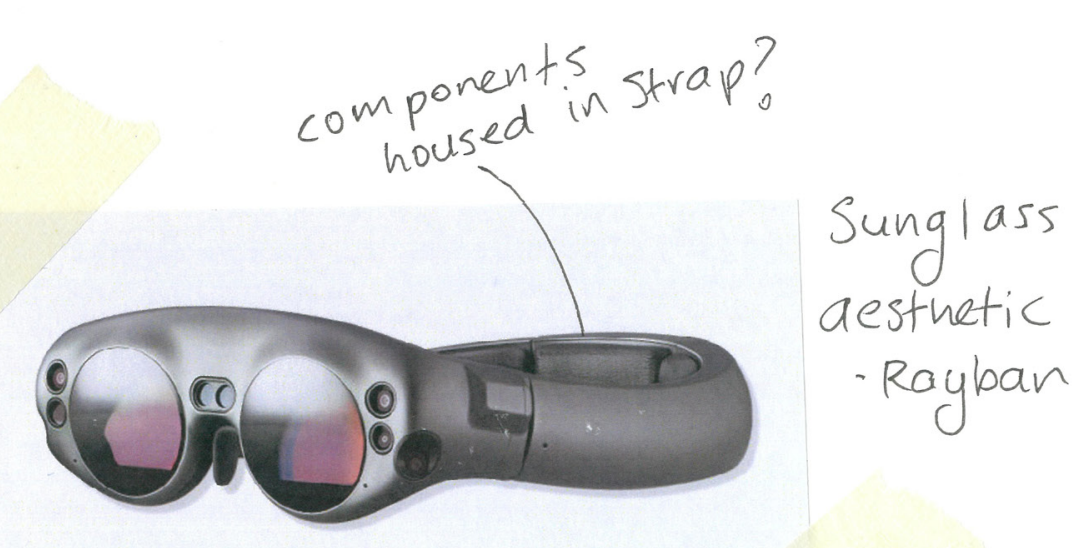

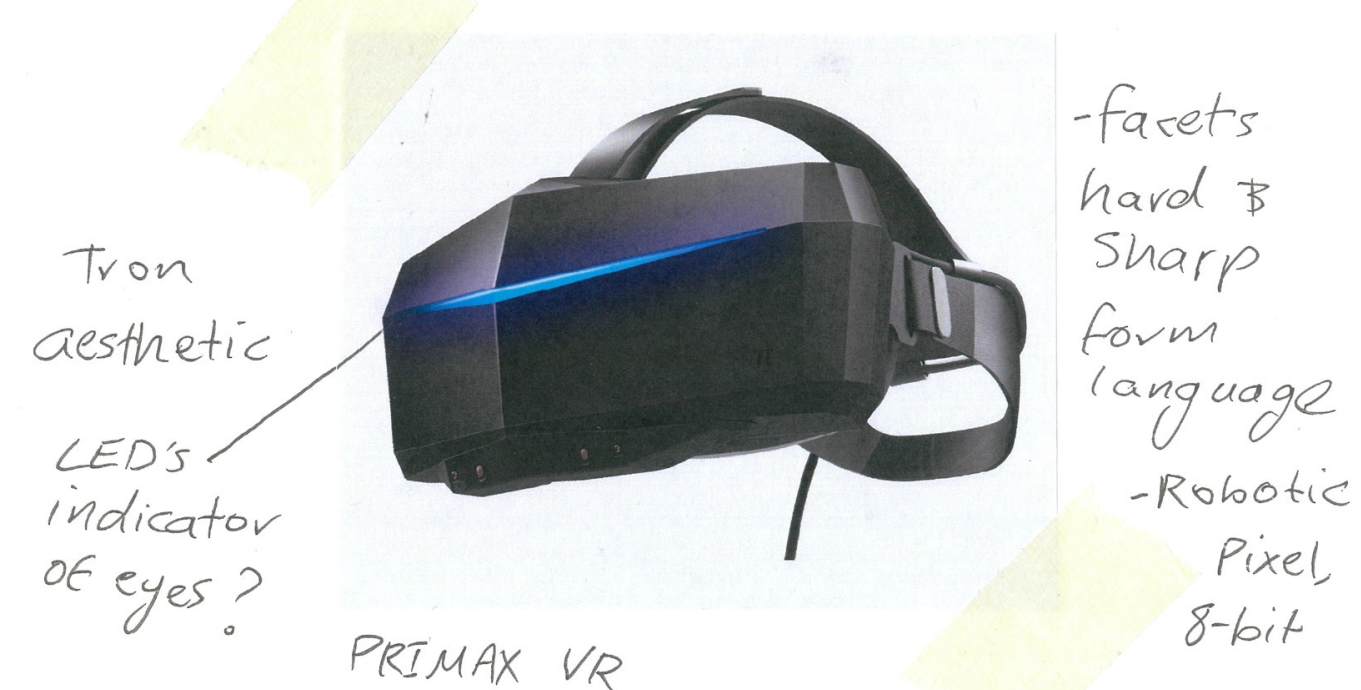




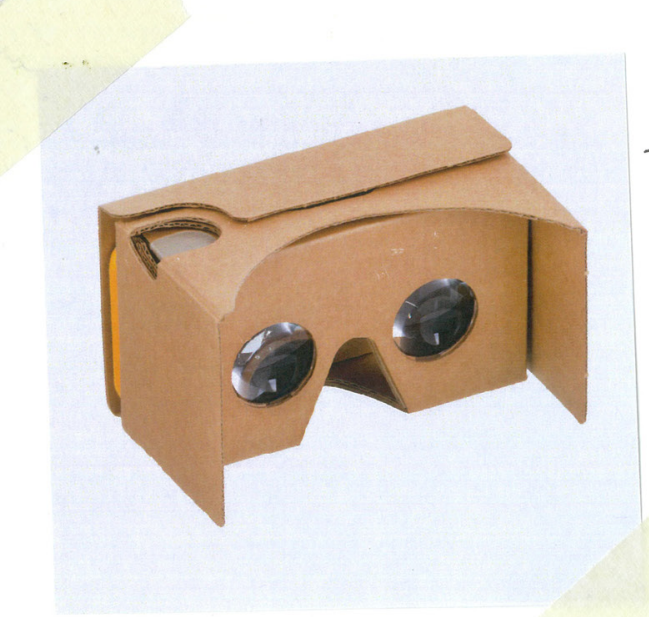

Google card board

- Low fidelity, cheap

material

- Simpre form languag
circles, (eye)

circles, (eye)

triangle (nose)

rectangle (face)

$$
\text { - Flat pack }
$$

-Disposable
technology

$$
\Delta^{0-} \begin{aligned}
& \text { facial } \\
& \text { indicators }
\end{aligned}
$$

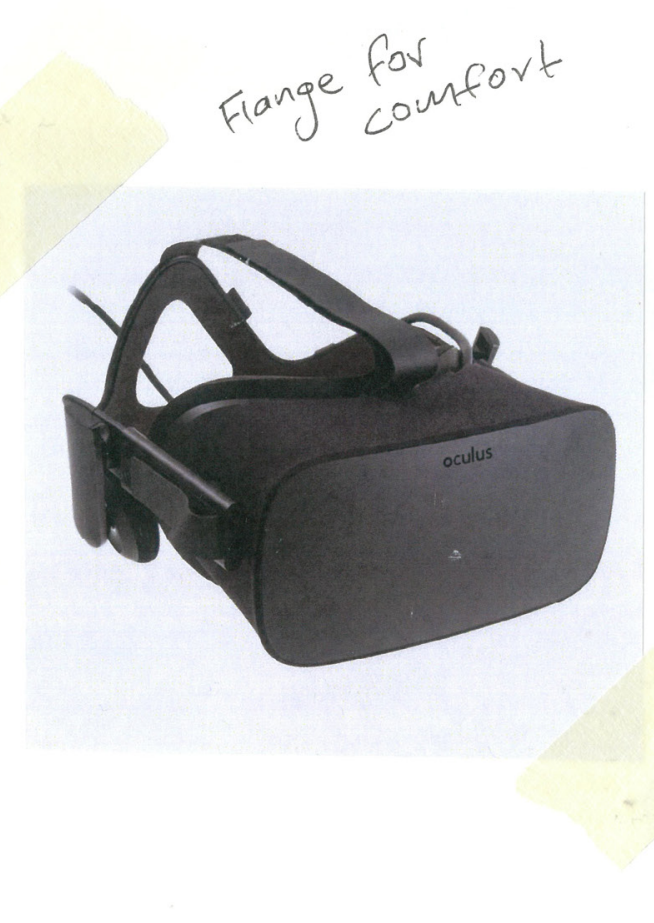

Oculus rift

- Traditional headset design

Rounded, boxey aesthetic

Black on weतk

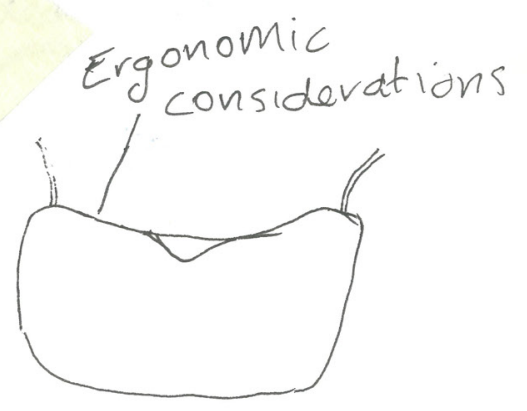

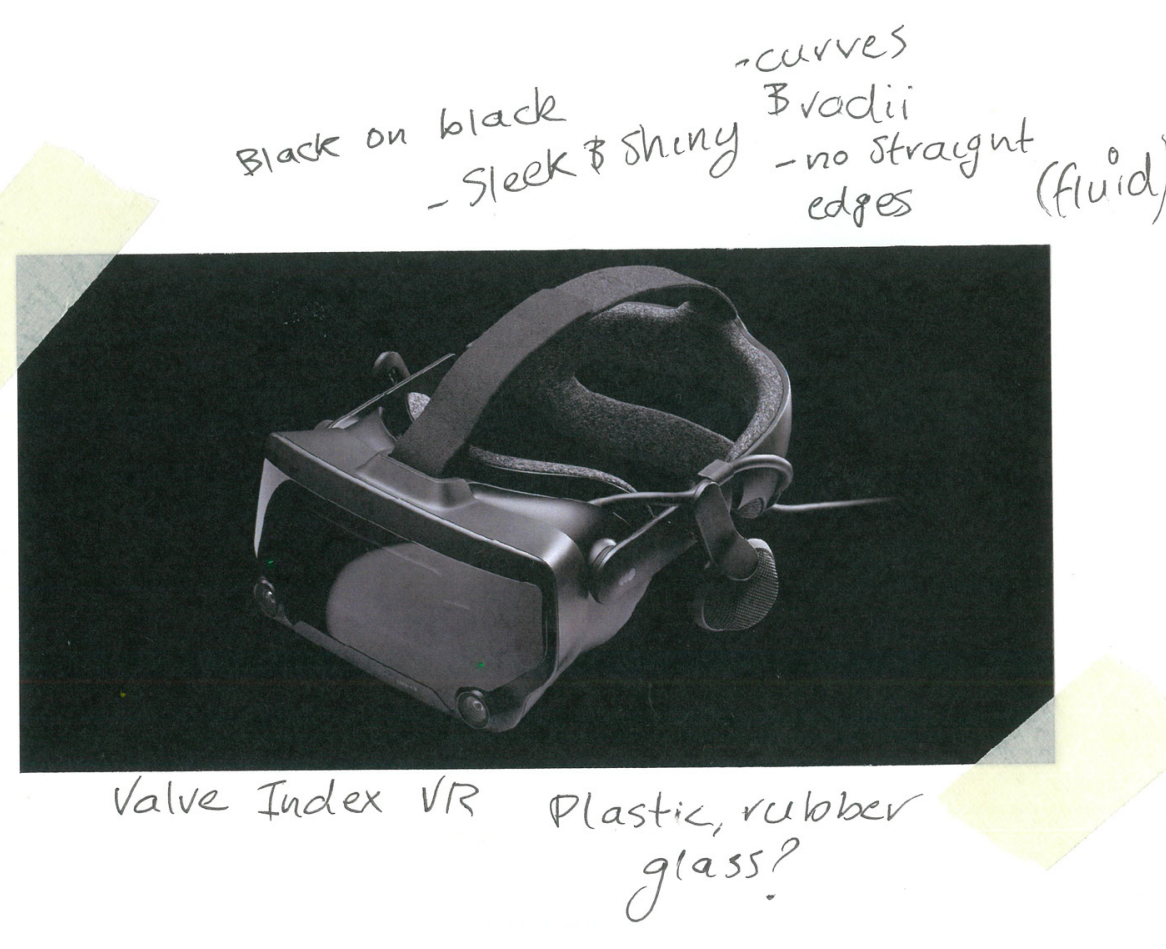

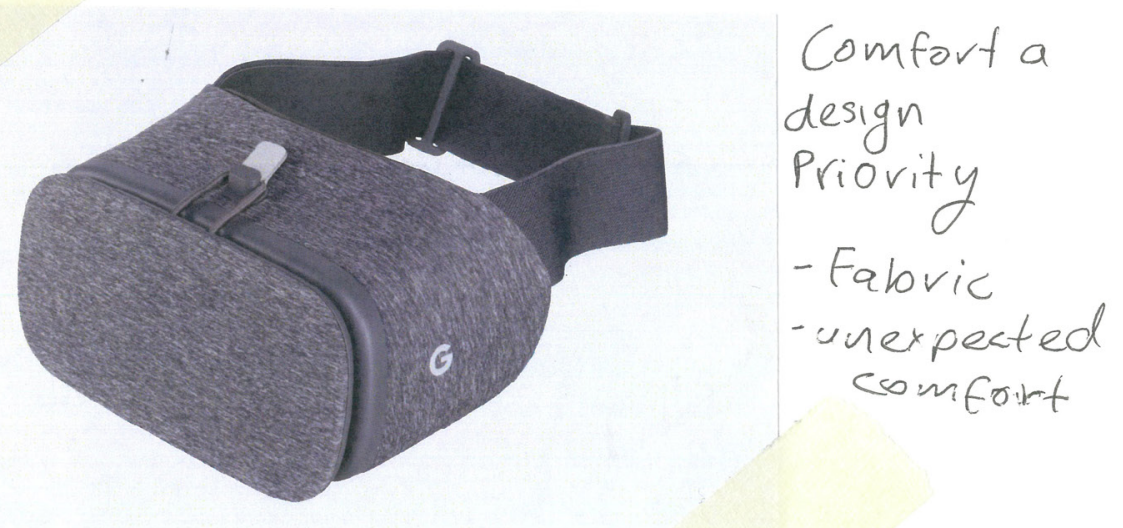

Google daydream

$$
\begin{gathered}
\text { - More a piece of } \\
\text { clothing then a VR? } \\
\text { heddset? }
\end{gathered}
$$




\section{Headset sketches}

Based on the VR precedent analysis, a number of

2D form finding sketches were produced. Sketching

is an effective method of rapidly generating ideas,

and was used to explore possible forms that could be applied to a head mounted design configuration.
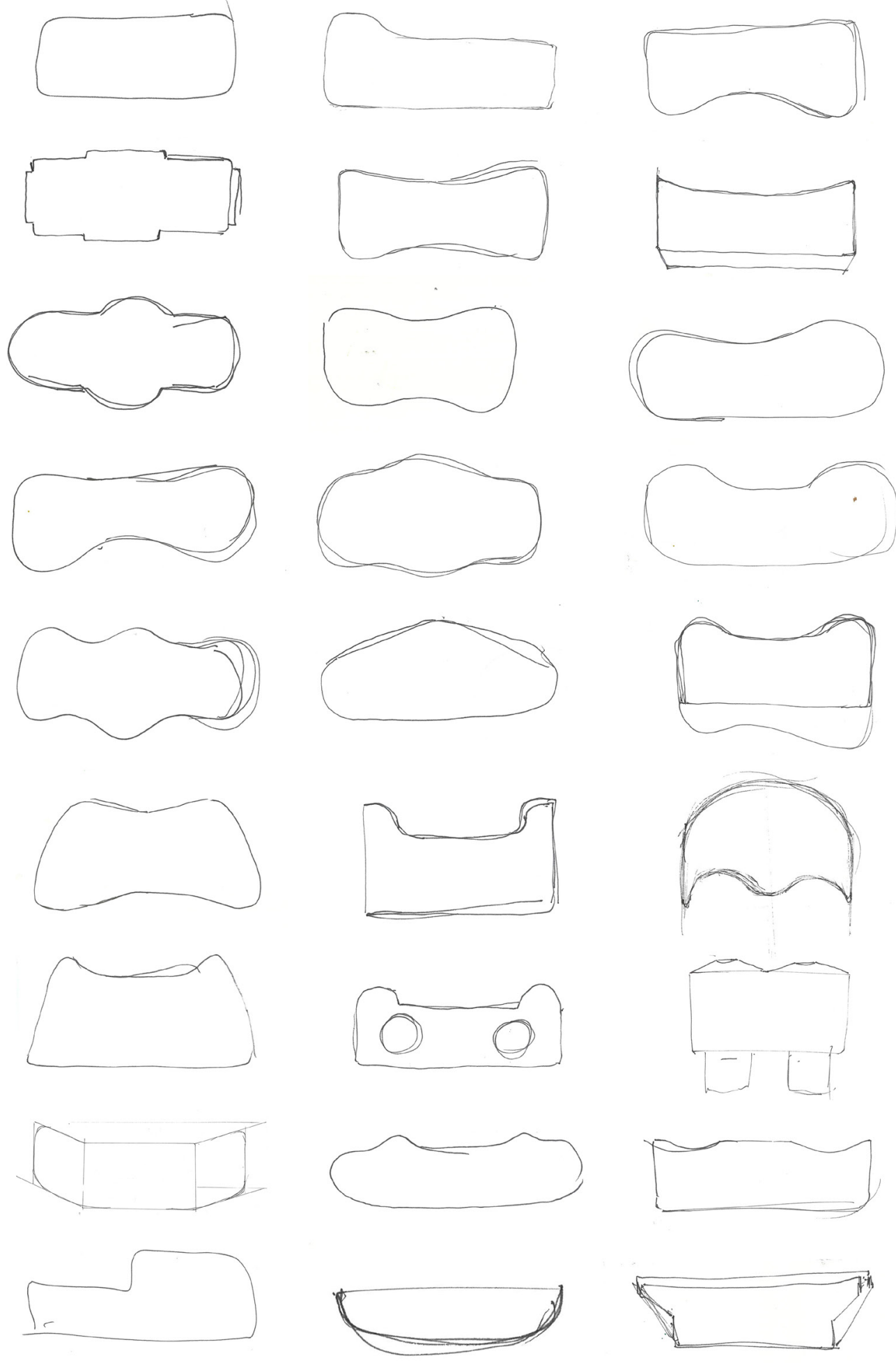

Figure 26. Ideation sketches based on VR headset precedents. 


\section{Ergonomic test}

To test the viability of the headset configuration, a low fidelity cardboard VR prototype was produced and two different head straps were tested. Both of the head straps performed well, providing a comfortable fit for both users.
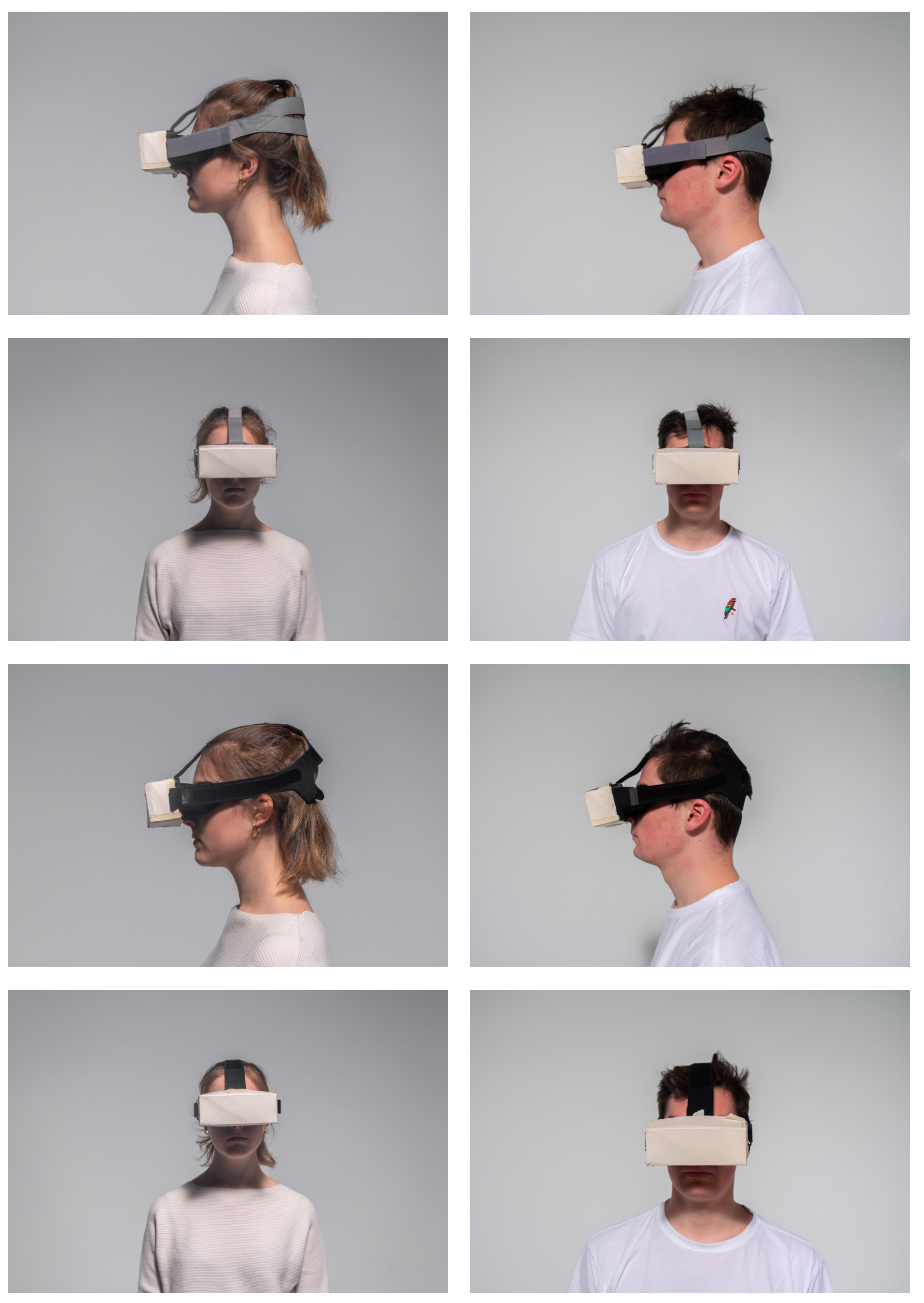
During the initial summer research scholarship, the device was conceived as a head mounted device. However, ergonomic testing conducted throughou the thesis stage of the project indicated a number
of issues relating to the head strap configuration.

Firstly, the size and weight of the battery made it unsuitable to be housed within the device over the users face. Instead, it would need to be mounted on the back of the head strap, resulting in expose cables running from the battery to the PI. The strap also made the device cumbersome to carry and me consuming to fit to the patient, particularly in the field. Taking into consideration the fact that the pupil tests only lasted several seconds, it became no real benefit to the testing process.

Another problem encountered during the design process was component obsolescence. It becam pen need to be continuously updated as new and To efficient contigurations become available. To accommodate this, the design needed to be
versatile and adaptable.
As a result, the device was ultimately conceived as a utility 'box' contiguration. By providing additional space around the electronic components, intern

additions/modifications to the device can easily be accommodated. This tormat also enables other users to 'hack' the device to their own specifications, increasing the versatility of the device in the field where portability, handling and durability in as yet unknown contexts need to be accommodated

Once it was established the device would be hand-held, a parallel prototyping process was conducted. Parallel prototyping is the act of producing a range of prototypes simultaneously and then selecting the best based on user feedback. To achieve this, a range of foam and card prototypes were produced, addressing how the device would be held, as well as how the components would be configured. Prototypes were then tested with users, where valuable ergonomic and usability feedback was gathered and applied to the design of the device.

From here, an FDM 3D printer was used to

ileratively develop each individual component to a enabled the assembly of the device to be ts and tred assembly of the device to be tested and troubleshot with each new iteration, unti the device was then 3 printed via Shapeways using an SLS nylon material.
Precedent analysis 2

\section{Binoculars}

When considering possible design configurations for the device, the question of whether or not the device was required to be mounted on the users head was asked. Through concultition with the wider team of Engineers and clinicians working on the project, it was decided that there was no reason the device could not be conceived as a hand held device, where the user holds the device to their eyes similar this remebody would hold a pair of binoculars. 
Nikon Travelite Ex
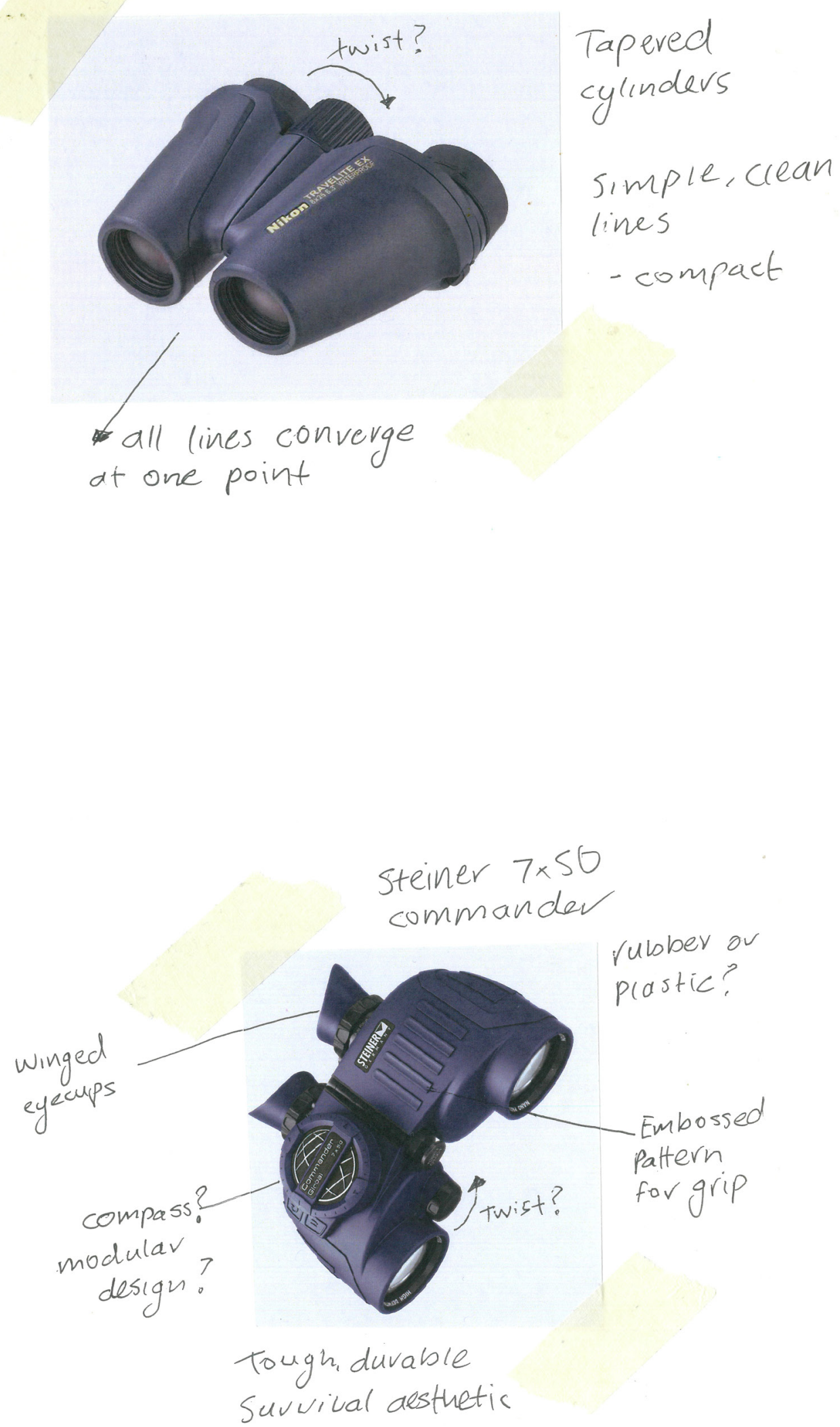

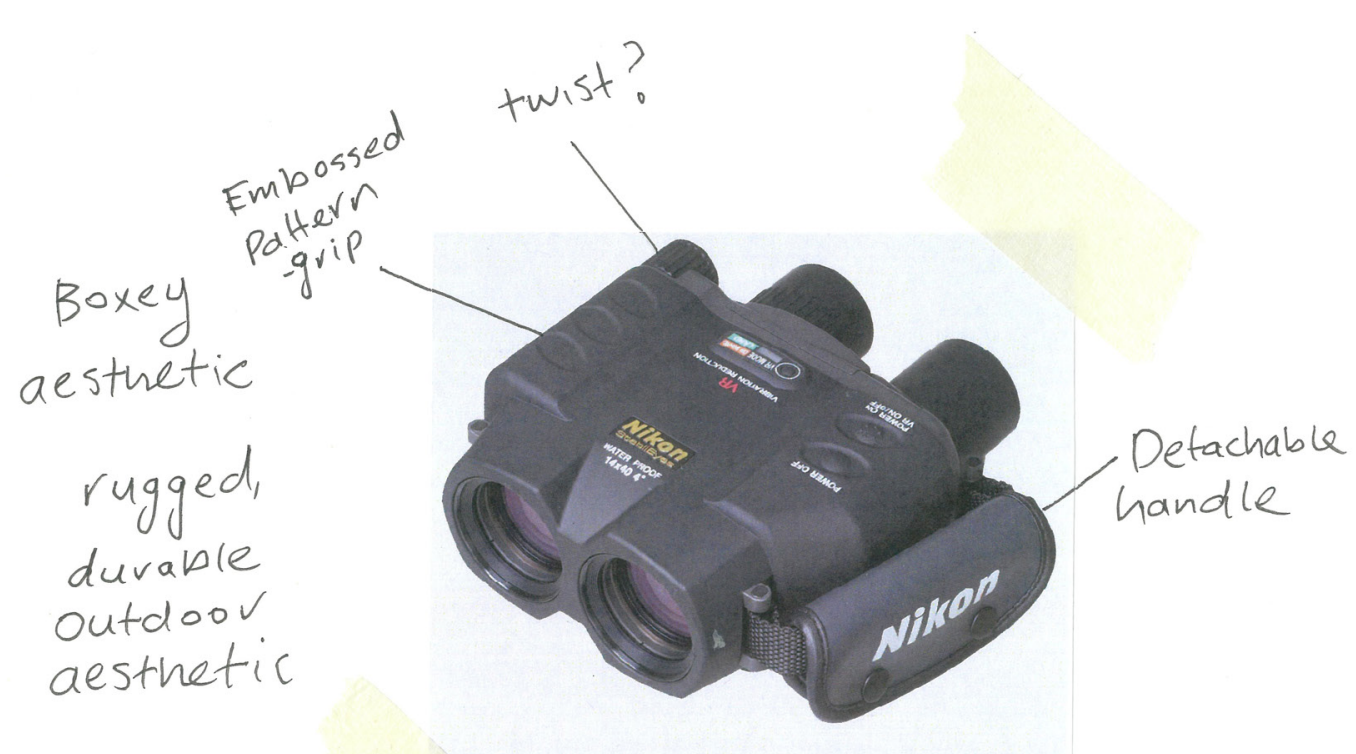

Nikon Stabileyes

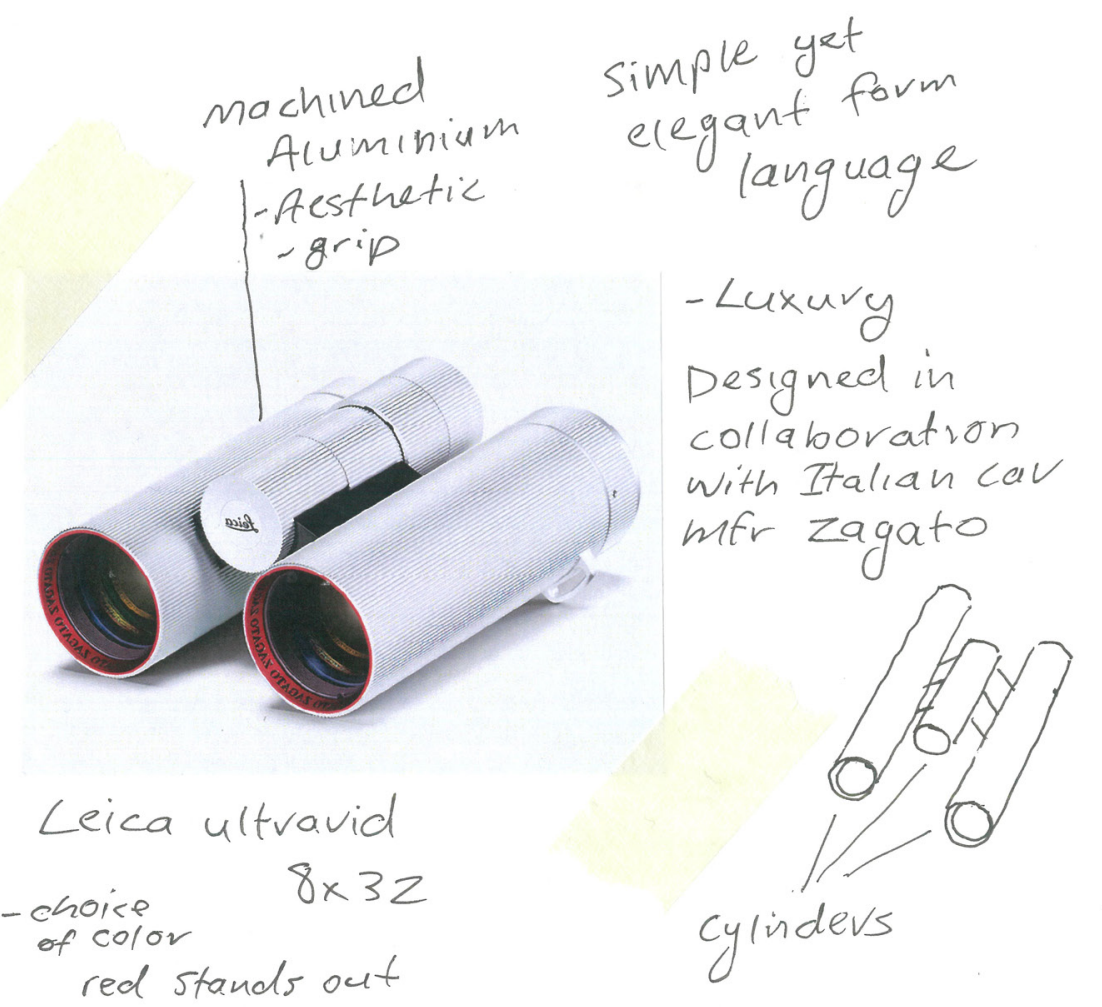




\section{Binocular sketches}

Based on the binocular precedent analysis, a

number of form finding sketches were produced.

These sketches started to explore 3-dimensiona

forms, and attempted to address how the use would comfortably grip a hand held pupilometer.
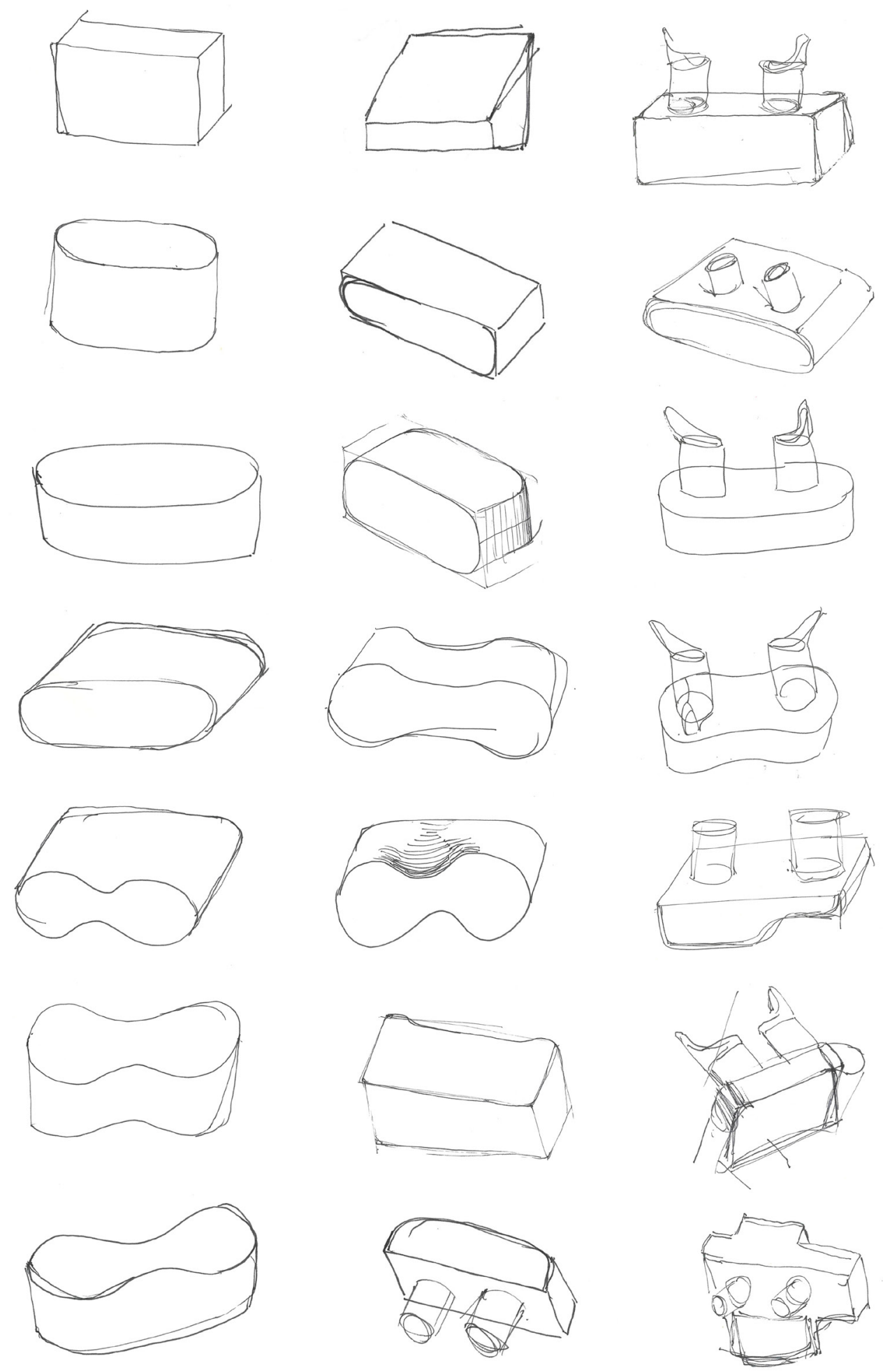

Figure 28. Ideation sketches based on binocular precedents. 


\section{Ergonomic test}

Based on the binocular precedents and subsequent

sketches, a range of gold foam models were

produced. These models focused on identifying the

prost com tortable forms to hold when positioned in

front of the users eyes.
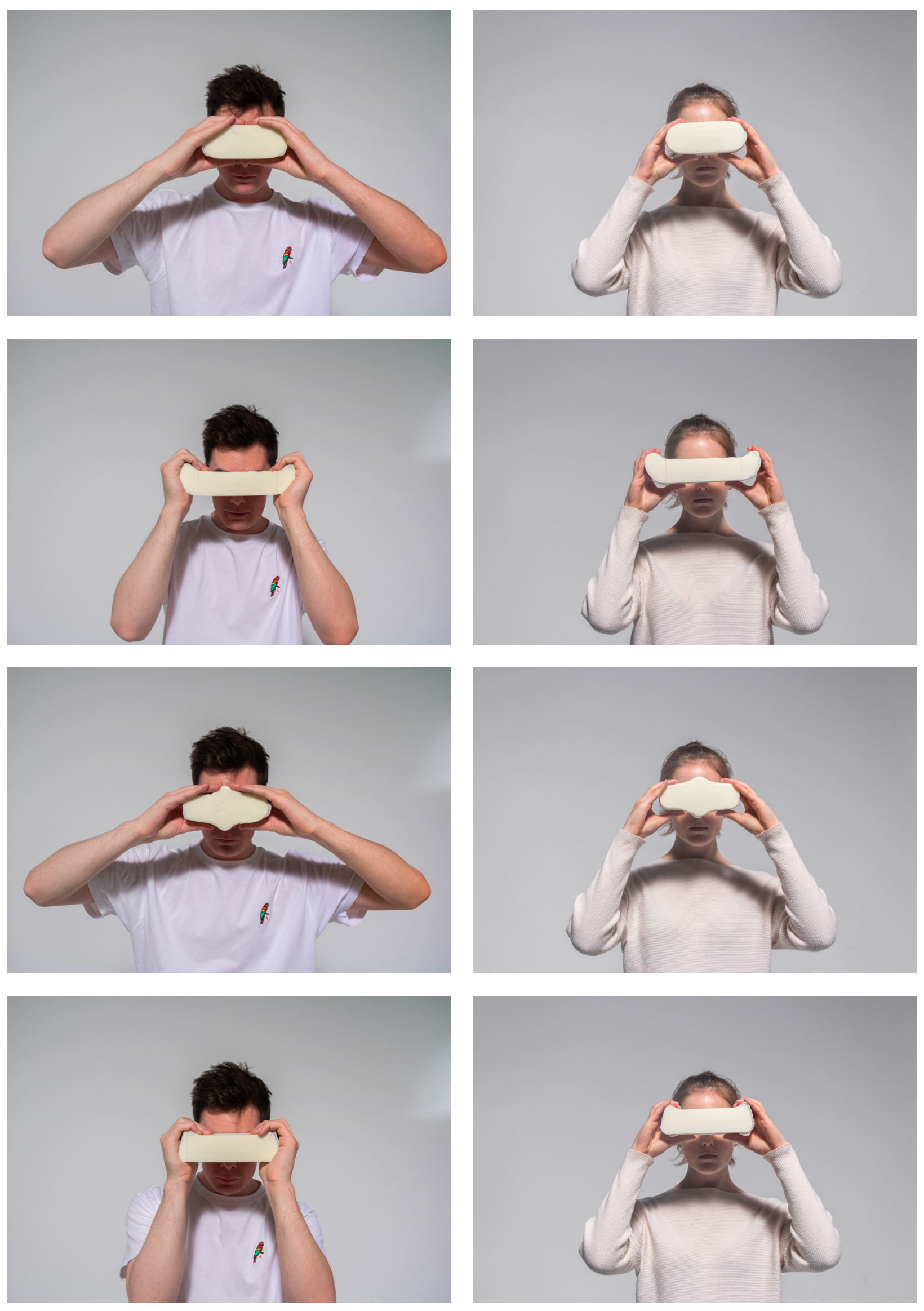

Figure 29. Gold-foam ergonomic experiments based on binocular precedent analysis. 


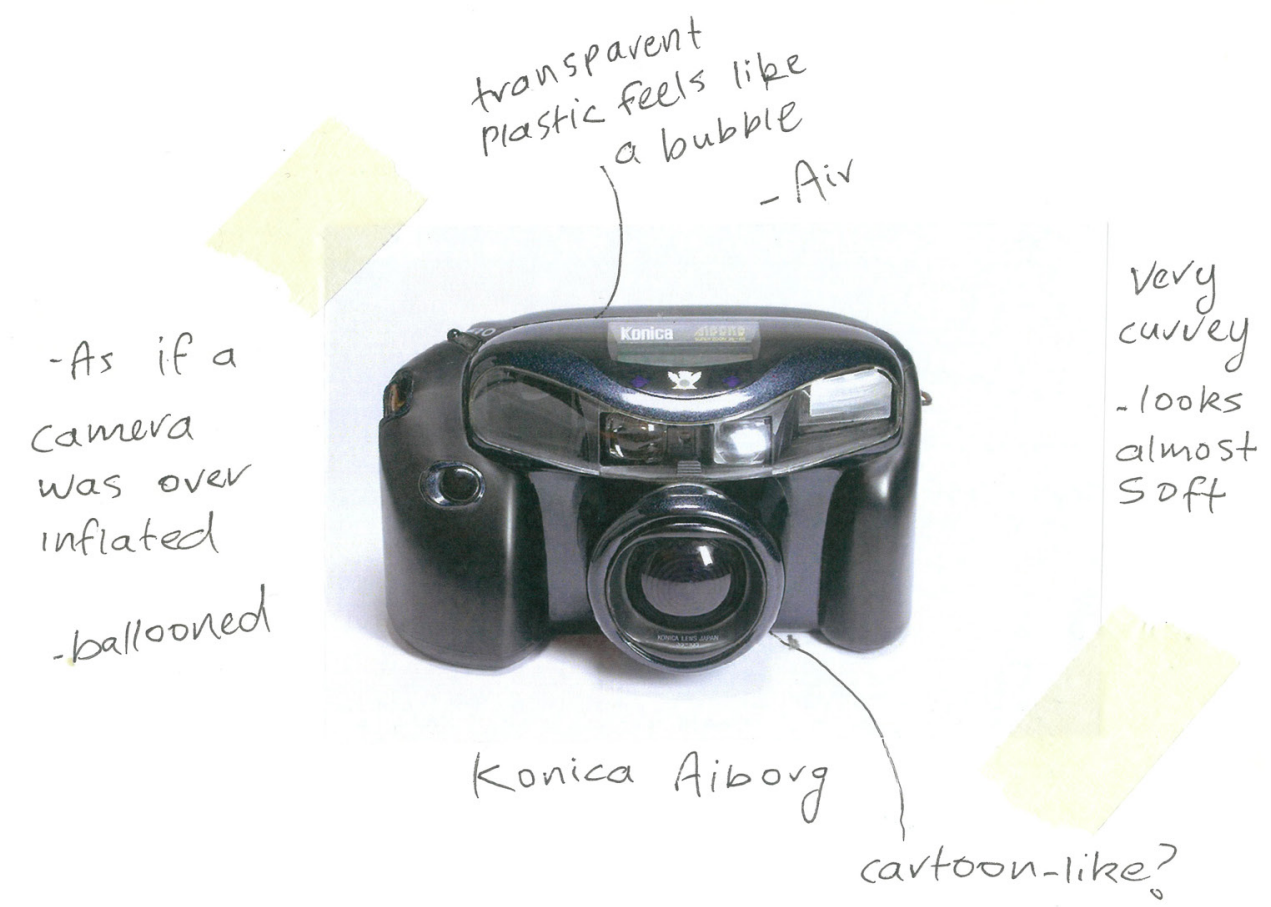

Camera

The camera is another hand held device that is used to capture and store still images of the externa environment. For a clear image to be captured, the camera must be held steady, and the shot lined up by staring through the cameras view finder.

To ensure both of these things occur, the camera must be easy to grip and comfortable to hold, while the view finder must also be comfortable when pressed up to the users face. For both of these things to occur, the ergonomics of the camera mus be well thought out.

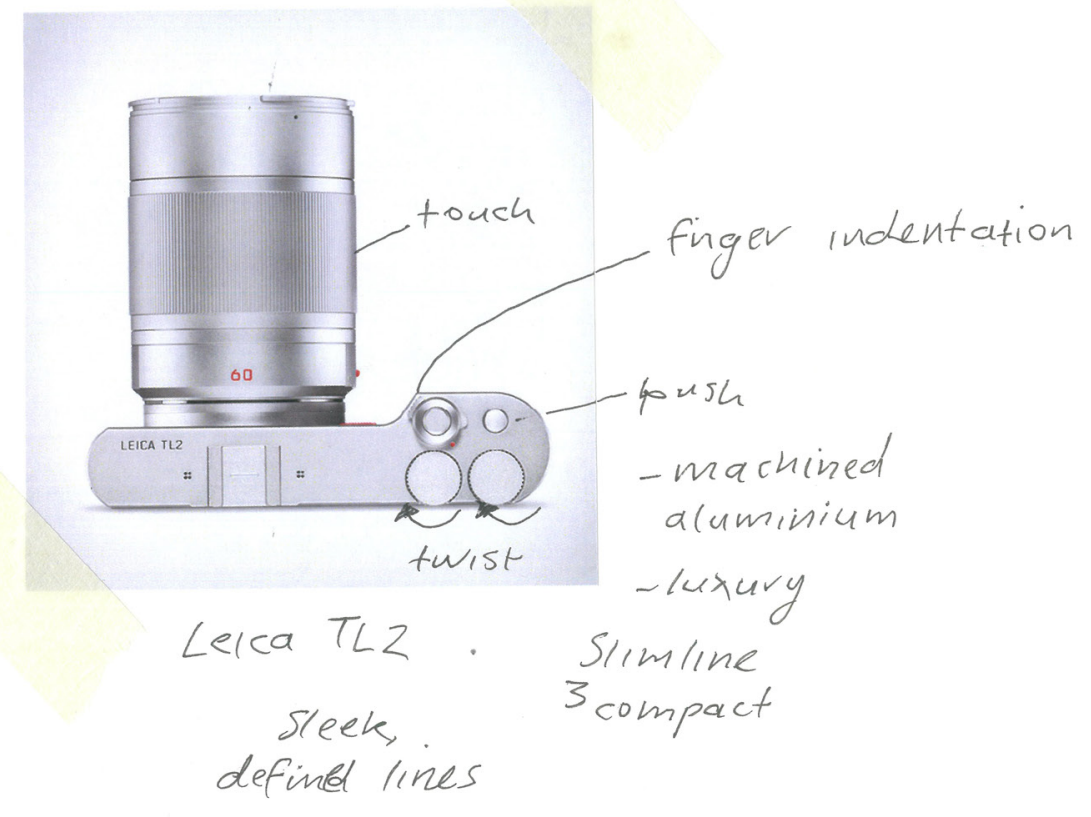




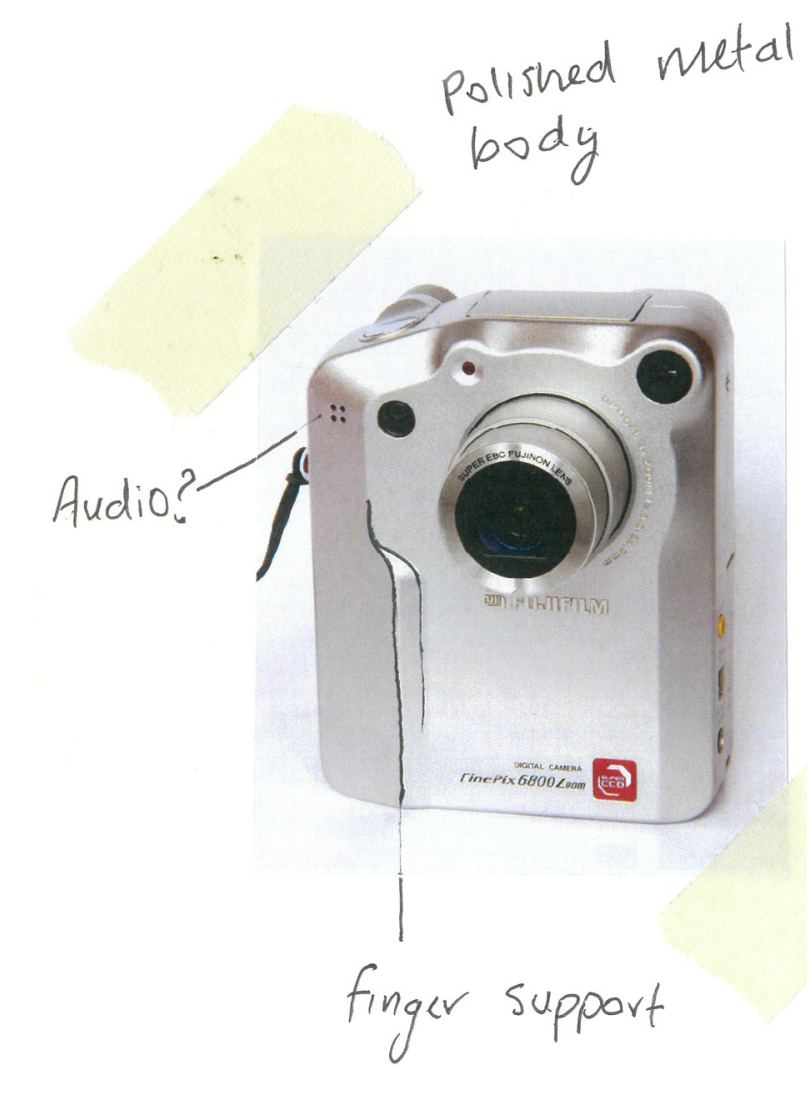

Fuijifim $x$ Porsche

Fine pix 6800

- Portrait orientation

00

- Distinat profile
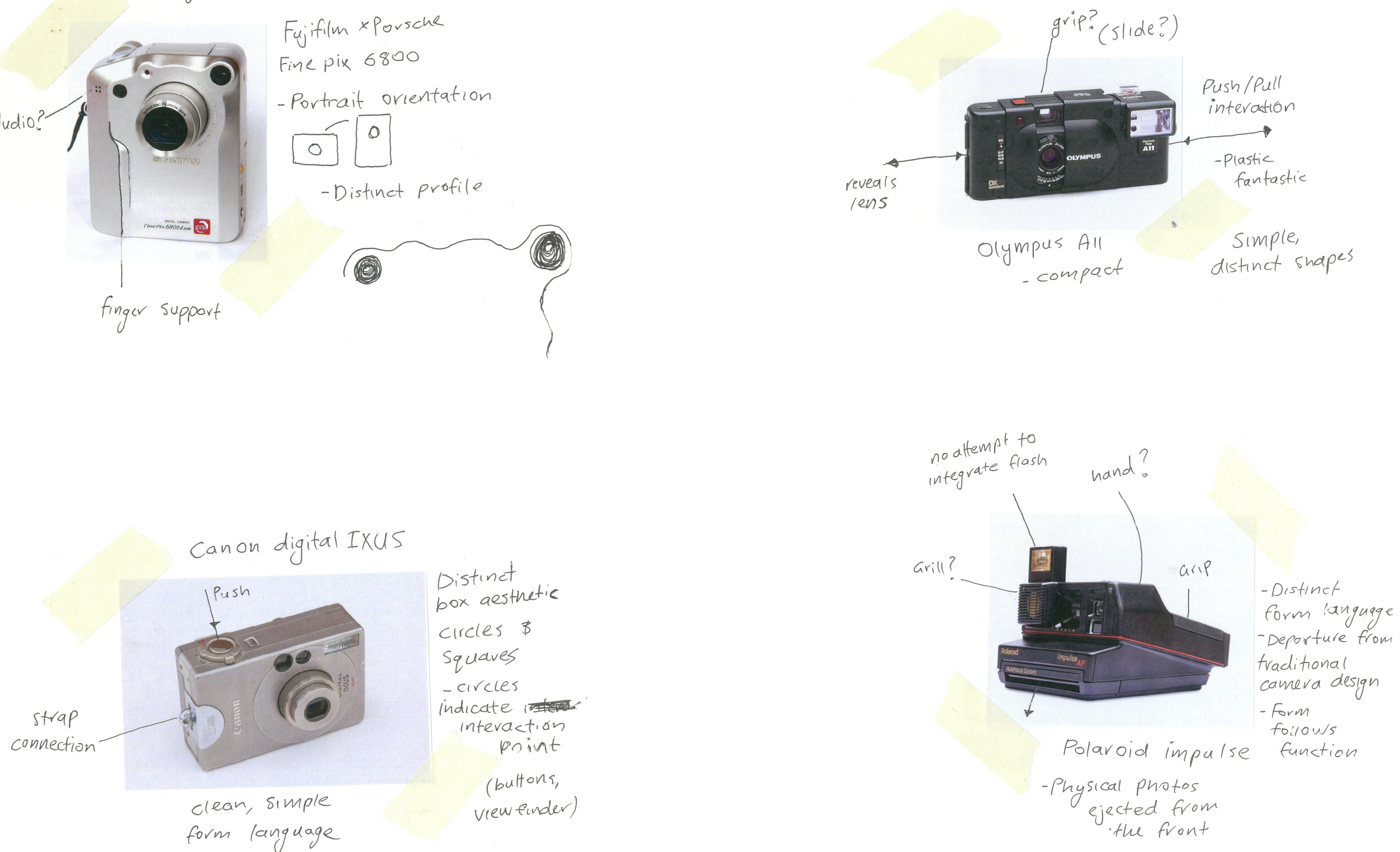


\section{Camera Sketches}

Based on both the Binocular and camera precedents, as well as the previous ergonomic research conducted in this chapter, a range of more resolved, higher detailed sketches were produced. These sketches focused on how to ensure the device would be comfortable to hold, while also being comfortable to hold up to the face. Components and other functional requirements of the device also began to be considered at this stage.

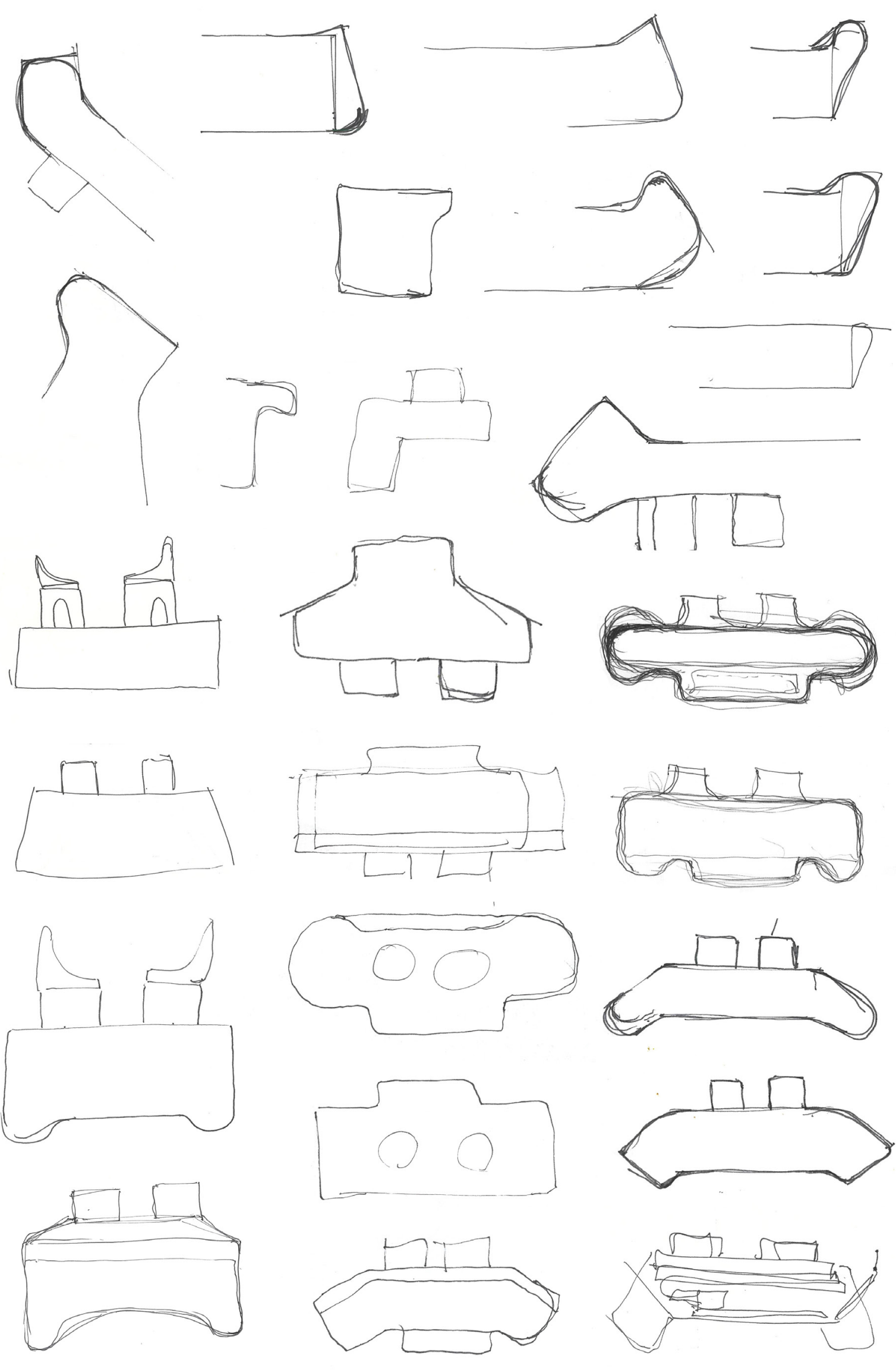


Ergonomic tests

Based on all previous ergonomic research conducted, a range of foam models were produced based on how a camera is typically held, as well as the forms cameras usually take. The battery was also introduced into the testing as this point, to get an idea or how much the device would weigh and whether or not this would affect how it was held.
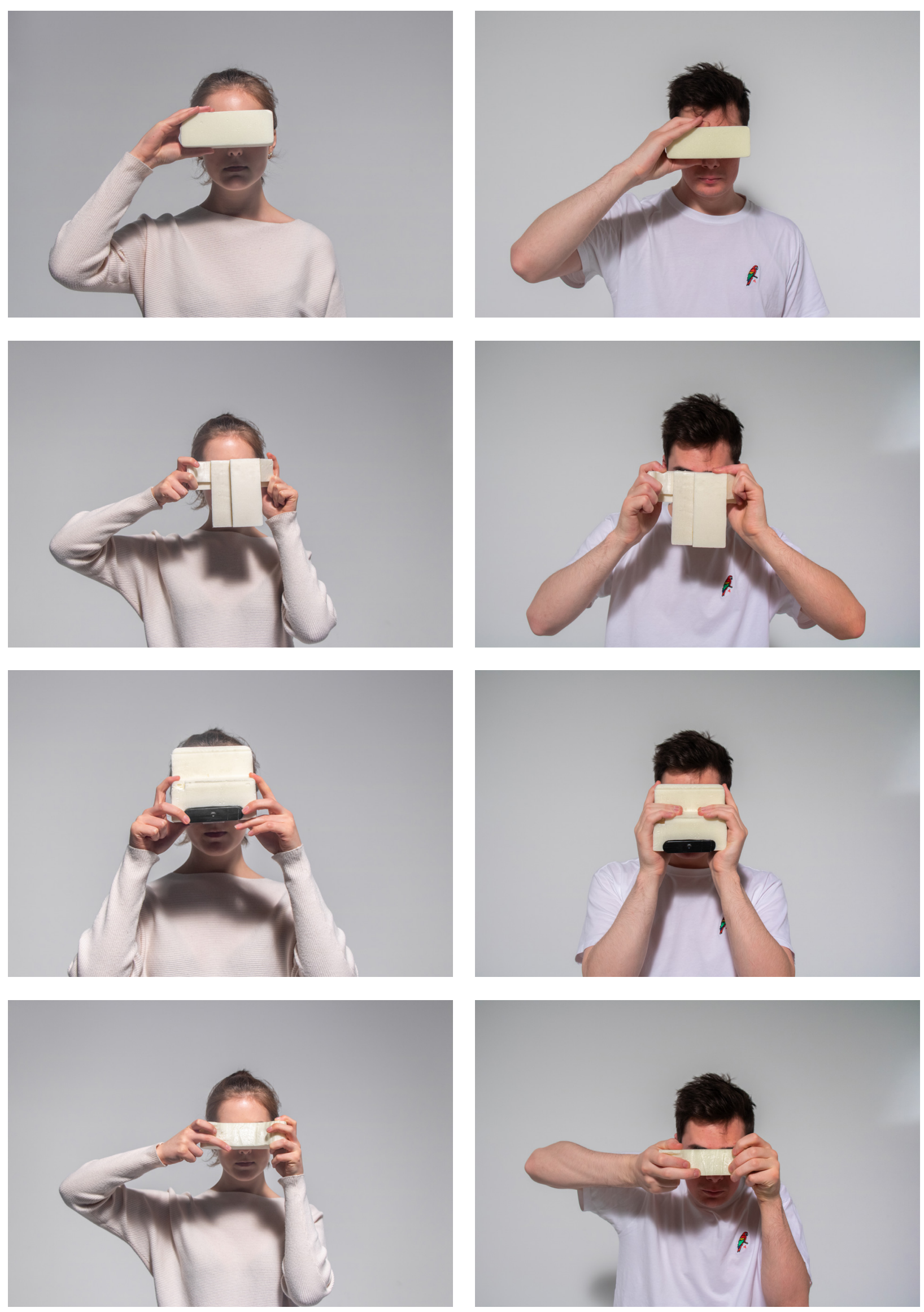

Figure 31. Gold-foam ergonomic experiments based on camera precedents. 
At this point, the components contained within the device began to play a larger role in how the device might be configured. Low resolution card models were produced to try and gauge how much room would be required to house the battery within the device, while old 3D printed prototypes and other spare parts were taped together in a range of configurations, in an attempt to try and find the optimal component configuration .

To get a better idea of how to effectively house all of the components, a range of utility containe precedents were examined.

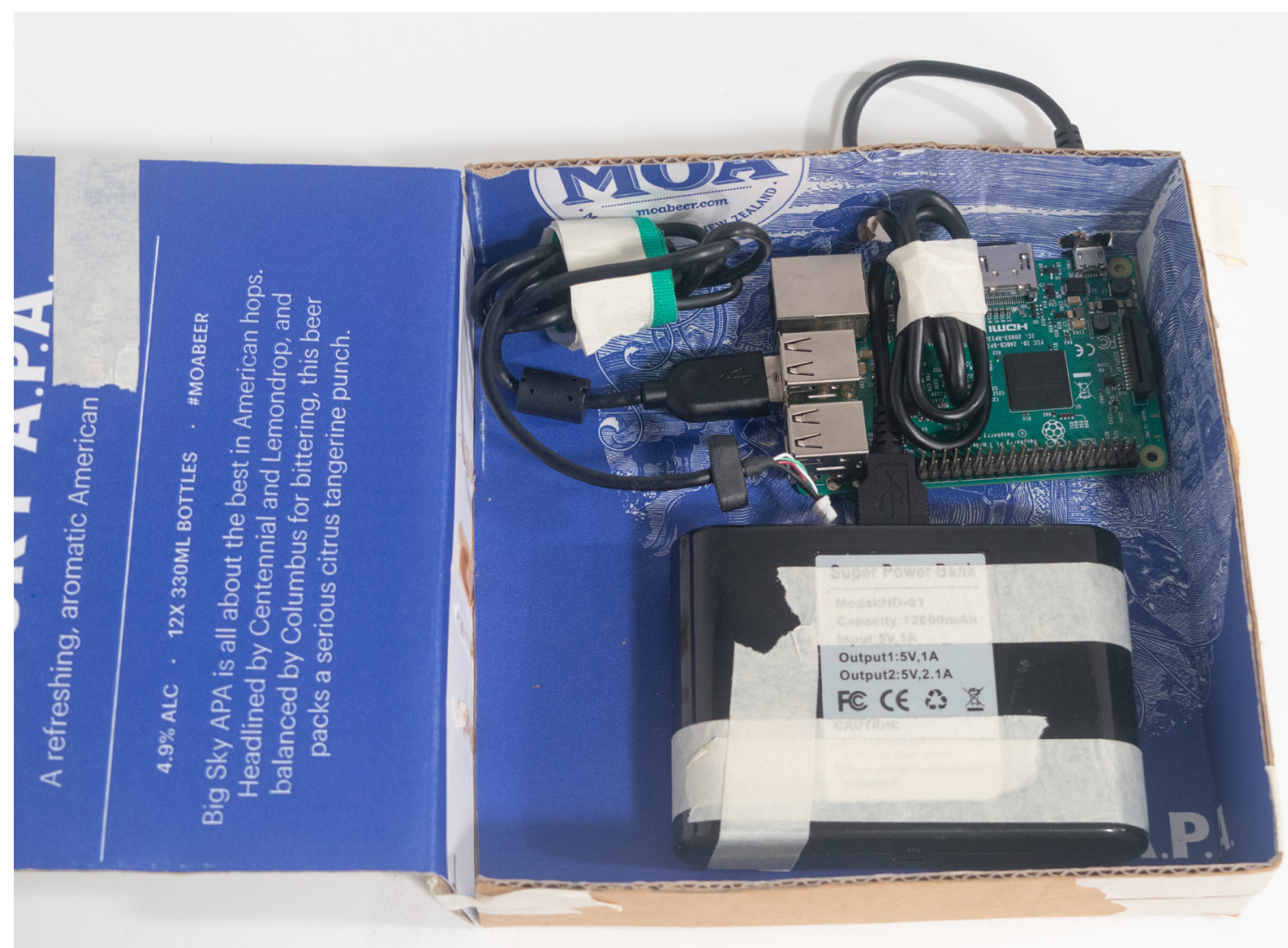

Figure 32 (a). Low fidelity card prototype used to contain a raspberry Pl and a battery.

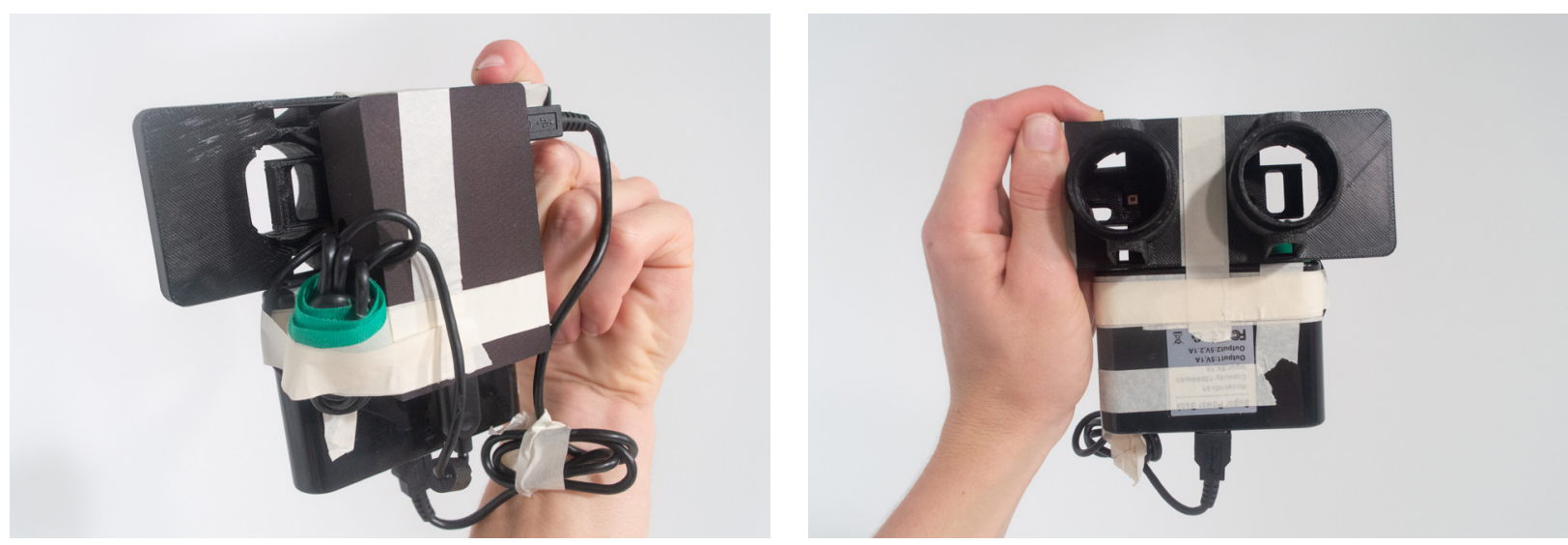

Figure 32 (b). Exploratory prototyping conducted by taping together a range of components to test different configurations. 


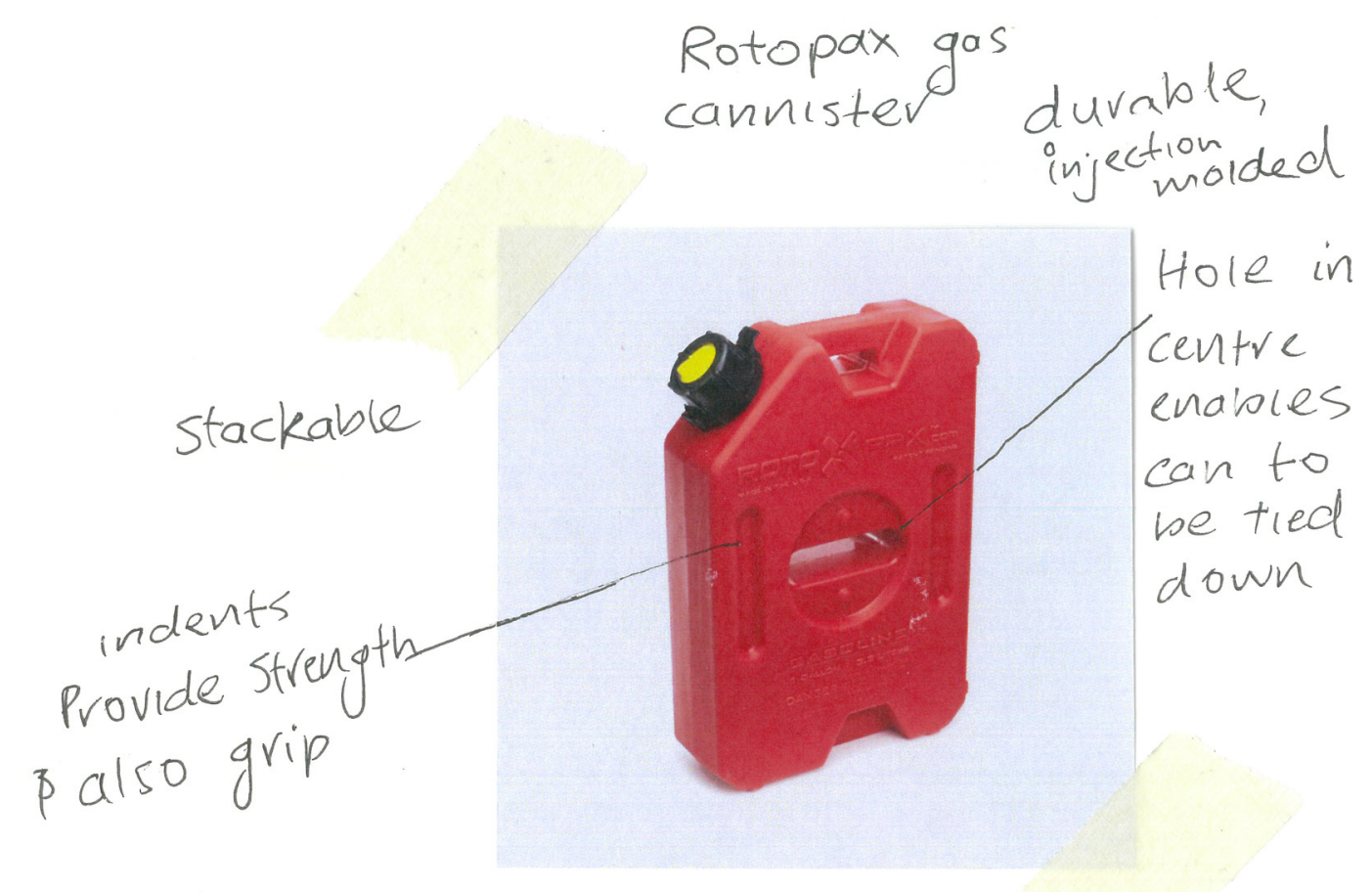

'Utility box'
Tin? Aluminlum?

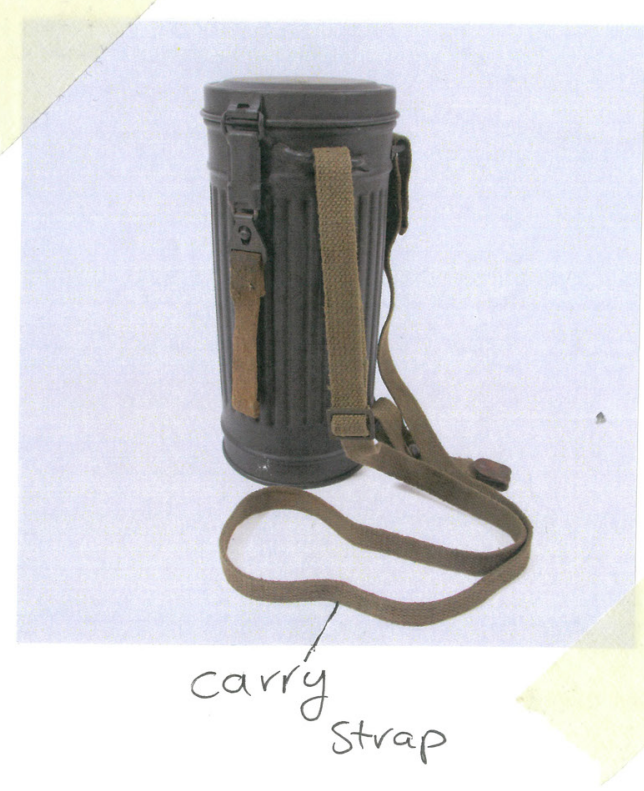

WW 2

cierman gas

onnister

Facets provide

rigidity \$ Strength

$\beta$ grip
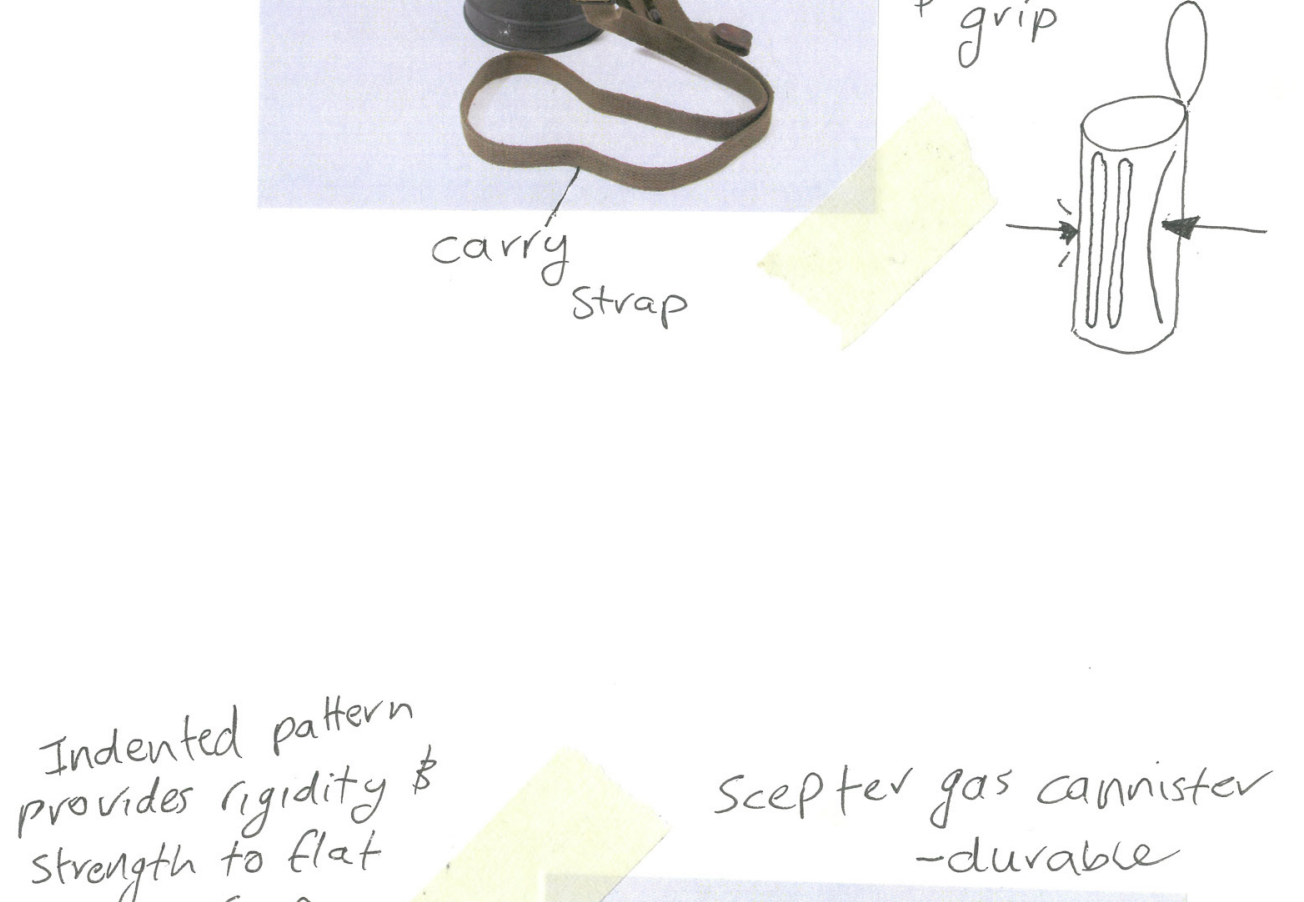

strength to flat

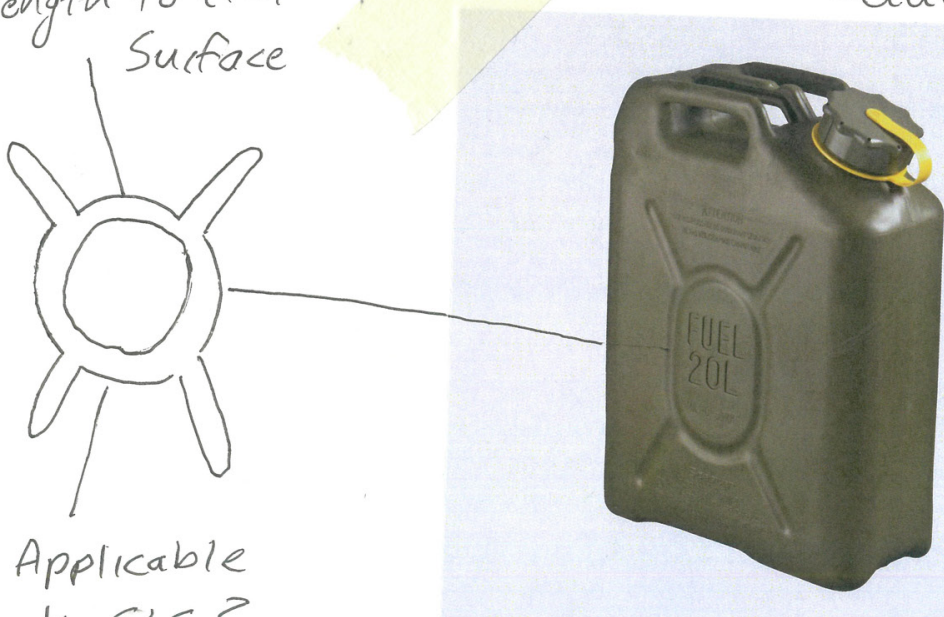

to SLS?

Military aesthetic 


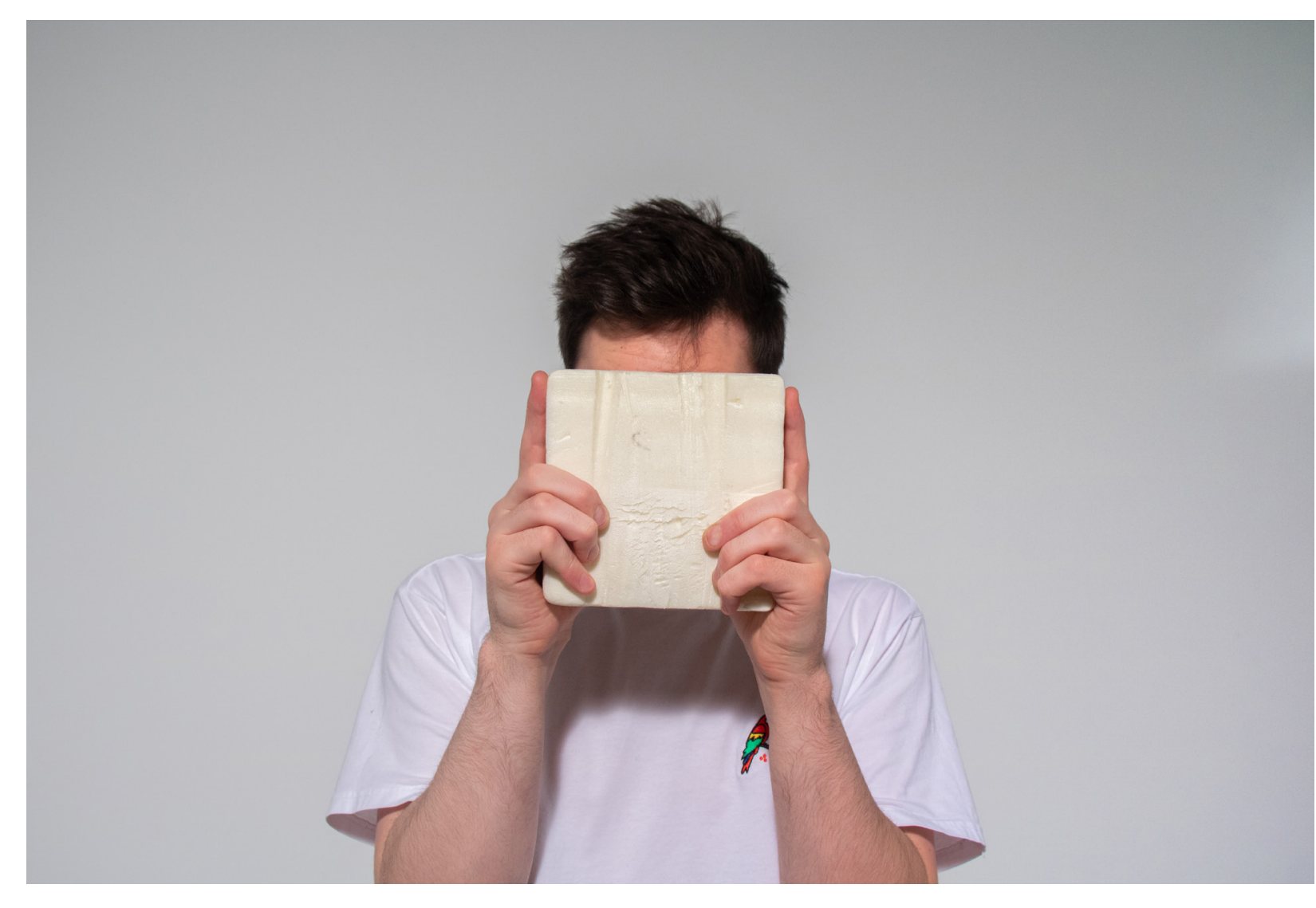

(a)
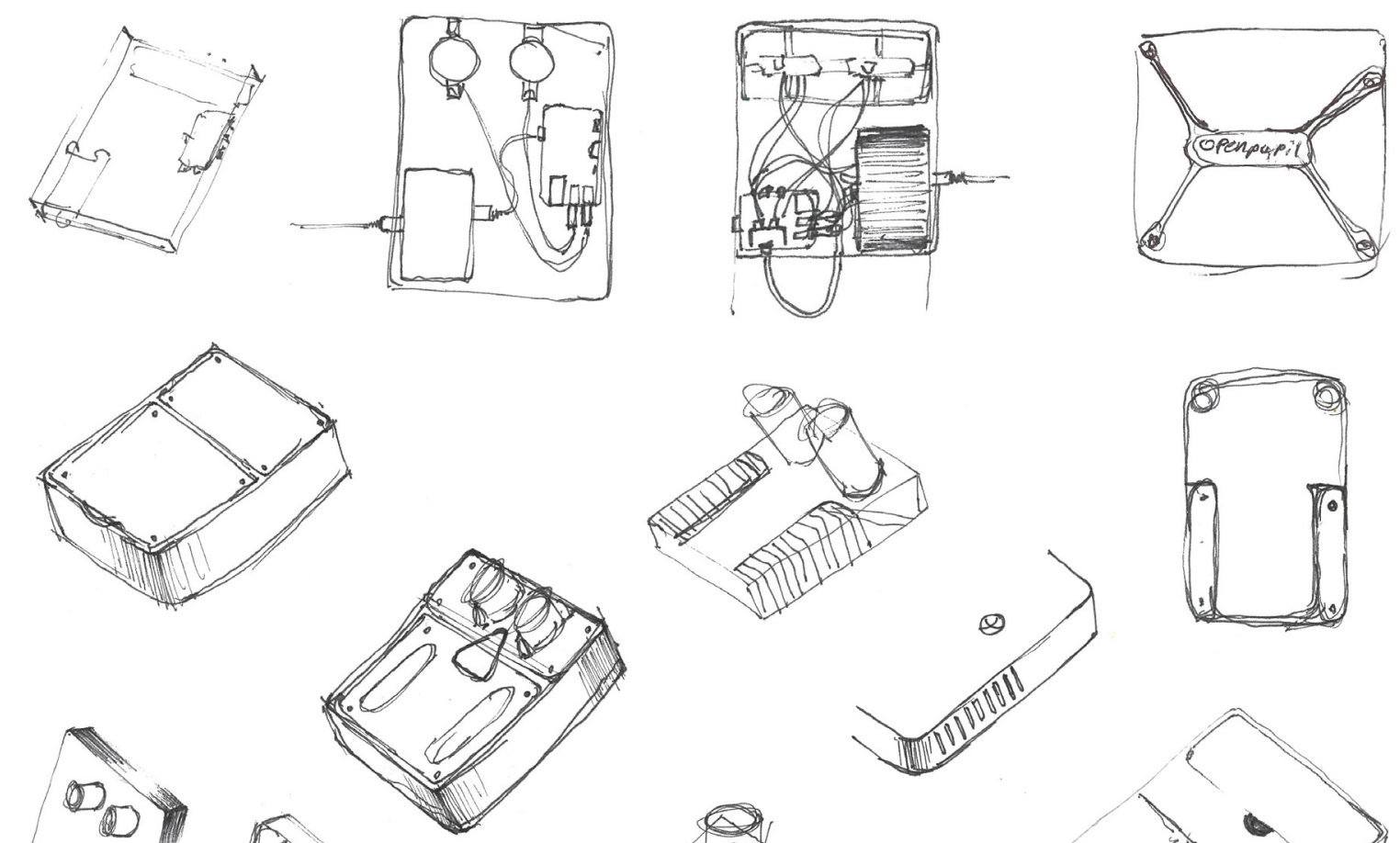

N.

D.

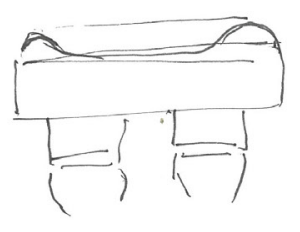

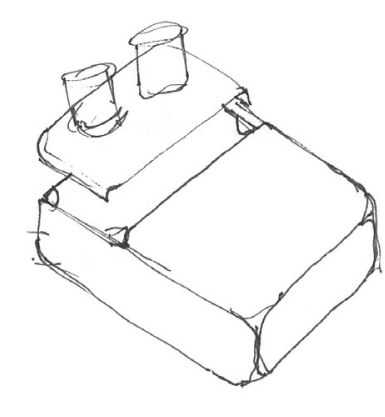

$\infty$

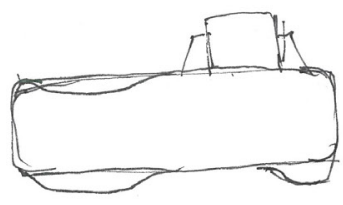

10

$\rightarrow$
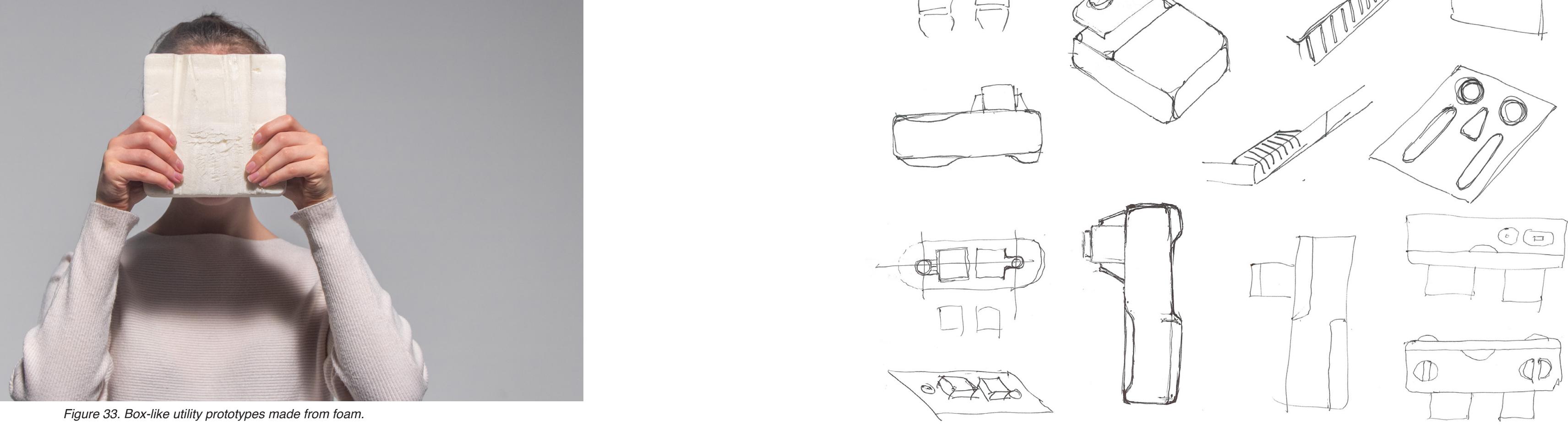

Figure 34. Refined sketches based on the utility cannister prototypes and the ergonomic research conducted thus far. 


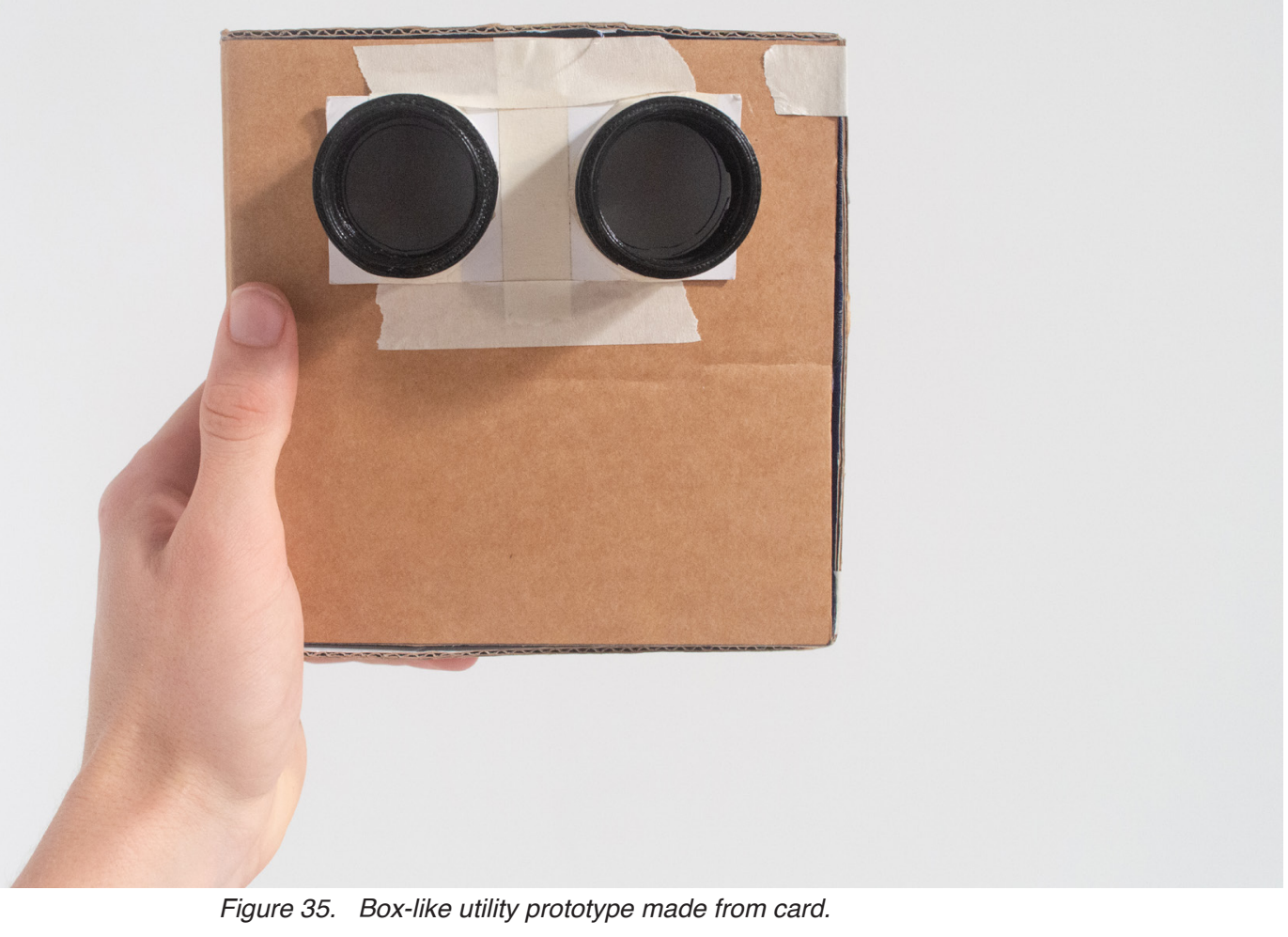

The findings from the ergonomic analysis phase of this thesis indicate that when the components are taken into consideration, a 'box like' configuration is the most suitable for a hand held, open source pupilometer.

By designing the device to be slightly larger then what is required, adaptations to the device can easily be made, encouraging oher users to hack the device to their own specifications. This simultaneously increases the versatility of the device, enabling it to be taken outside of the clinical context, into the field.

Findings from the ergonomic analysis also indicate that for box-like designs to be successful, the design details need to be carefully considered to ensure the device does not become cumbersome 


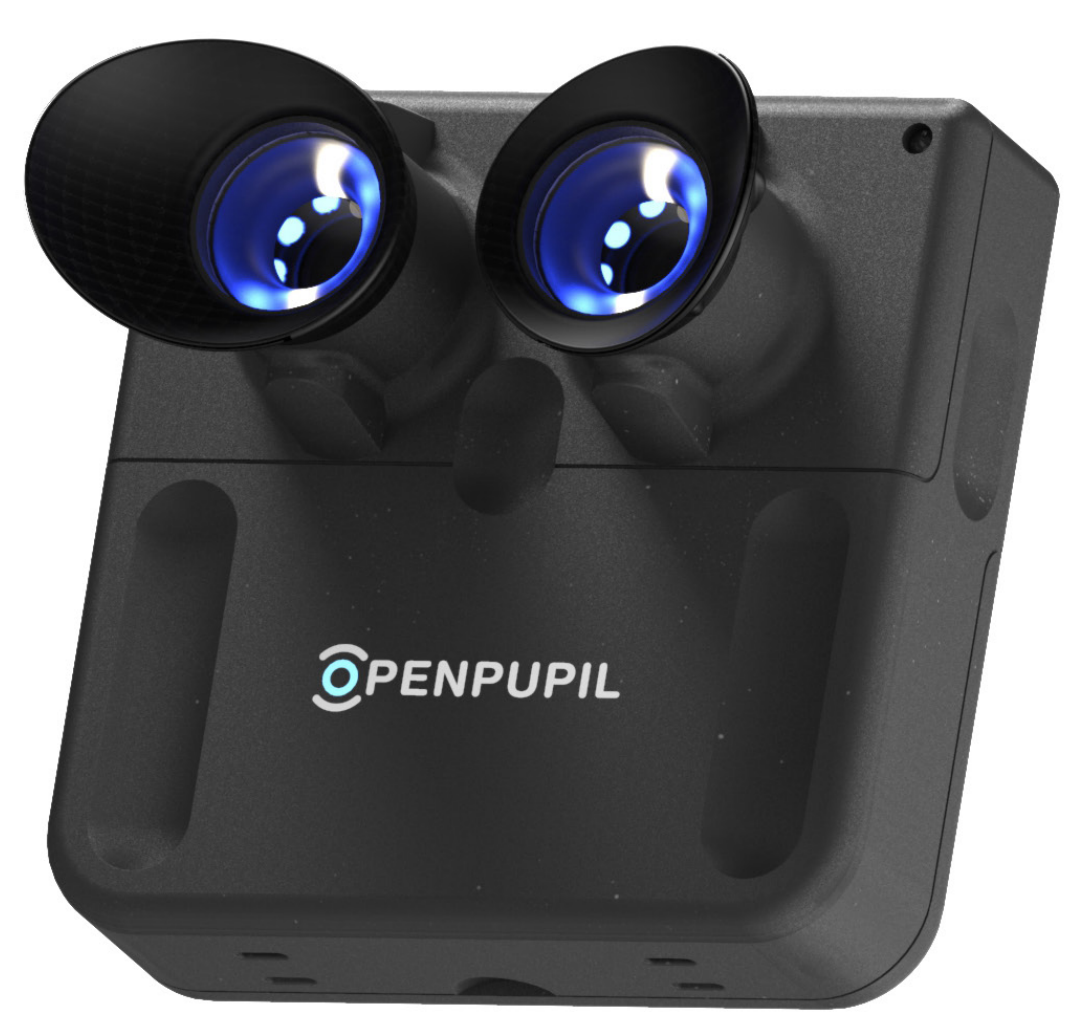

\section{Design phase 4.}

Design synthesis \& contextualising the final design

The goal of design phase 4 was to reflect on the knowledge gained from the previous three design phases, and then synthesise this knowledge to produce a final design output.

Using both the technical and ergonomic insights gained from design phases $1,2 \& 3$ an FDM 3D printer was used to iteratively develop each individual component to a satisfactory level of refinement. This process also enabled the assembly process of the device to be troubleshot and developed with each new iteration, until the components fit together seamlessly to form the final device.

Once this was achieved, the design files of the device were manufactured via the Shapeways online 3D printing service using the SLS nylon 


$$
\text { 荧 }
$$




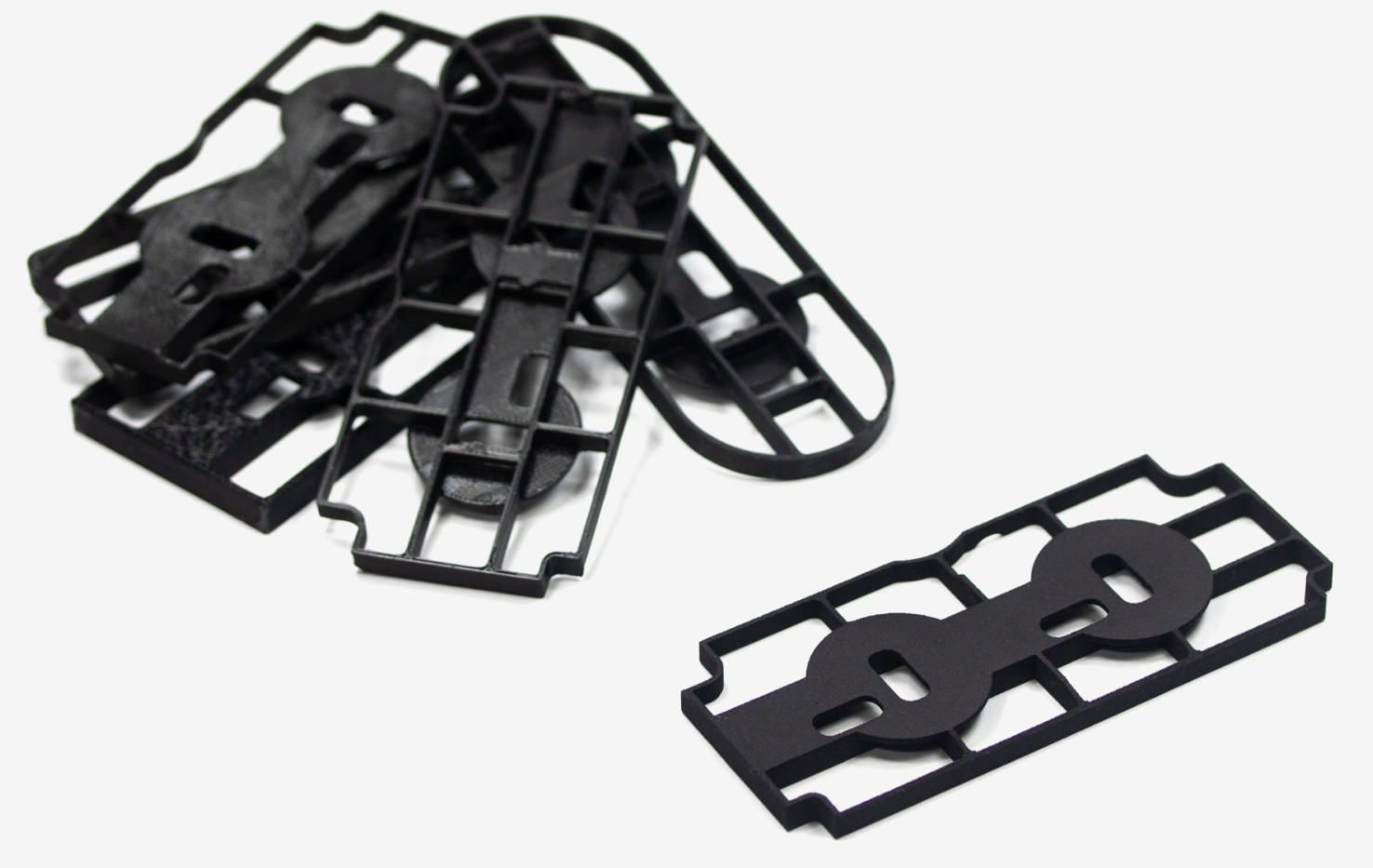

Figure 39. Prototypes created during the development of the final camera housing design

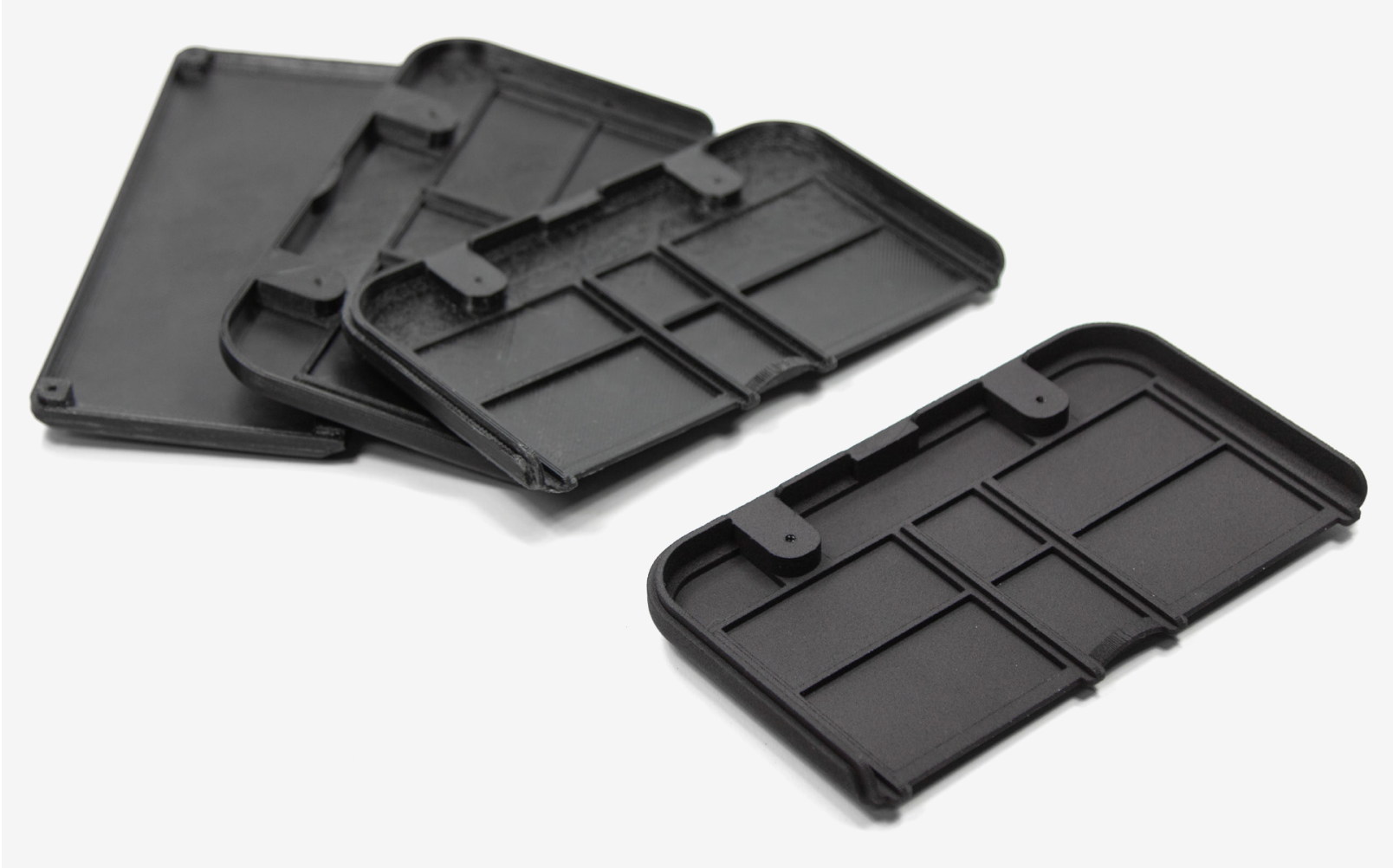

Figure 40. Prototypes created during the development of the final battery housing design. 


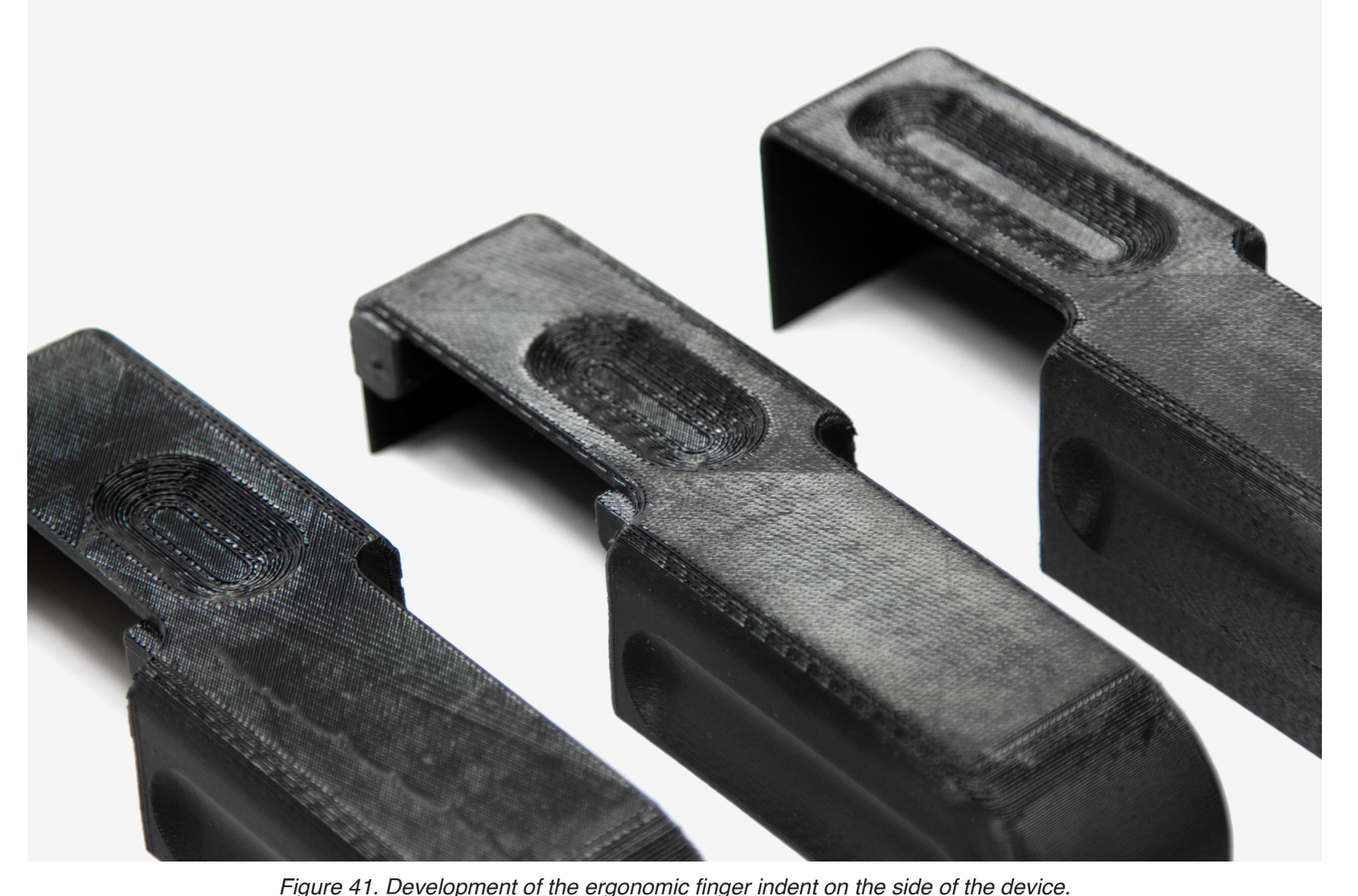

Figure 41. Development of the ergonomic finger indent on the side of the device.

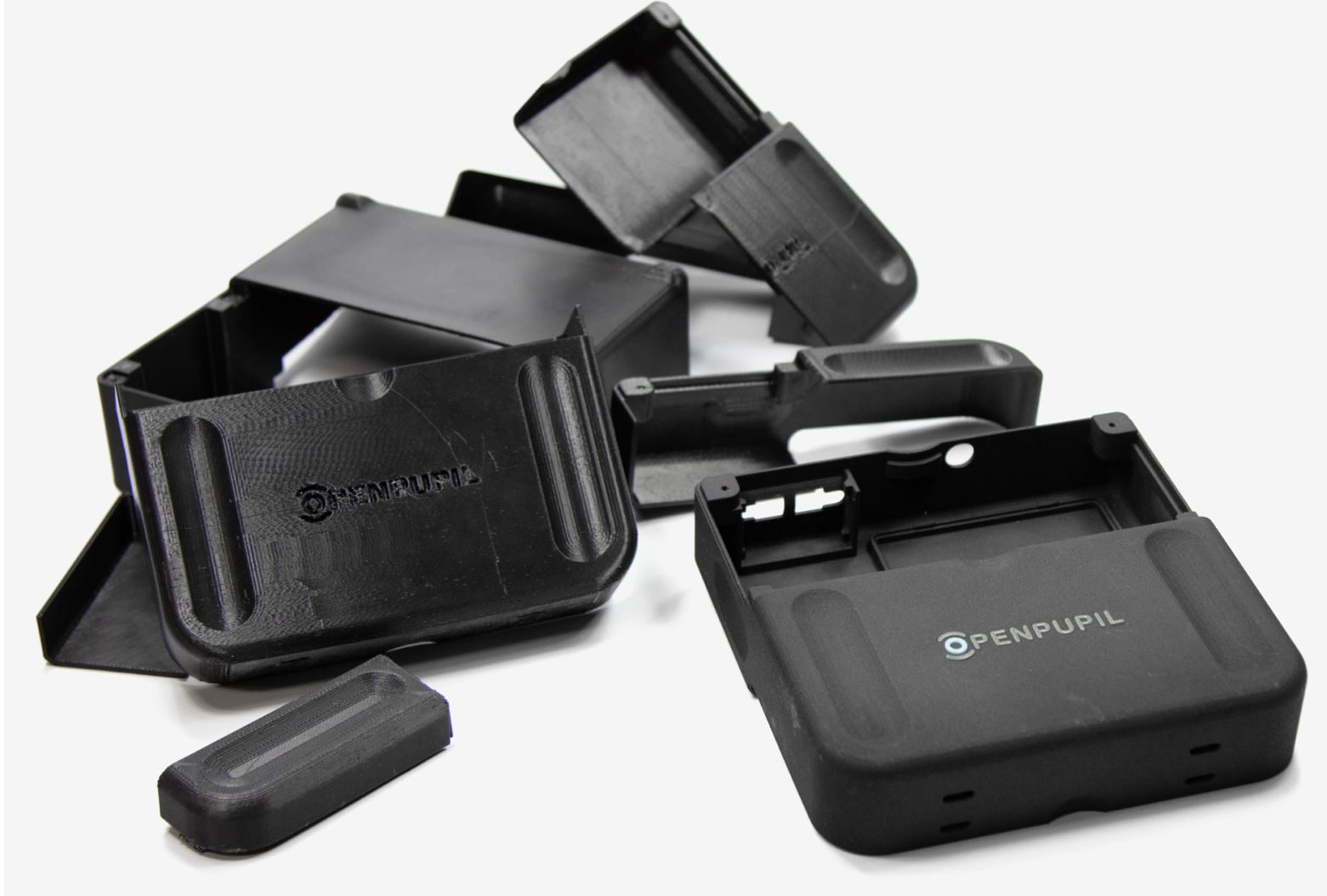

Figure 42. Prototypes created during the development of the final body design. 

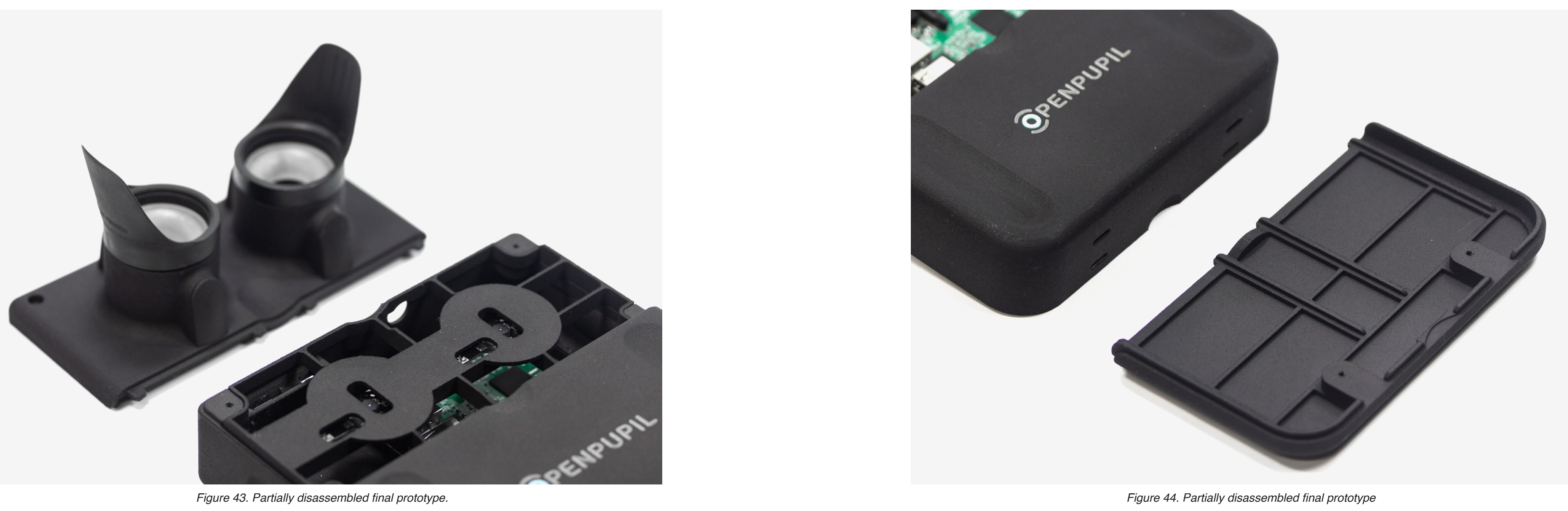

Figure 44. Partially disassembled final prototype 


$$
R
$$




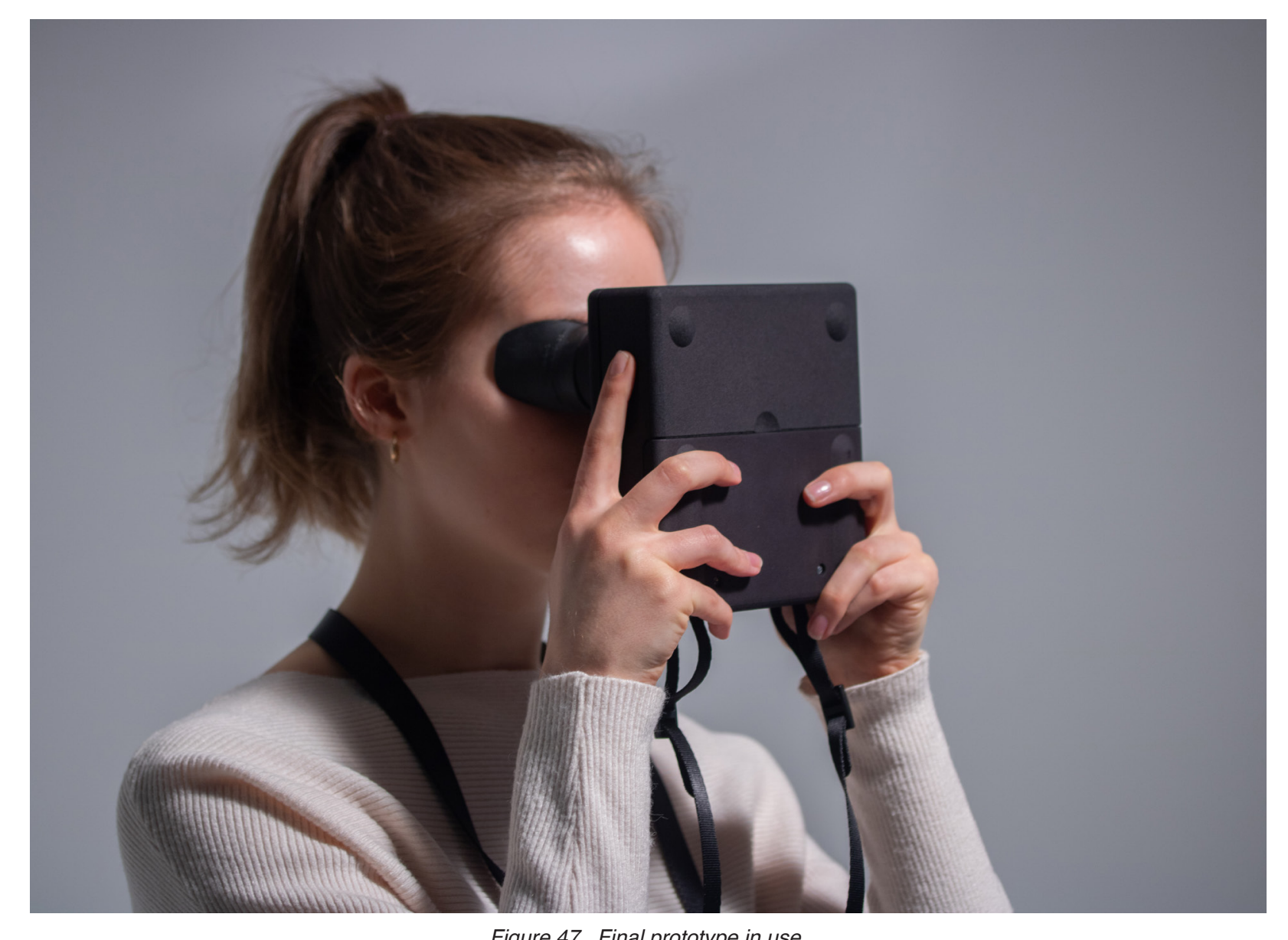

Figure 47. Final prototype in use. 

Table 7. Table depicting the cost to purchase the non 3Dprintable parts and component of the Openpupil device.

\begin{tabular}{|c|c|c|}
\hline Component & Cost of part (NZD) & Total cost (NZD) \\
\hline Carry strap & $\$ 14.87$ & \\
\hline Google cardboard lens (x2) & $\$ 2.00$ & \\
\hline Infrared camera (x2) & $\$ 74.00$ & \\
\hline Infrared LEDs (x2) & $\$ 4.00$ & $\$ 204.23$ \\
\hline NeoPixel ring (x2) & $\$ 28.27$ & \\
\hline Raspberry Pi & 63.25 \\
\hline Rubber eyecups & 17.84 \\
\hline
\end{tabular}

Table 7 displays the cost of each 3D printed

component that makes up the Openpupil device

while table 8 displays that total costs associated with the non 3D printed parts required to assembe the device.

In total, the device costs approximately $\$ 676.25$ NZD to source all of the required parts of the device.

This is substantially cheaper then what it would cost to purchase a commercially available pupilometer, most of which range from between $\$ 10,000$ to $\$ 100,000$

Table 8. Table depicting the cost to print the Openpupil device using Shapewats SLS nylon .

\begin{tabular}{|c|c|c|}
\hline Component & Cost of part (NZD) & Total cost (NZD) \\
\hline Battery housing & $\$ 69.73$ & \\
\hline Body & $\$ 166.66$ & \\
\hline Eyepieces & $\$ 107.11$ & \\
\hline Camera housing & $\$ 40.30$ & $\$ 472.42$ \\
\hline LED caps & $\$ 44.71$ & \\
\hline NeoPixel diffusers (х2) & $\$ 22.35$ \\
\hline IR LED Diffusers (×2) & $\$ 22.35$ \\
\hline
\end{tabular}





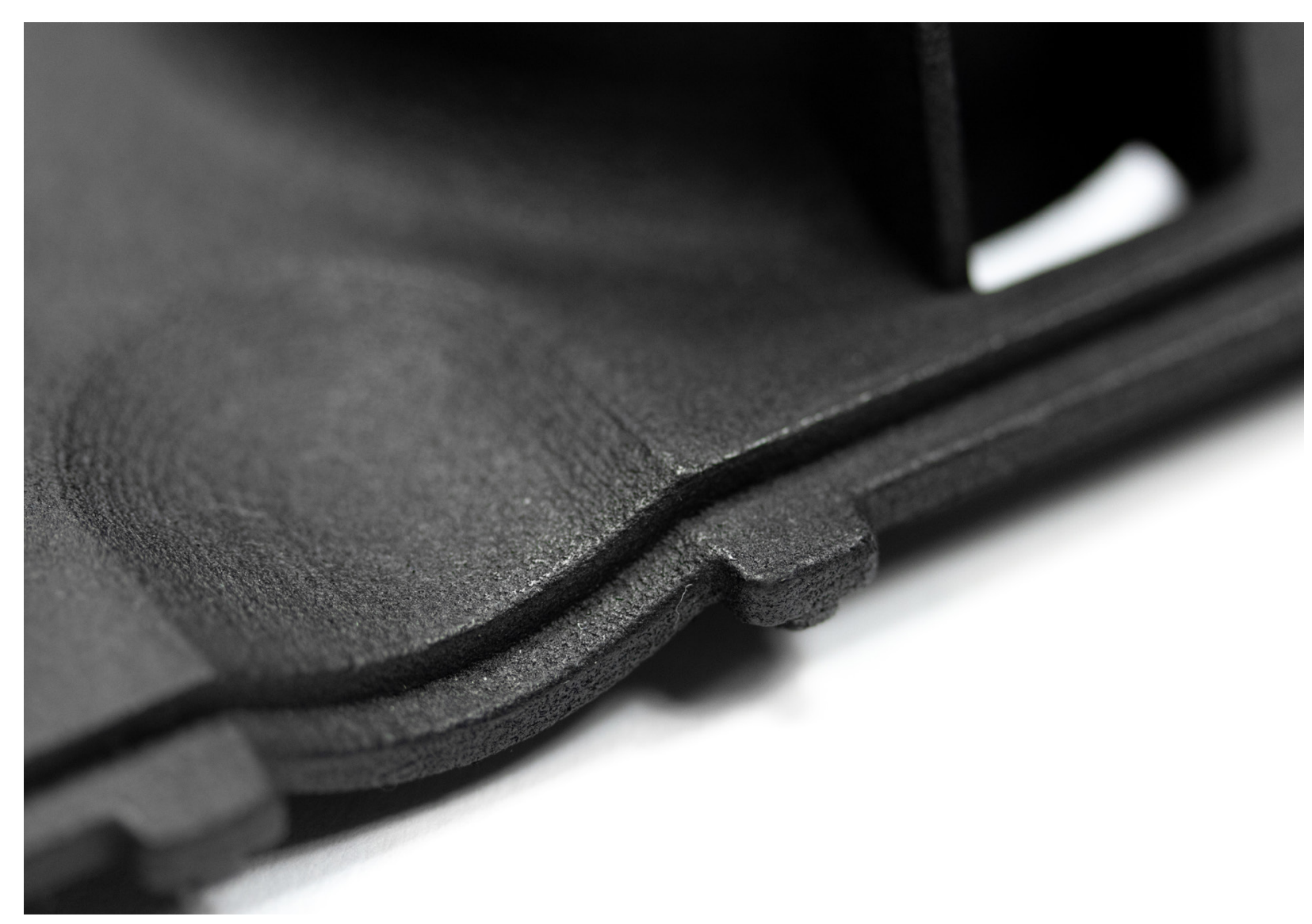

Figure 50(a). Design detail of the Polished SLS printed eyepiece.

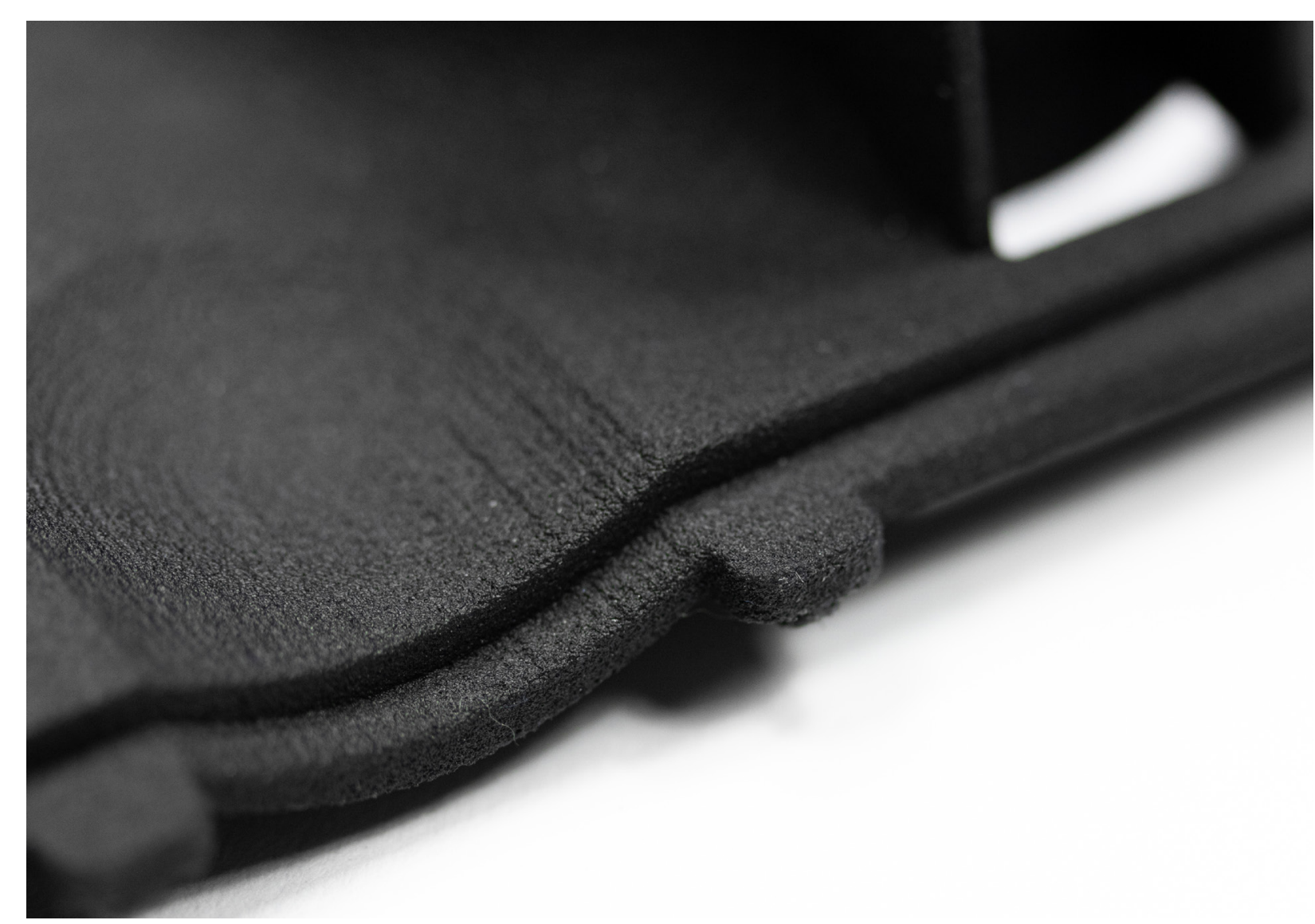

Material analysis

Based on the test prints, the Polished finish is of a much higher quality then the natural finish. The surface texture of the polished part was glossy, and did not mark as easily in comparison to the more porous, matte surface of the natural finish.

In terms of cost, the Polished part cost $\$ 171.85$ NZD, in comparison to the natural part, which cost $\$ 107.11$ NZD, meaning the polished part was considerably more expensive.

When tested, each component functioned exactly the same, meaning the only advantages to the polished surface finish are of a cosmetic nature. Another constraint associated with the polishing process is that parts bigger then a certain size cannot be polished.

Based on the above, the polished surface finish is not suitable for use on open source products due to high costs, size constraints and lack of functional benefits, however may find application when offered as a 'premium' option for smaller objects. 
One of the most immediate applications for the Openpupil device is for use within a clinical research setting, such as the office of an Ophthalmologist. Currently, the device is capable of studying a group of intrinsically photosensitive retinal ganglion cells (ipRGC) located in the inner retina of the eye. These ipRGC are interesting for numerous academic reasons, as they appear to serve the nonconscious visual functions such as circadian rhythm entrainment and pupil constriction (Gale, et al).

With more technical development, application of the device could be expanded to a range of diagnostic applications, such as measuring pupil asymmetry when assessing neurological problems (which may include brain aneurysms, impending strokes, lung tumours), as well as testing the relative constriction to light in each eye when looking for problems with the optic nerve (Gale, et al). There is also emerging interest in using pupil signals to study

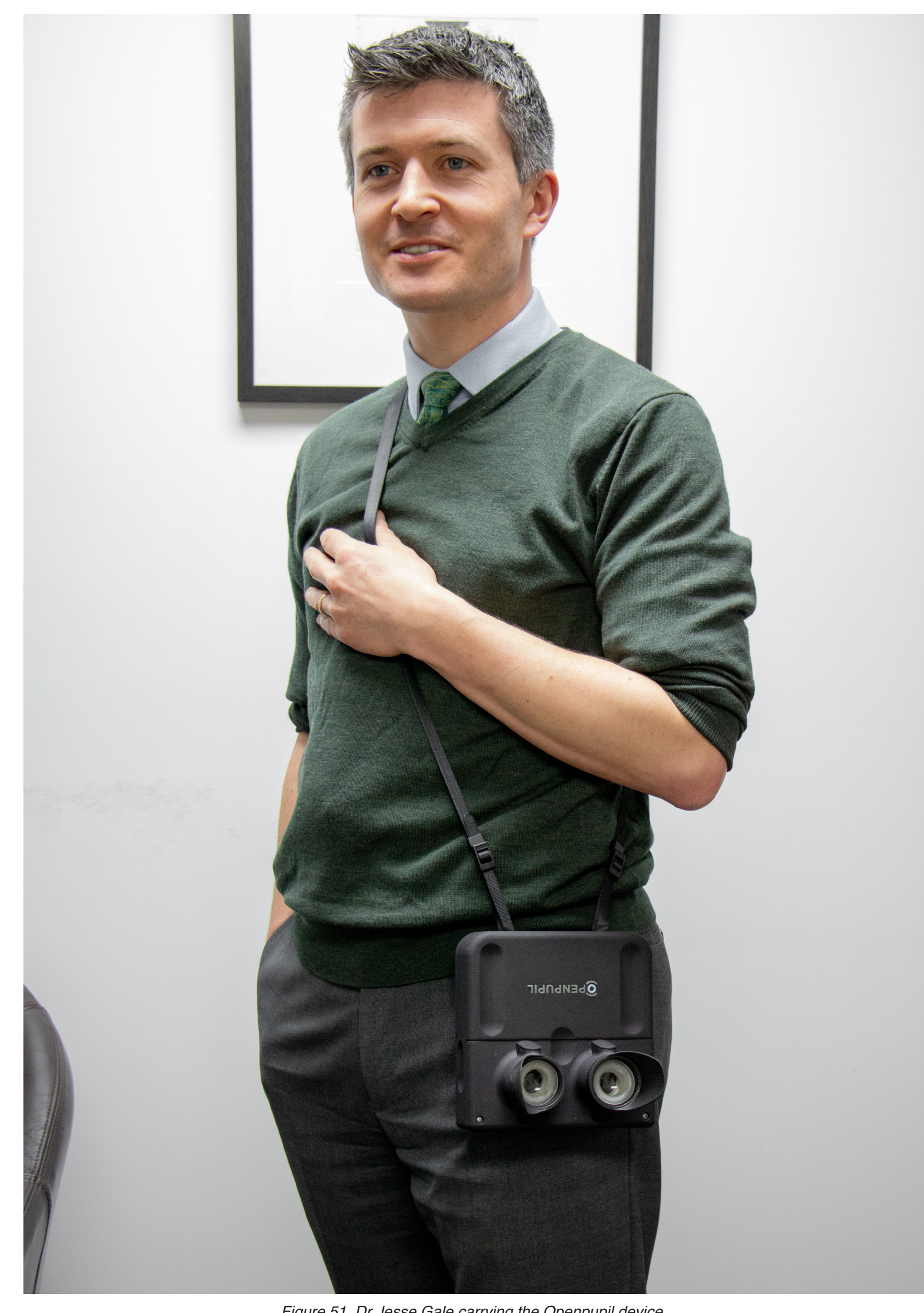

Figure 51. Dr Jesse Gale carrying the Openpupil device. 


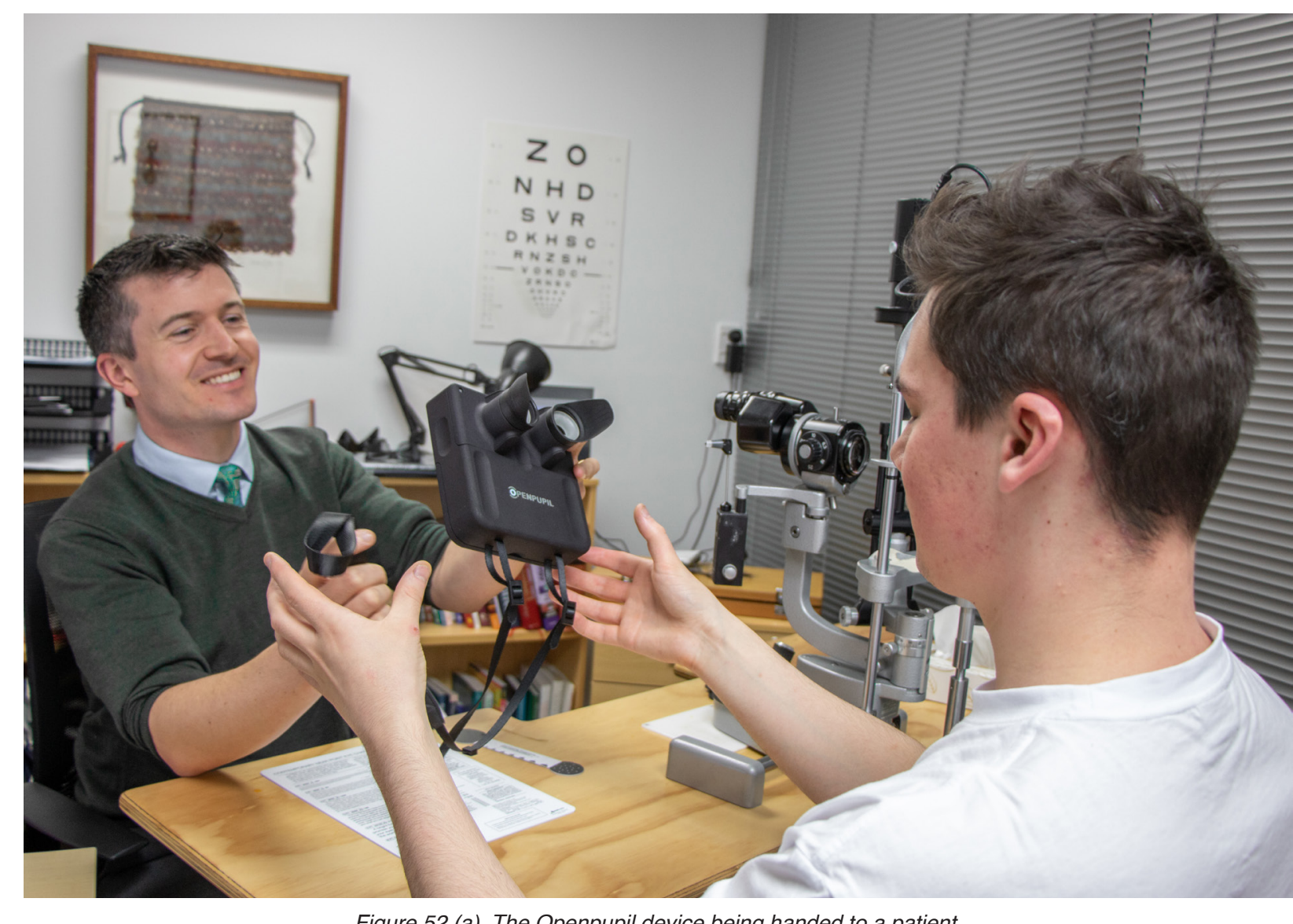

Figure 52 (a). The Openpupil device being handed to a patient.

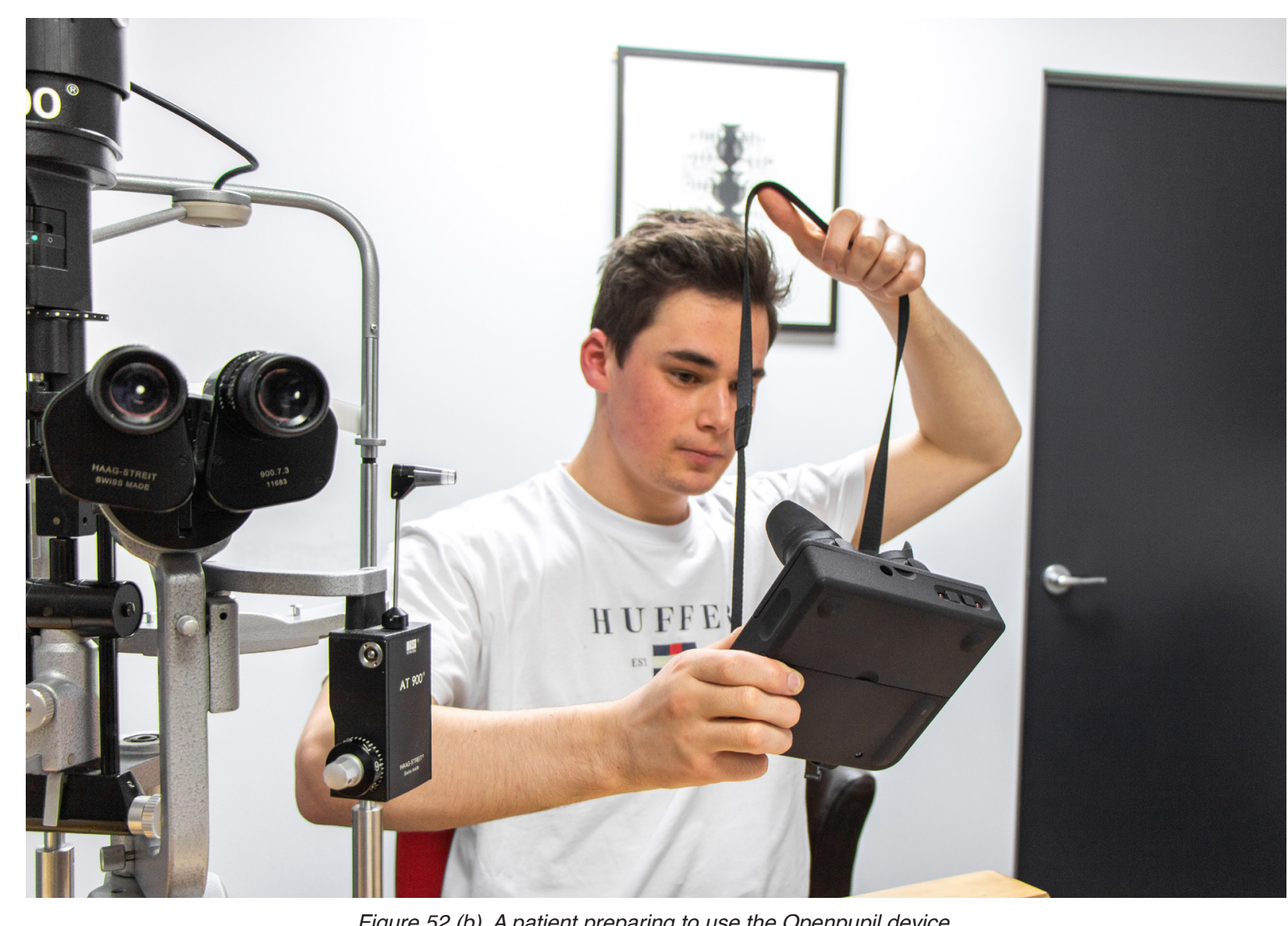

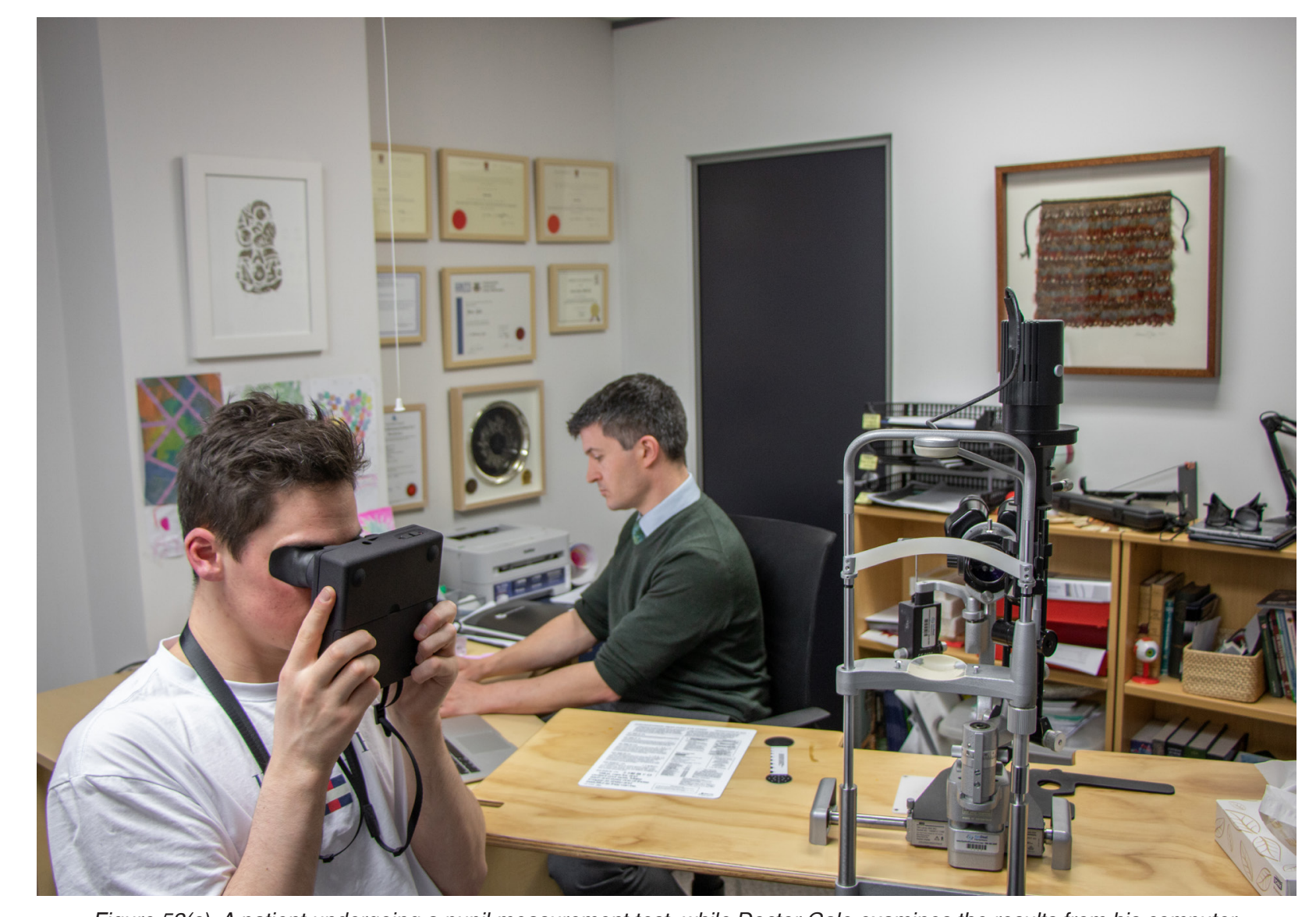

Figure 52(c). A patient undergoing a pupil measurement test, while Doctor Gale examines the results from his computer.

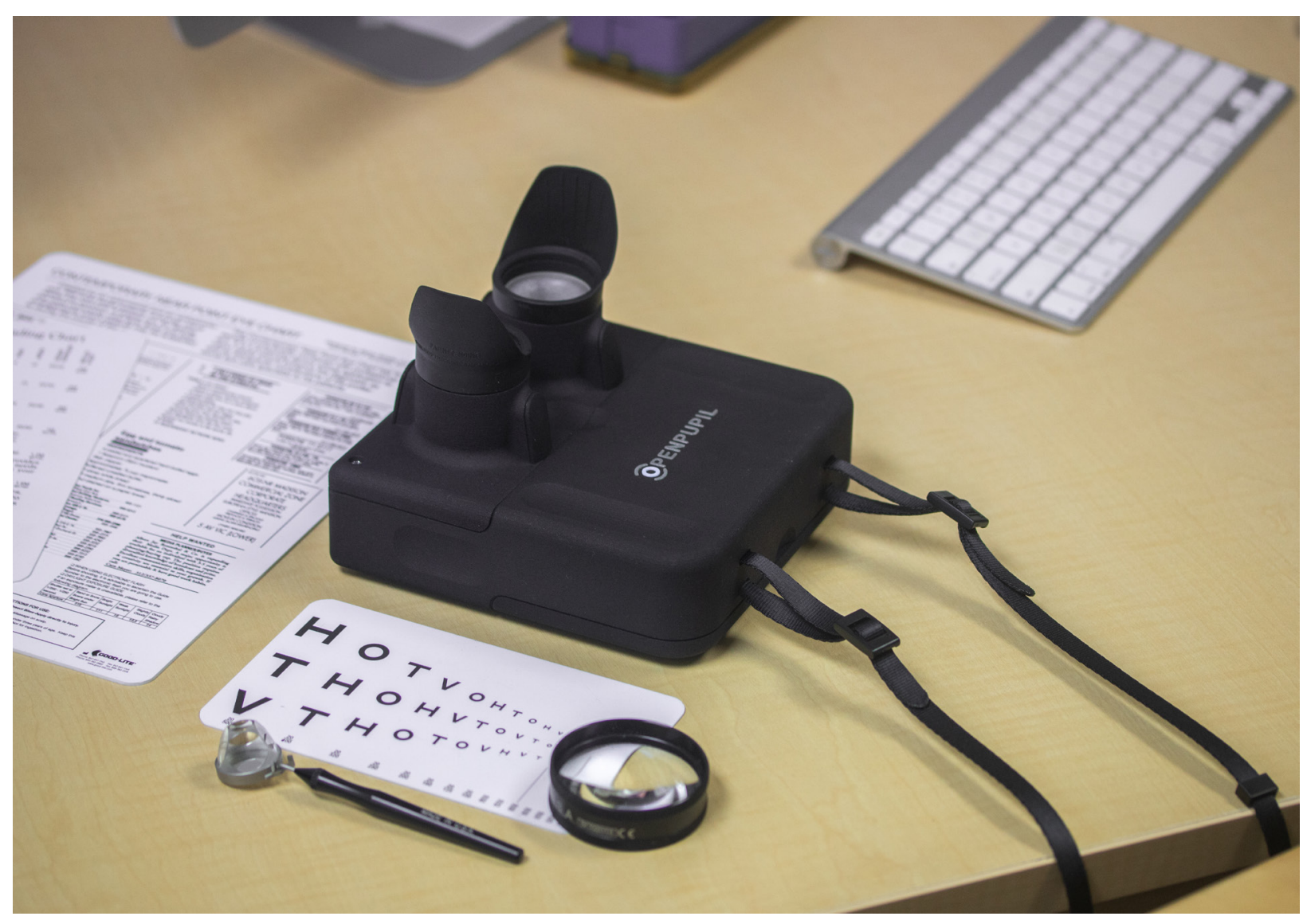

Figure 52 (d). Openpupil device placed amongst other Opthalmologic tools. 
The ability to record objective pupil data using a

portable pupilometer would enable paramedics

and other emergency medical staff to diagnose and

monitor the condition of injured patients rapidly and

more accurately then current methods. Because

the device has bluetooth/witi capabilities, the data

collected from the patient can then be sent to

existing monitoring equipment, for example, within

ambulances. This enables enhanced data collection

capabilities, and seamless integration of the devic

to existing diagnostic/monitoring processes.

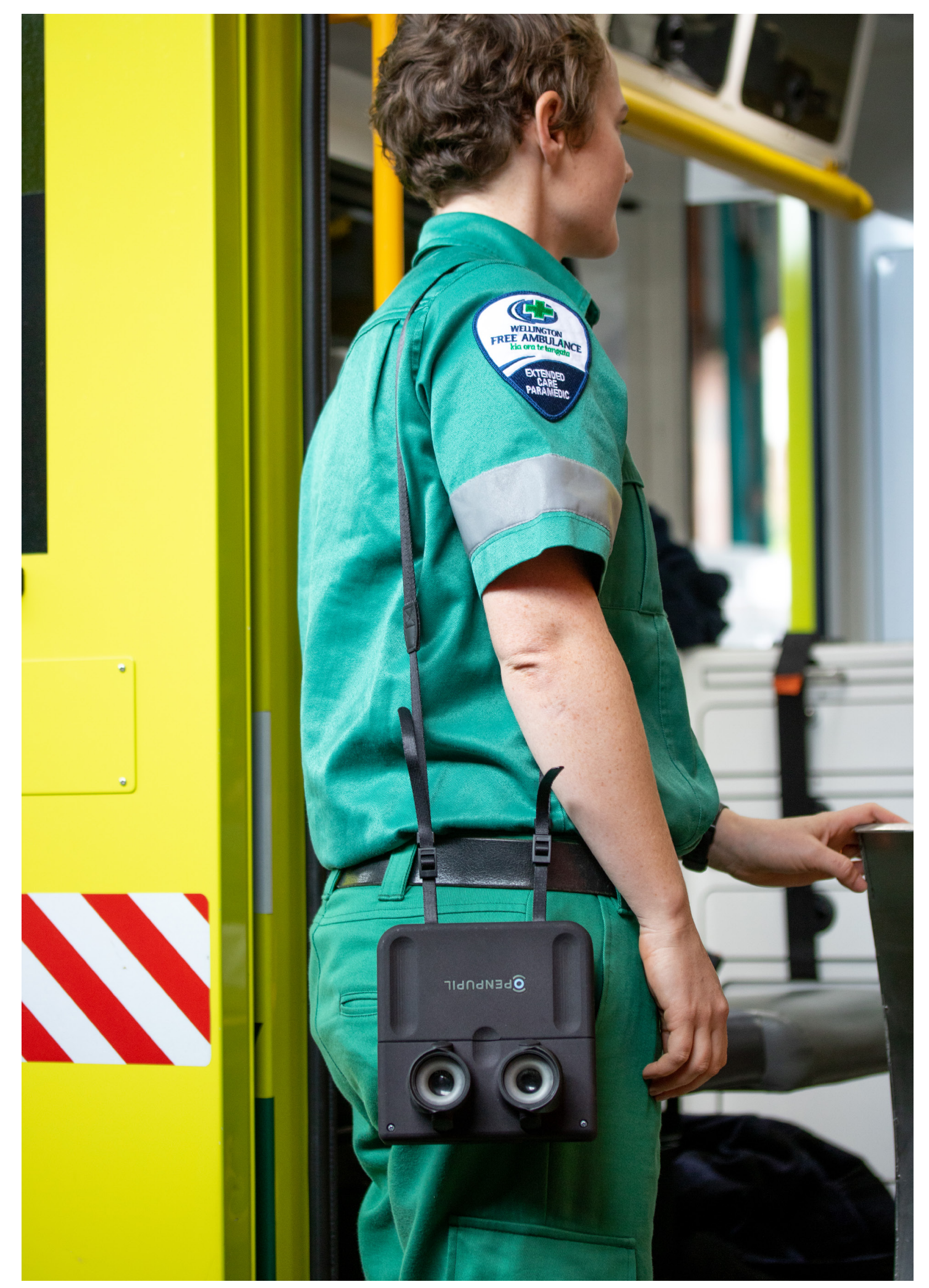

Figure 53. Wellington free ambulance paramedic wearing the Openpupil device. 


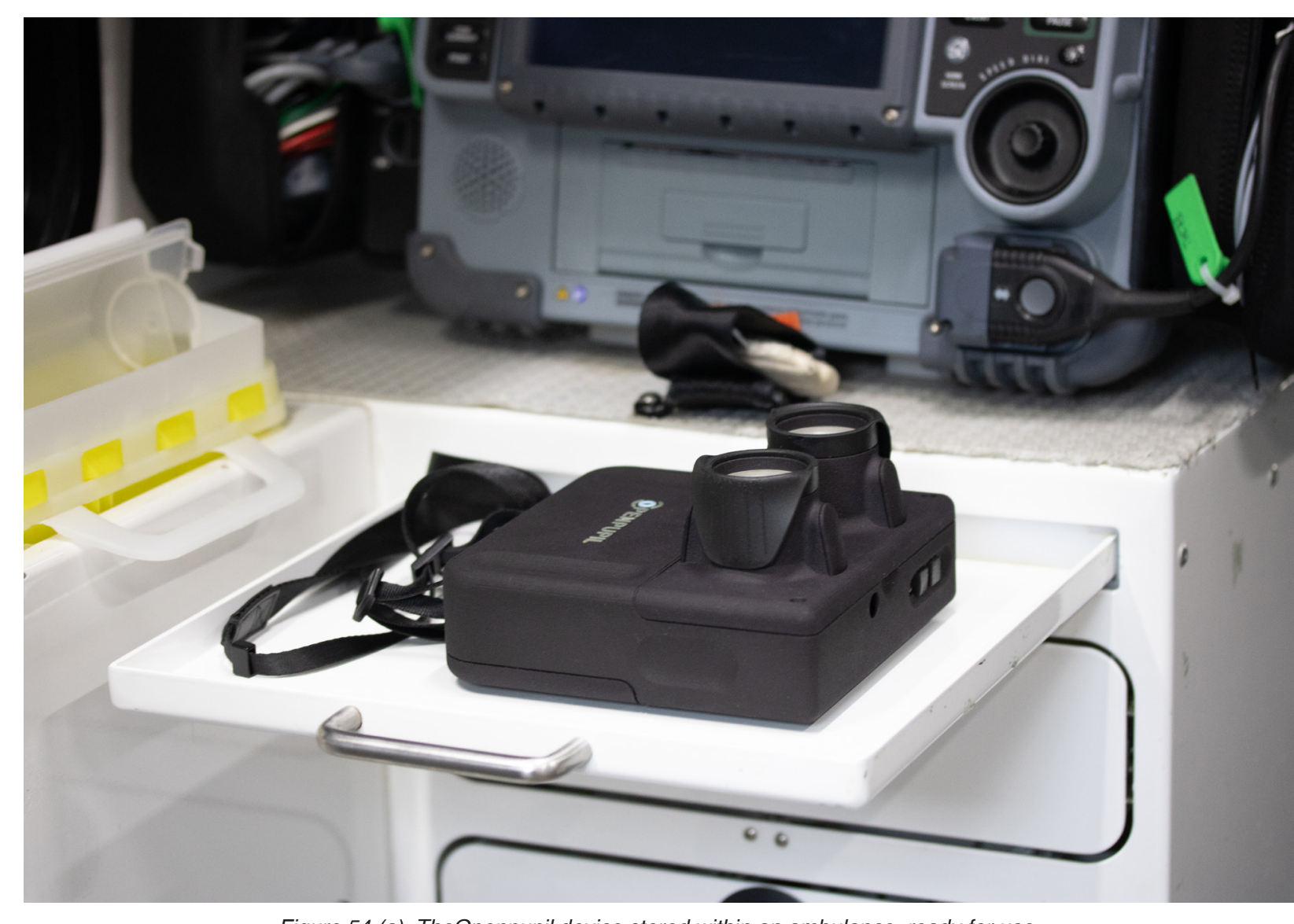

Figure 54 (a). TheOpenpupil device stored within an ambulance, ready for use.

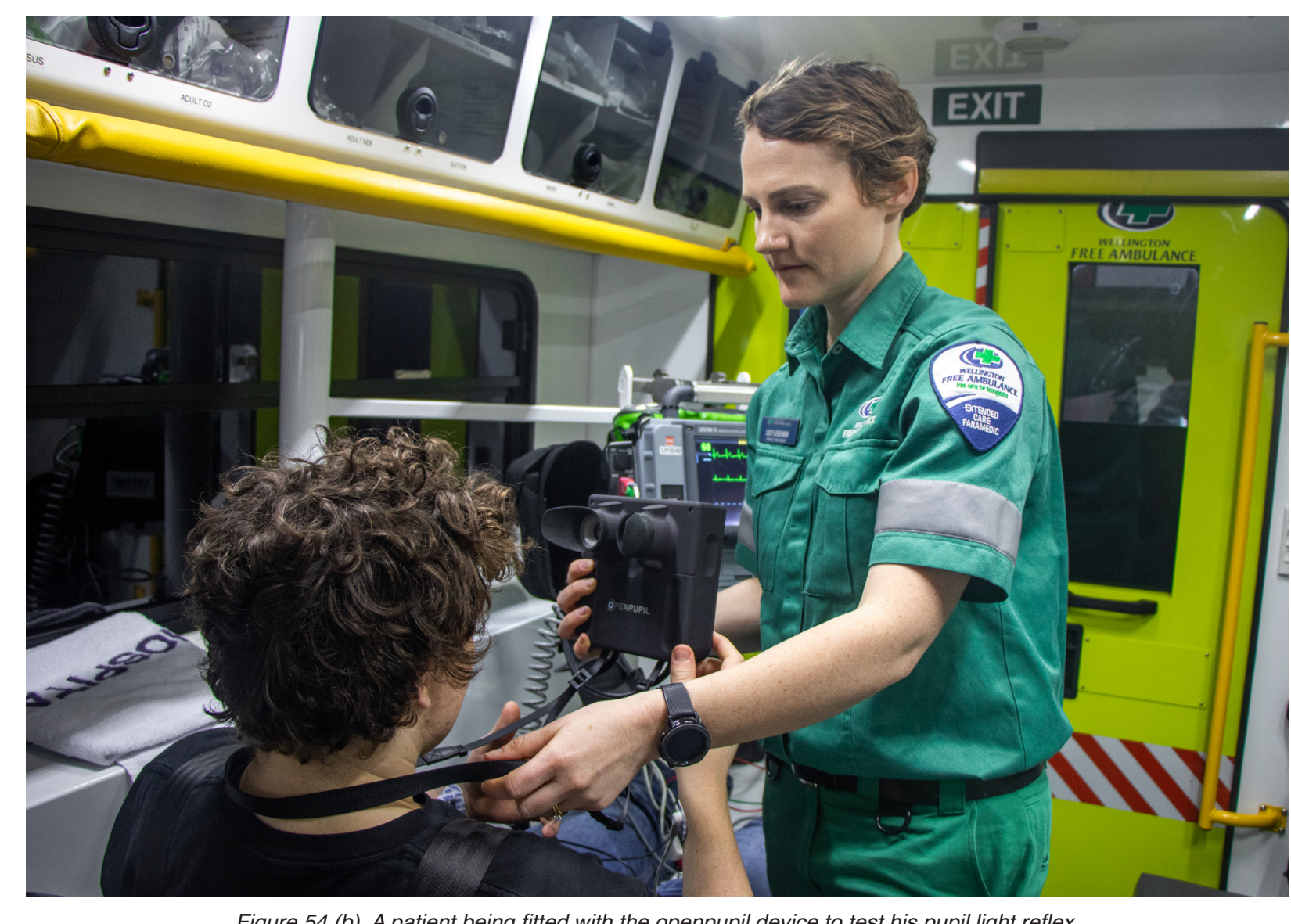

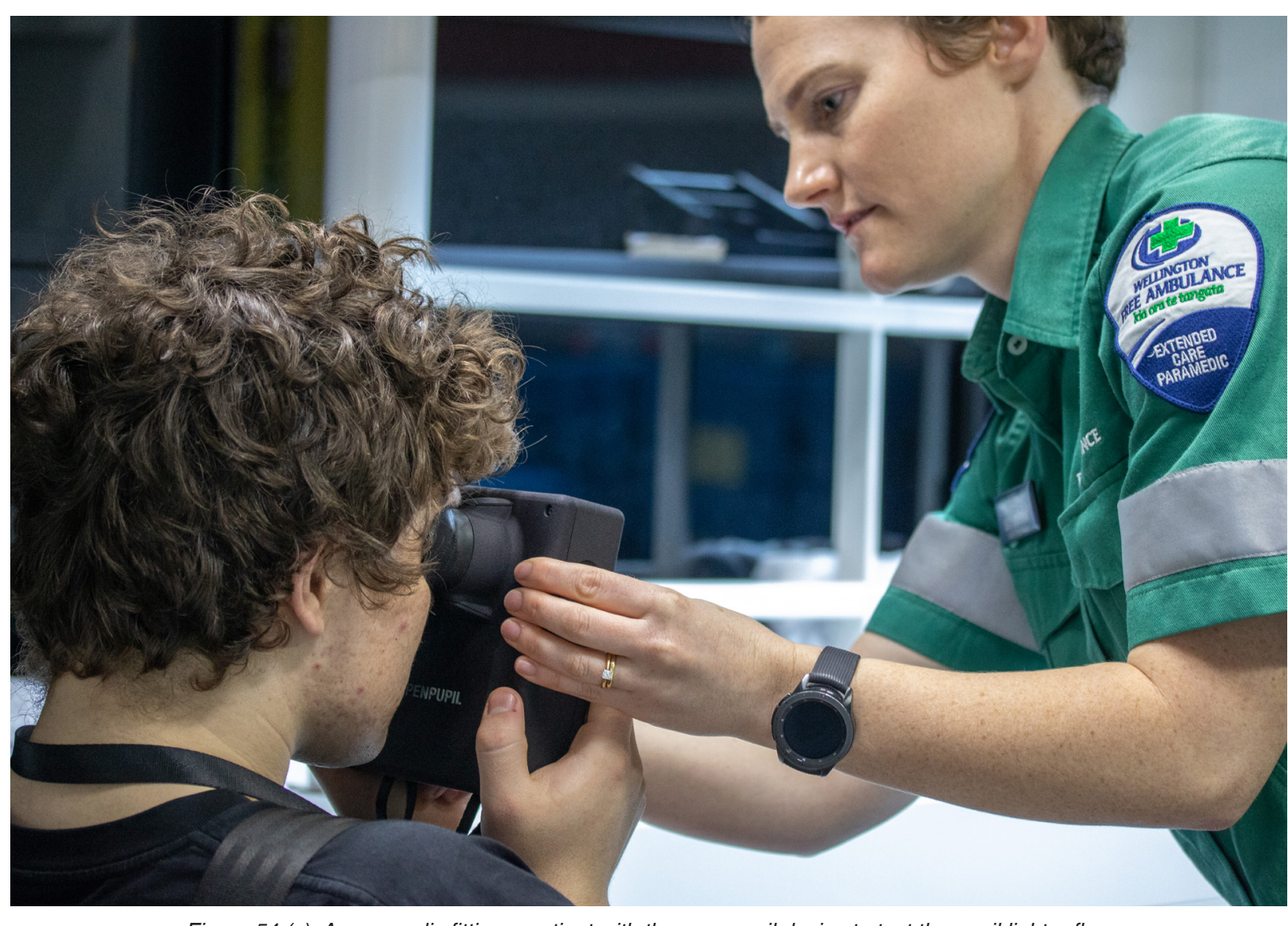

Figure 54 (c). A paramedic fitting a patient with the openpupil device to test the pupil light reflex.

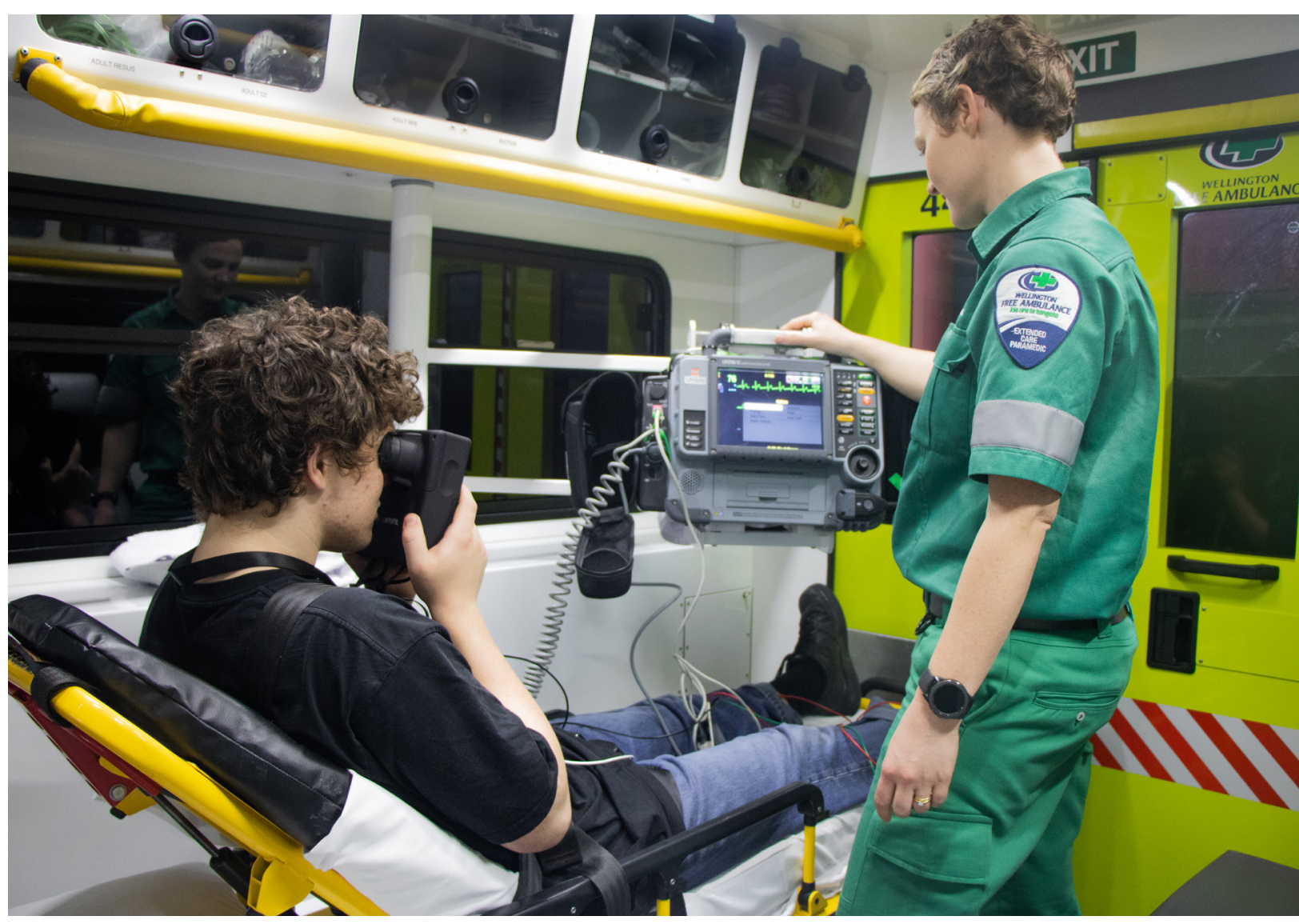

Figure 54 (d). A paramedic monitors the pupil data of the patient 


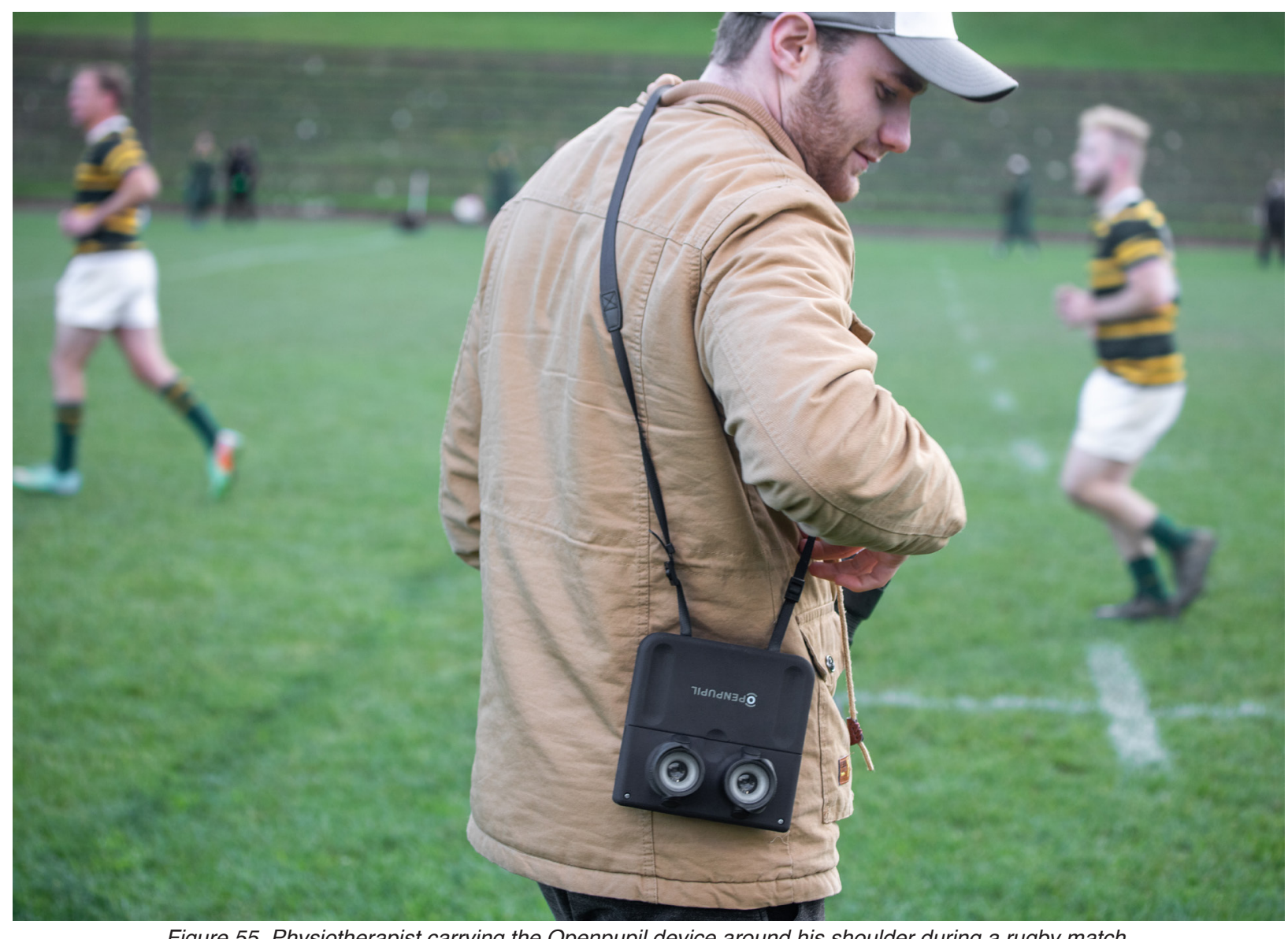

Although the Openpupil device is currently no capable of diagnosing concussion, use on the sports field was identified as a possible application for the device with further development.

Currently, concussion tests are performed on the sideline, usually by a coach or physiotherapist after a player receives a significant blow to the head. The test involves holding a finger up in front of the players eyes, and moving it from left to right whils simultaneously monitoring the players abilty to track the finger with his pupils. This test is very subjective, and can lead to players being sent back onto the field of play with an undiagnosed concussion.

A compact, versatile device capable of performing pupil tracking tests would mitigate this problem by enabling objective concussion tests to be performed by anybody, resulting in less instances of misdiagnoses. 


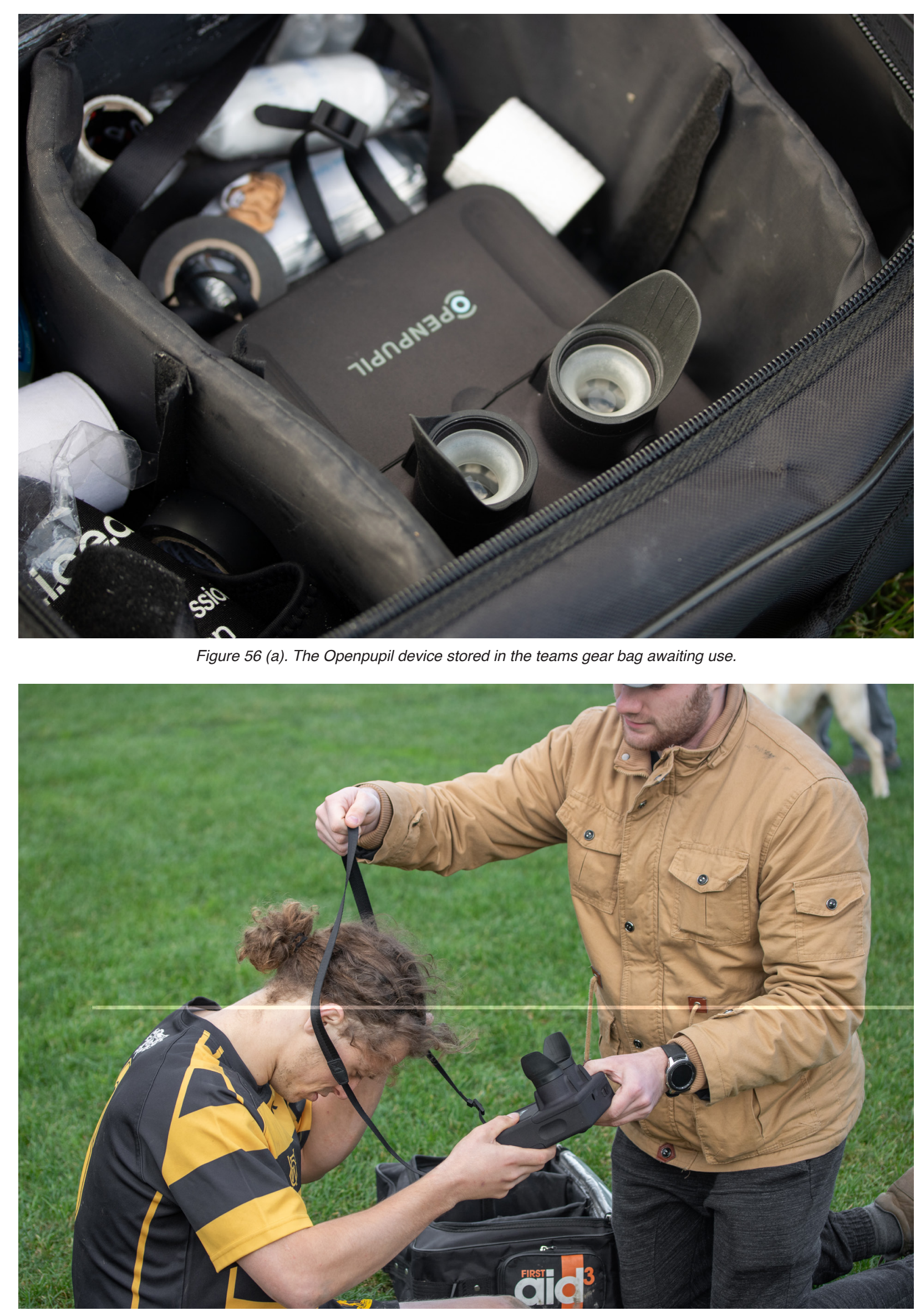

Figure 56 (b). Player suspected of suffering a concussion prepares to undergo a pupil screening test.

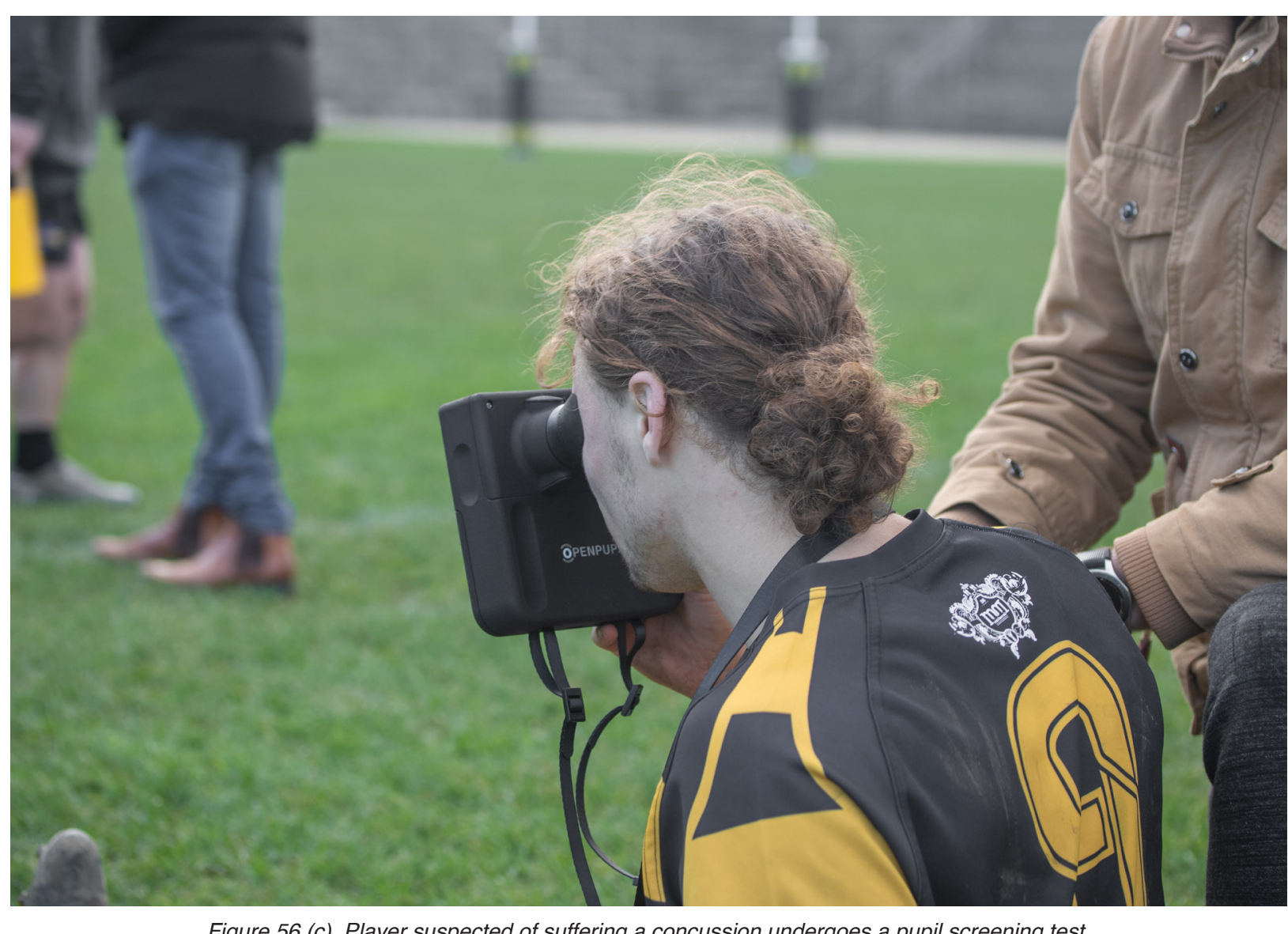

Figure 56 (c). Player suspected of suffering a concussion undergoes a pupil screening test.

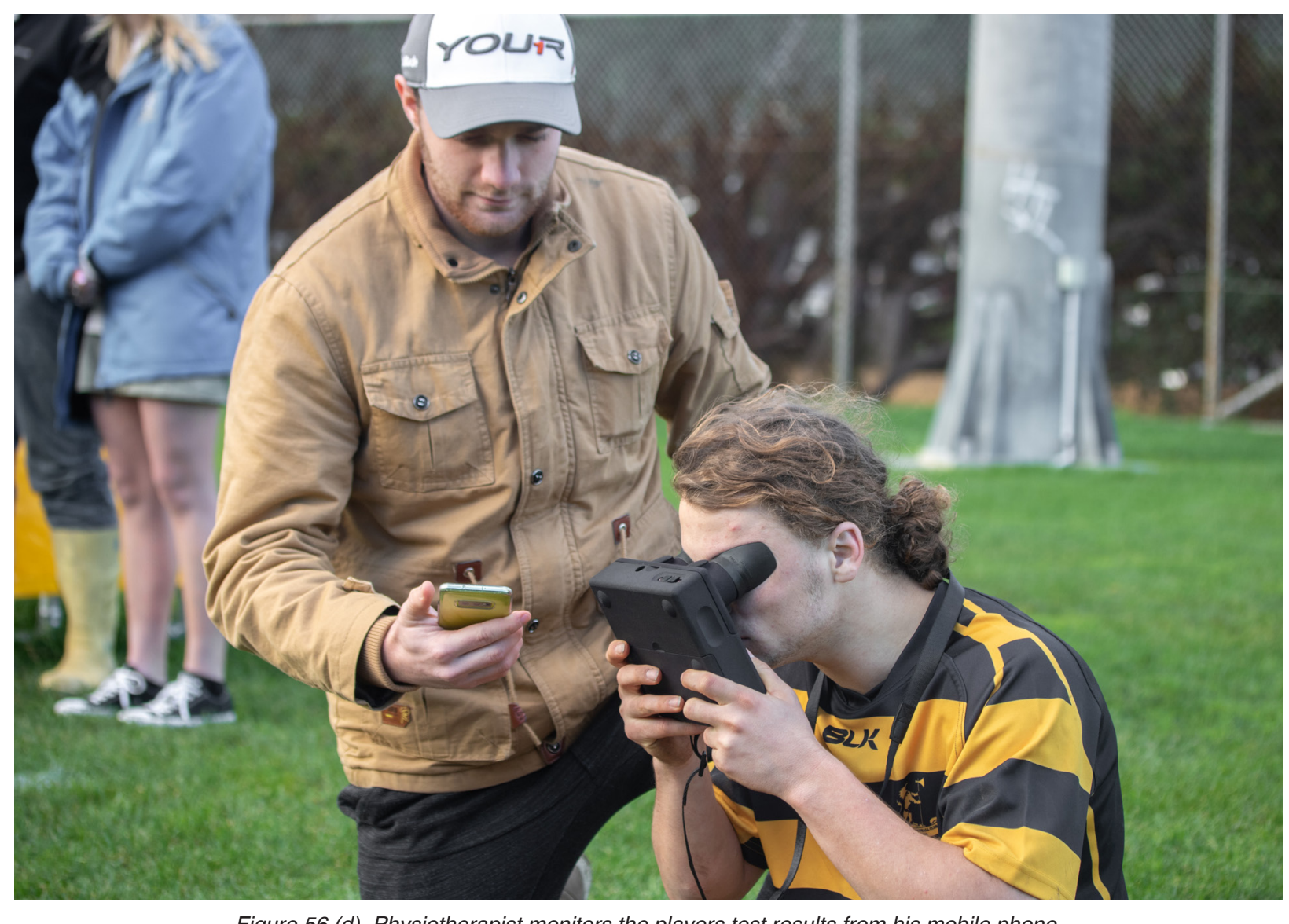

Figure 56 (d). Physiotherapist monitors the players test results from his mobile phone. 
Navigating the regulatory environment New Zealand, while simultaneously securing New Zealand producers a positive position in the globa marketplace ("Therapeutic products regulatory regime," 2019).

To assess the commercial viability, as well as the legality of the Openpupil device, a screening report was conducted by Vic link, Victoria University of What is a Therapeutic product? Wellington's commercialisation office. The goal of the report was to firstly evaluate the market potential of the device, and secondly map the most effective way to get the device to market. The screening
report also identified any legal issues surrounding report also idenified any legal issues surrounding the open source nature of the device.

\section{Therapeutic products ac}

Putting the OpenPupil device on the market in New Zealand is very easy under the current legislative system, however the New Zealand government is currently developing a new therapeutic products
regulatory regime that will provide regulation of regulatory regime that will provide regulation of This includes medical devices in New Zealand. -Testing the susceptibility of humans to a disease This includes medical devices and cell and tissue or ailmen

therapies which are currently not fully regulated in Zelan (the Openpupil device

regime," 2019). The new regime will look to align would be classed as a therapeutic product under
with international standards, and will assure the the proposed therapeutic products act. we
According to the most recent draft of the therapeutic products bill, a product is therapeutic if it is intended for use in, on, or in relato to humans for a pose. The bill defines a therapeutic purpose as:

-Preventing, diagnosing, monitoring, alleviating, treating, curing, or compensating for a disease,$$
\text { ect, or injury }
$$

fluencing, inhibiting, or modifying a human hysiological process as made to take the device to market following the traditional regulatory pipeline, gaining Agency) makes the most sense as the CE mark is Agency) makes the most sense as the CE mark is aspected by most country's regulators. Doing so in any county following the EU model is not a cheap any coune folowing the El mode is not acheap process ane confusing Pre-Market Assessment a process and regulators have both one-off fees during application and recurring fees once market access is granted. Gaining FDA (Food and Drug Administration) approval to enter the United States market is even harder, as proof of efficacy (Proof of a therapeutic effect, usually through clinical trials) is required. Releasing the device's files without going
through the regulatory process and indicating it is ready for use in a clinical environment may lead to

legal issues

However, the intention of the Openpupil project is not to take a traditional route to market. Instead, the made up of clinicians from around the world, each made up of clinicians from around the world, each and in turn building a more robust dataset around the intrinsically photosensitive retinal ganglion cells (ipRGC).
To achieve this, making the device accessible to as 政 政 or the greater good.

One way to sidestep the expensive and time in regulatory process is to release an (intelloctual property) required to source and assemble the Openpupil device, but stipulating (hrough a license agreement as a preference) that (he device is not a registered the rapeulic product, and is only suitable for research purposes. This sits

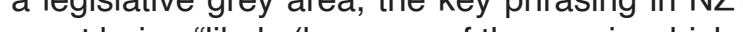
in act being glkely (because of the way in which it presented or for any other reason) to be used for therapeutic] purpose".

The points which make it unlikely for a regulato Thervene include: the device being treated as work-in-progress academic project that seeks input tren ing the intangible nent of this. Another reason not something regulators would encounter often ind an unlikely to possess the lacoun is evice As long as ethics approval can be gained a researcher, there are much fewer he ganes jump through to get a device such as this into use as a research tool, however regulators do require some form of notification that research on/using an unproved product is occurring. 


\section{Discussion}

Research question

This thesis asked the question: How can an open source development and distribution model be used conjunction with online 3D printing services and widely available parts and components to produce an inexpensive and open source pupilometer? answer this question, a research through design Krogh, Markussen \& Bang, 2015) methodology was applied.

$3 D$ printing

3D printing's ability to produce parts from digita CAD (Computer Aided Design) files makes singular [AJ1] or small batch production runs economically
viable. This is ideal for the production of open viable. This is ideal for the production of open
source products, as parts can be manufactured to order, rather than relying on the traditional mass manufacture model, which relies on economies of scale to make a product economically viable. Of the
$3 \mathrm{D}$ printing processes tested during the expansive design phase of this thesis, the SLS (selective laser sintering) printing process was identified as device. The SLS printing process produces durable, chemical resistant and high-resolution parts from a chemical resistant and high-resolution parts from products designed for a medical context.

The research also indicated that flexible 3D printing materials are not yet of a high enough quality to produce soft and flexible, yet robust parts. This where each of the printing processes tested were either too rigid, too rough, or not durable enough. In response, rubber binocular eyecups were outsourced as analternative. The binocular eyecups were a suitable alternative as they were cheap widely available online and came in a standardised size.
Distributed manufacture

Online 3D printing services such as Shapeways are currently the most effective manufacturing option for producing open source medical products. These platforms allow users to upload and customise CAD files through a web interface, which are then printed and dispatched from a centralised manufacturing facility. Because parts are manufactured in centralised location, production quality can be monitored and assessed before dispatch, resulting in a higher quality, more consistent service.

In comparison, distributed manufacturing services simply connect 3D printer owners to individuals requiring 3D printing services using an online user interface. This model does not allow for any centralised quality control, resulting in orders being frequenty late and of unsalisfactory quality. This is reflected by 3Dhubs recent transition from a distributed manufacturing network to a centralised 3D printing service ("3D Hubs," 2018). Despite this, the literature suggests that if $3 \mathrm{D}$ printing technology continues to improve at its current rate, distributed manufacturing networks may be able to consistently supply high quality parts in the near future (Attaran. 2017).

The research conducted throughout this thesis supports the literature, with parts ordered through distributed manufacturing network Treatstock coming back warped and low resolution, while al parts ordered through centralised online 3D printing coming back at a consistently high quality.

Of the centralised online $3 D$ printing services, Shapeways was found to be the most suited for the SLS prints the Openpupil device. Although higher surface quality, they were over double the price of the SLS prints sourced from Shapeways Overall the Shapeways prints provided a balance between cost and quality. This is idea for manufacturing open source products, as low production costs are one of the main advantages

developing open source products.
Because it is expected that the components used within the device will become obsolete and need to be updated over time, Openpupil was designed to be as adaptable as possible. For example, the device is powered by a standard 12500 mah power bank, however a wide variety of 12500 mah power banks exist in a range or shapes and sizes, and are updated frequently. Openpupil's utility 'box' design leaves enough room within the device for a range of power banks to fit. This enables users to select a power bank most suited to the context they intend to use the device within. For example, if the device is being taken into the field (for example to a rugby game), users can install a higher capacity battery so that the device lasts longer. However if it is being used in a clinical context, a smaller power bank patients.

Future research

To improve the adaptability of Openpupil further the device needs to be rebuilt using a parametric CAD system such as Solidworks ("3D CAD Design
Software," 2019) or the free Rhinoceros plugin Software," 2019) or the free Rhinoceros plugin
grasshopper ("Grasshopper - algorithmic modeling grasshopper ("Grasshopper - algorithmic modeling the device to be easily updated to accommodate new components as they become available, while also lowering the costs associated with keeping also lowering the costs associated with keeping the device up to date. The adoption of parametric modify or 'hack' the device for use in a range of contexts.

To achieve this, several technical aspects of the device need to be developed further. Firstly, the electronics need to be optimised by an electronics engineer to ensure the device functions as effectively possible. This process is also critical to the nod a troubleshoot their software and develop it further. Once a stable and robust prototype that has pased the ANSI 2000 safety standard has been achieved, validation study can be conducted, testing the evices ability to pligme ligh (Post Mllumination (Pun be compared gevices to gange the Openpupils level of accuracy.

Another aspect of the project that needs to be Andressed is the user experience. Because users e required to assemble the device themselves, clear and concise assembly instructions wir eed to be designed and trialled. Furthermore, smartphone app that acts as a user interface for cherians to pertom pupil tests, as well as interpre e data collected through the testing process wil need to be developed.

\section{mplications}

This thesis demonstrates the implications of using D printing in conjunction with an open source

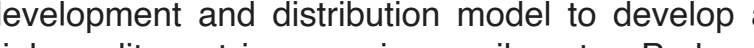

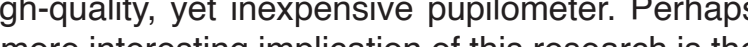
of a mer community, wherishing a global, online research cerch colle cter understanding of the pupil. There is potentia en 列

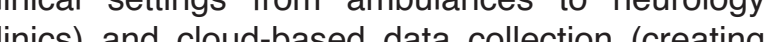
large biometric database). For this to (ccur, it is mperative the device is made as occur, it is user friendly to as many clinicians as possible.

terms of manufacturing and design, this research may have significant implications as a case study individuals and organisations seeking to design and distribute their own open source products by on through the development of similar devices; coreby supporting the growth of new open source 
Safety

From a regulatory perspective, at minimum the device is required to pass the safety standard titled Maximum permissible exposures for ocular safety (ANSI 2000), with emphasis on ophthalmic devices (Delori, Webb, \& Sliney, 2007) to ensure the LEDs within the device are safe. These tests were being conducted by the Measurement Standards Laboratory of New Zealand (MSL) prior to the start of this thesis. While inilal tests gave confidence the device was not hazardous, further testing had to be postponed due to the instability of the prototype, which eventually stopped working midway through the testing process. To ensure these tests can be conducted effectively, a more robust, stable prototype in terms of both hardware and software is required.
Conclusion

The research conducted throughout this thesis ent and distribution models, online $3 \mathrm{D}$ printing services and inexpensive, widely avalable components can be used in conjunction to substantially lower the costs associated with developing, manufacturing and distributing medical devices. By leveraging Shapeways online 3D printing services, in conjunction with a range of widely available parts and components, the Openpupil device was produced for approximately $\$ 650.00$ NZD. With more development, this cost could be reduced even further, however it is still substantially cheaper than other pupil measuring devices currently available, all of which cost between $\$ 10,000$ and $\$ 100,000$. These findings are consistent with the literature, which suggests that for 3D printing to compete with traditional mass manufacturing processes such as injection moulding, niche applications that provide an advantage in terms of cost, quality and/or accessibility need to be identified. In the case of this thesis, the niche identified is an open source pupilometer that leverages online 3D pring sovices, readily avalable components and worldwide distribution newworks to deliver an expensive alternative to expensive commercial devices, and aims to demonstrate how open source cinology cander ence (Bradford, n.d.). 
Appendix 
Table 9. Additive manufacturing processes defined by the International Organisation for Standardisation (ISO)

\begin{tabular}{|c|c|c|c|c|c|}
\hline Classification & Description & Technology & Materials & Advantages & Disadvantages \\
\hline Binder jetting & $\begin{array}{c}\text { Additive manufaccturing tech- } \\
\text { nique where a liquid bonding } \\
\text { agent is selectively deposited } \\
\text { to join powder materials on a } \\
\text { layer by layer basis }\end{array}$ & Binder Jetting & $\begin{array}{l}\text { Metals, sand (Sil- } \\
\text { ica), sandstone, } \\
\text { glass }\end{array}$ & $\begin{array}{l}\text { Can produce full color } \\
\text { parts at relatively low } \\
\text { costs compared to } \\
\text { other processes. } \\
\text { Can produce large } \\
\text { parts and complex } \\
\text { metal geometries. }\end{array}$ & $\begin{array}{l}\text { Limited mechanical } \\
\text { properties due to High } \\
\text { porosity. Parts can } \\
\text { be Brittle and more } \\
\text { complex geomemetry is } \\
\text { prone to cracking. }\end{array}$ \\
\hline Material extrusion & $\begin{array}{l}\text { Additive manufacturing tech- } \\
\text { nique where molten thermo- } \\
\text { plastics are extruded through } \\
\text { a nozzle and deposited onto a } \\
\text { build tray. Build material is then } \\
\text { deposited layer by layer until } \\
\text { the object is complete }\end{array}$ & $\begin{array}{l}\text { Fused deposition } \\
\text { modelling (FDM) } \\
\\
\text { Fused Filament } \\
\text { Fabrication (FFF) }\end{array}$ & $\begin{array}{l}\text { Polymers } \\
\text { (PLA, ABS, TPU, } \\
\text { PETG) } \\
\text { Polymer compos- } \\
\text { ites (wood, fibre- } \\
\text { glass, copper) }\end{array}$ & $\begin{array}{l}\text { Lowest costing and } \\
\text { most widely available } \\
\text { printing method, } \\
\text { resulting in shorter } \\
\text { lead times. Relatively } \\
\text { durable. } \\
\text { Wide range of } \\
\text { thermoplastics and } \\
\text { composite materials } \\
\text { available. }\end{array}$ & $\begin{array}{l}\text { Low dimensional } \\
\text { accuracy. Layered, } \\
\text { low resolution surface } \\
\text { finish. } \\
\text { Support material is re } \\
\text { quired to build certain } \\
\text { geometries. This can } \\
\text { be difficult to remove } \\
\text { in post processing } \\
\text { and limit the geomet- } \\
\text { rical complexity of } \\
\text { the part. }\end{array}$ \\
\hline Material jetting & $\begin{array}{l}\text { Additive manufacturing tech- } \\
\text { nique that utilises a similar pro- } \\
\text { cess to standard inkjet printing, } \\
\text { but instead of depositing ink } \\
\text { onto paper, the nozzle deposits } \\
\text { a liquid photopolymer onto } \\
\text { the build tray. This process is } \\
\text { then repeated on a layer by } \\
\text { layer basis until the object is } \\
\text { complete }\end{array}$ & Polyjet & $\begin{array}{l}\text { Resin based } \\
\text { plastic } \\
\text { (Liquid photopoly- } \\
\text { mer) }\end{array}$ & $\begin{array}{l}\text { Can produce full color } \\
\text { parts with a high reso- } \\
\text { lution surface finish. } \\
\text { Ability to combine soft } \\
\text { and hard materials } \\
\text { within a single object. }\end{array}$ & $\begin{array}{l}\text { Expensive printing } \\
\text { process } \\
\text { Photopolymers } \\
\text { degrade overtime, } \\
\text { Unsuitable for func- } \\
\text { tional parts }\end{array}$ \\
\hline Material jetting & $\begin{array}{l}\text { Additive manufacturing tech- } \\
\text { nique that utilises a similar pro- } \\
\text { cess to standard inkjet printing, } \\
\text { but instead of depositing ink } \\
\text { onto paper, the nozzle deposits } \\
\text { a liquid photopolymer onto } \\
\text { the build tray. This process is } \\
\text { then repeated on a layer by } \\
\text { layer basis until the object is } \\
\text { complete }\end{array}$ & Polyjet & $\begin{array}{l}\text { Resin based } \\
\text { plastic } \\
\begin{array}{l}\text { (Liquid photopoly- } \\
\text { mer) }\end{array}\end{array}$ & $\begin{array}{l}\text { Can produce full color } \\
\text { parts with a high reso- } \\
\text { lution surface finish. } \\
\text { Ability to combine soft } \\
\text { and hard materials } \\
\text { within a single object. }\end{array}$ & $\begin{array}{l}\text { Expensive printing } \\
\text { process } \\
\text { Photopolymers } \\
\text { degrade overtime, } \\
\text { Unsuitable for func- } \\
\text { tional parts }\end{array}$ \\
\hline
\end{tabular}

\begin{tabular}{|c|c|c|c|c|c|}
\hline Classification & Description & Technology & Materials & Advantages & Disadvantages \\
\hline Powder bed fusion & $\begin{array}{l}\text { Additive manufacturing } \\
\text { technique that uses lasers } \\
\text { to selectively fuse or melt } \\
\text { particles from a bed of } \\
\text { plastic powder on a layer by } \\
\text { layer basis, until the object } \\
\text { is complete }\end{array}$ & $\begin{array}{l}\text { Selective Laser } \\
\text { Sintering (SLS) } \\
\text { Multi Jet Fusion } \\
\quad \text { (MJF) }\end{array}$ & $\begin{array}{l}\text { Metals, Nylon } \\
\text { polymers, Nylon } \\
\text { composites }\end{array}$ & $\begin{array}{l}\text { Does not require } \\
\text { support material, so } \\
\text { designs with complex } \\
\text { geometries can be } \\
\text { easily produced. SLS } \\
\text { produces strong, } \\
\text { durable objects at } \\
\text { relatively affordable } \\
\text { prices. }\end{array}$ & $\begin{array}{l}\text { Grainy surface may } \\
\text { require post process- } \\
\text { ing depending on the } \\
\text { required finish. } \\
\text { Large flat geometries } \\
\text { are prone to warping }\end{array}$ \\
\hline Sheet Lamination & $\begin{array}{l}\text { Additive manufacturing pro- } \\
\text { cess in which sheets of ma- } \\
\text { terial are bonded together to } \\
\text { form the finished object. }\end{array}$ & $\begin{array}{l}\text { Laminated Object } \\
\text { Manufacture (LOM) }\end{array}$ & $\begin{array}{l}\text { Paper, plastic, } \\
\text { sheet metal }\end{array}$ & $\begin{array}{l}\text { Poor surface finish } \\
\text { Process makes it diffi- } \\
\text { cult to produce hollow } \\
\text { geometries }\end{array}$ & $\begin{array}{l}\text { High manufacturing } \\
\text { speeds } \\
\text { Components don't } \\
\text { need support struc- } \\
\text { tures }\end{array}$ \\
\hline $\begin{array}{l}\text { Vat photo polymeri- } \\
\text { sation }\end{array}$ & $\begin{array}{l}\text { Additive manufacturing } \\
\text { process that uses a beam of } \\
\text { UV light to harden or 'cure' } \\
\text { liquid resin on a layer by } \\
\text { layer basis. After each layer } \\
\text { of the object is cured, the } \\
\text { build plattorm is lowered } \\
\text { into the liquid resin and then } \\
\text { raised to the appropriate } \\
\text { height where the ext layer } \\
\text { is then cured. This process } \\
\text { continues until the object is } \\
\text { complete }\end{array}$ & $\begin{array}{l}\text { Stereolithography } \\
\text { (SLA) }\end{array}$ & $\begin{array}{l}\text { Resin based } \\
\text { plastic } \\
\text { (Liquid photopoly- } \\
\text { mer) }\end{array}$ & $\begin{array}{l}\text { Produces high reso- } \\
\text { lution parts at a high } \\
\text { detail }\end{array}$ & $\begin{array}{l}\text { Expensive printing } \\
\text { process } \\
\text { Photopolymers } \\
\text { degrade over time } \\
\text { when exposed to } \\
\text { sunlight. Unsuitable } \\
\text { for functional parts }\end{array}$ \\
\hline
\end{tabular}

Note: Printing classifications for additive manufacture from the International Organization for Standardization (ISO)/American Society for Testing and Materials (ASTM) ASTM52910. Description and printing technology columns compiled from Prince, 2014 and Prakash, Nancharain, \& Rao, 2018. Advantages and disadvantages columns compiled from https://www.3dhubs.com/3d-printing/ processes/. Copyright (2019) by 3D hubs. 


\section{Anthropometry}

In 2001 the National Institute for Occupational Safety database representing the heads and faces of When designing products for human use, the body United Ste dimensions of the target population are a critical plan called for roughly racial/ethnic groups (White factor that need to be carefully considered. Attributes female subjects in four racial/ethnic groups (White, such as gender, ethnicity and age all have a strong African American, Hispanic, and 4 and over 45) influence on the anthropomorphic measurements or a population. If not taken into account, designers can unintentionally exclude large groups of potential users (de Vries \& Parkinson, 2014).

In total 4026 subjects were measured for 21 dimensions. Figure 9. displays the relevant perican anthropometric measurements identified as crucial population could potentially prevent $35 \%$ of Chinese in terms of ensuring a comfortable and functional fit users from using the mask due to an incorrect fit for the pupilometer.

Yang, Shen, \& Wu, 2007). Because the pupilometer

bexpeted to be downloaded, assembled and used

by clinicians across the globe, the device is required

fit comfortably across a range of different facial

ypes.

Table 10. Table comparing the range of $3 D$ printing services, processes, and materials used to manufacture the diffuser

\begin{tabular}{|c|c|c|c|}
\hline Measurement & Male (mean) & Female (mean) & Average (mean) \\
\hline Interpupillary distance & $64.5 \mathrm{~mm}$ & $61.9 \mathrm{~mm}$ & $63.2 \mathrm{~mm}$ \\
\hline Bizygomatic Breadth & $143.5 \mathrm{~mm}$ & $135.1 \mathrm{~mm}$ & $139.3 \mathrm{~mm}$ \\
\hline Nasal Root Breadth & $16.6 \mathrm{~mm}$ & $16.3 \mathrm{~mm}$ & $16.45 \mathrm{~mm}$ \\
\hline Maximum Frontal Breadth & $112.3 \mathrm{~mm}$ & $108.6 \mathrm{~mm}$ & $11 \mathrm{~mm}$ \\
\hline
\end{tabular}

Note. From Facial anthropometric differences among gender, ethnicity, and age groups, by (Zhuang, Landsittel, Benson, Roberge, \& Shaffer, 2010)
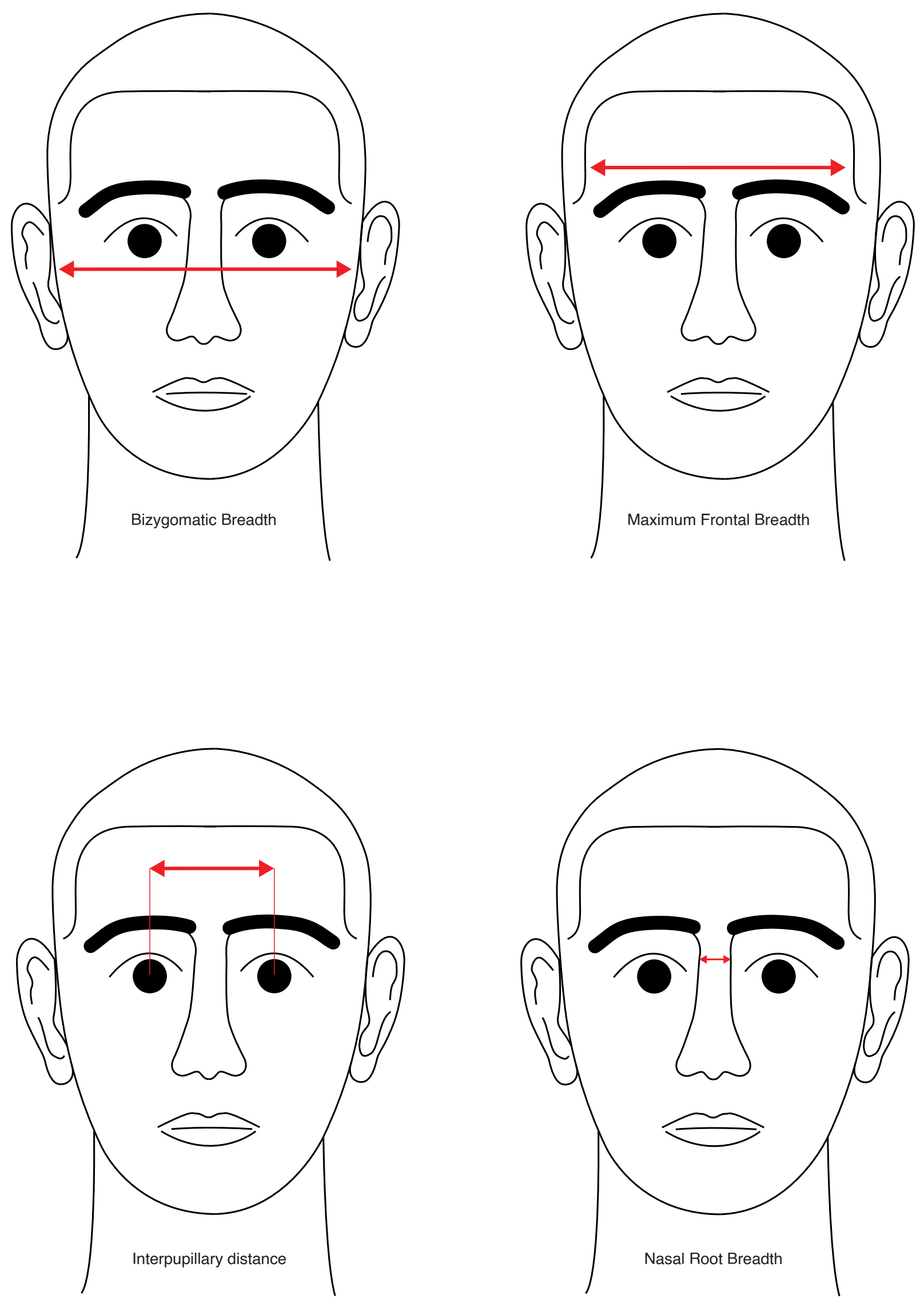


\section{OPPENPUPIL CPENPUPIL}




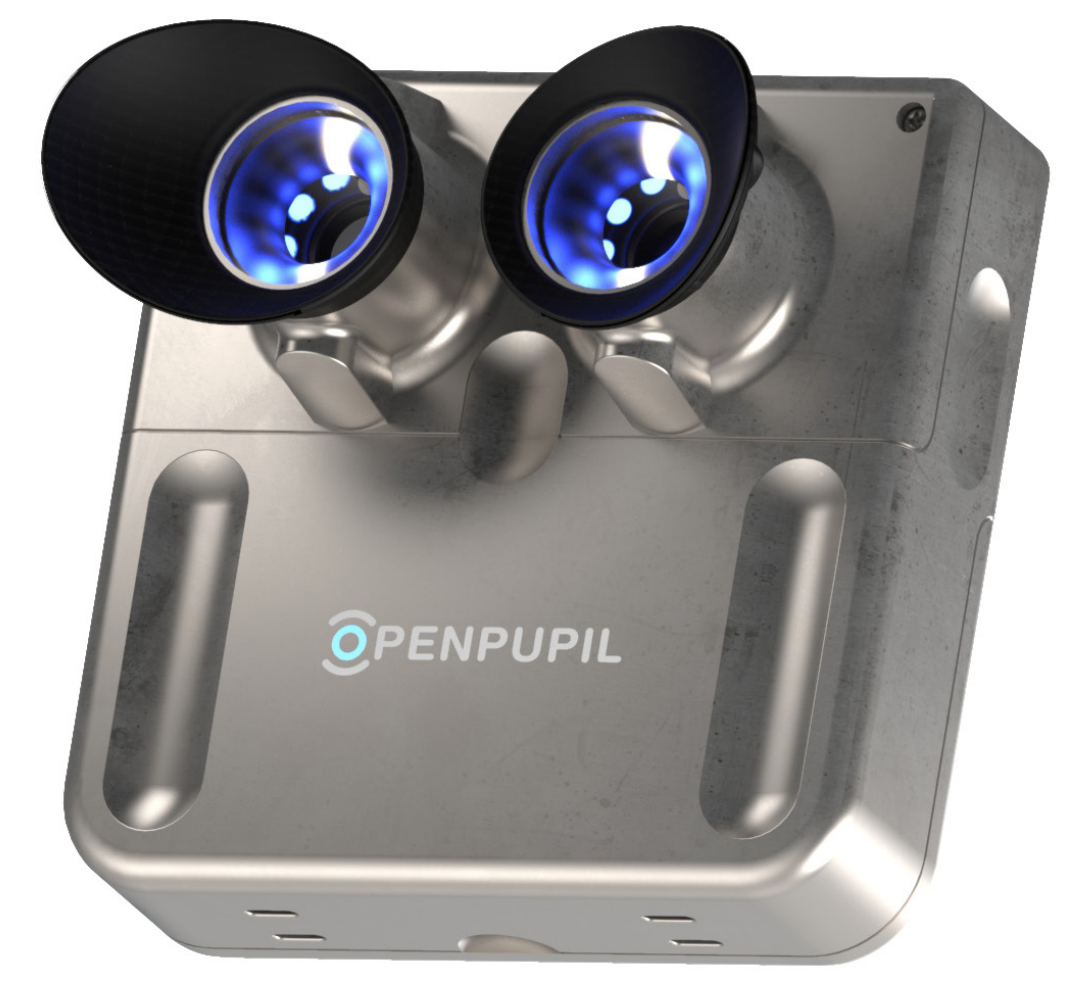

Figure 59 (a). Conceptual render of the Openpupil device made from a titanium material.

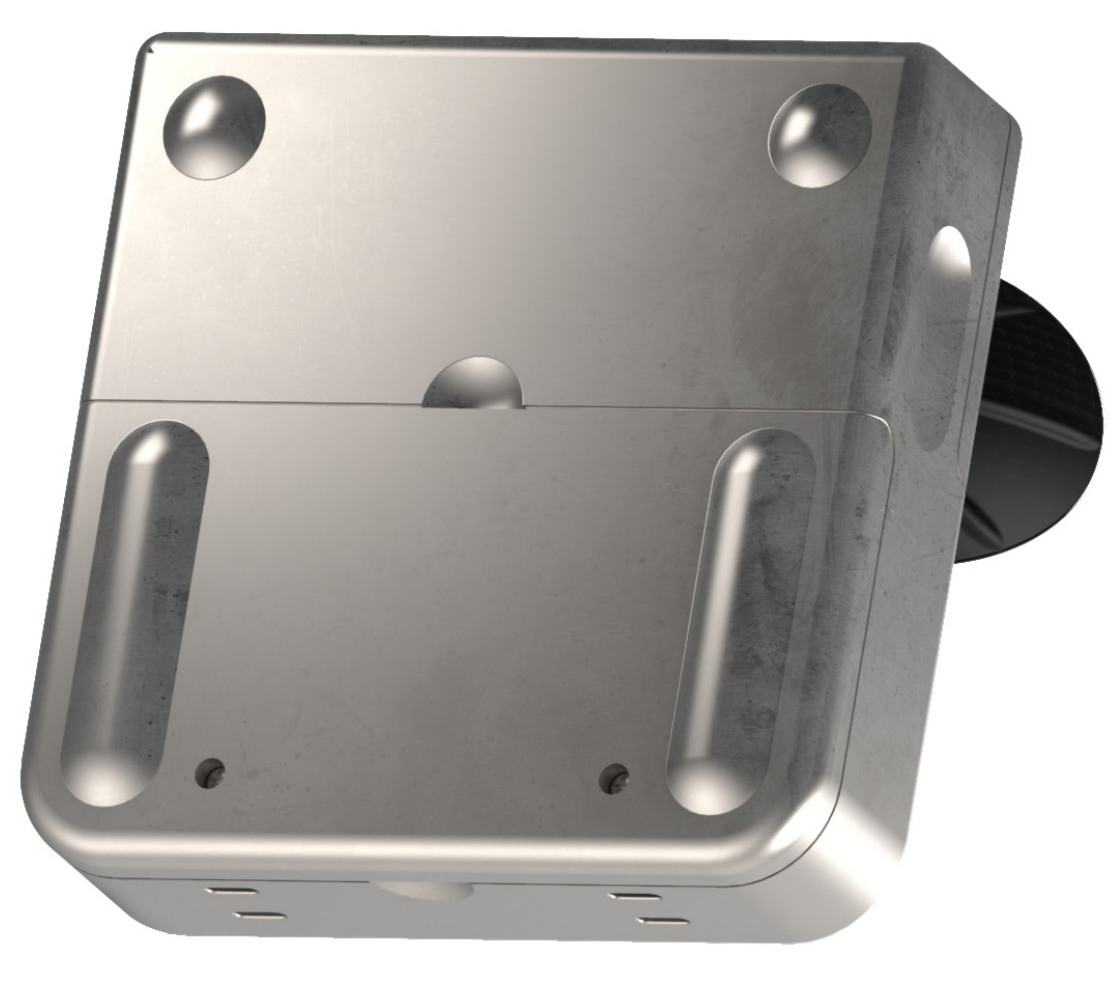

Figure 59(b). Conceptual render of the Openpupil device made from a titanium material. 


\section{List of figures}

Figure 1. Fred Hollows treats a young Vietnamese boy, 1992.

Figure 2. Diagram visualising the design process used in this thesis.

Fuure 3. Diagrams showing the differences between a distributed manufacturing network and a centralised, online 3D printing service.

Figure 4. oDocs visoscope. Retrieved November 5, 2018, from https://web.archive.org

web/20190713104307/http://www.odocs-tech.com/visoscope/\#

Figure 5. 3D printed Glia stethoscope. Retrieved June 15th, 2019, from https://web.archive.org

web/20190713104550/https://newatlas.com/glia-model-3d-printed-stethoscope/53811/

Figure 6. E-nable raptor prosthetic hand. Retrieved June 14th, 2019, from https://web.archive.org/ web/20190713104807/https://3dprint.niih.gov/sites/defaultffiles/model/sadditional_images/large_IMG_4824. $J P G$

Figure 7. Defense Distributed's $3 D$ printed Liberator handgun. Retrieved July 1st, 2019, from https./ web.archive.org//ave/hips.//Www.dezeen.com/2018/07/24/downiloadable-files-3d-printed-guns-publiclisaccessible-cody-wilson-defense-distributed/

Figure 8. Poster showing work completed on the pupiliomeler during the first summer research scholarship. Retrieved from: https://web.archive.org/web/20190713164133/https://github.com/kaiwhata/OpenPupil

Figure 9. Poster showing work completed on the pupillometer during the second summer research scholarship.

Figure 10. Iterative prototypes produced during the second summer research scholarship.

Figure 11. Head mounted pupilometer prototype produced during the second summer research scholarship.

Figure 12 (a). Digital representation of the eyecup.

Figure 12 (b). Digital representation of the Raspberry P

Figure 12 (c). Digital representation of the Eyepiece

Figure 12 (d). Digital representation of the Diffuser

Figure 13 (a). Eyecup printed via Treatstock using the FDM printing process

Figure 13 (b). Eyecup printed via Shapeways using the SLS printing process

Figure 13 (c). Eyecup printed via $3 D$ hubs using the SLA printing process

Figure 14. Standardised rubber eyecup

Figure 15 (a). Raspberry Pi housing printed via Treatstock using the FDM printing process

Figure 15 (b). Raspberry Pi housing printed via 3Dhubs using the FDM printing process

Figure 15(c). Raspberry Pi housing printed via 3D3Dhubs using the SLS printing process

Figure 15 (d). Raspberry Pi housing printed via Shapeways using the SLS printing process

\begin{tabular}{|c|c|}
\hline Figure 16 (a). Eyepiece printed via 3 Dhubs using the FDM printing process & 63 \\
\hline Figure 16 (b). Eyepiece printed via 3 Dhubs using the FDM printing process & 63 \\
\hline Figure 16 (c). Eyepiece printed via 3D Hubs using the SLS printing process & 63 \\
\hline Figure 16 (d). Eyepiece printed via Shapeways using the SLS printing process & 63 \\
\hline Figure 17. Diffuser printed via Shapeways using the SLA printing process & 65 \\
\hline Figure 18. Non 3D printed Components housed within the pupilometer. & 68 \\
\hline Figure 19. The $0.04 \mathrm{~mm}$ tolerance test provided the best slot fit. & 71 \\
\hline Figure 20 (a). & 73 \\
\hline Figure 20 (b). Infrared LED housed within the $5.02 \mathrm{~mm}$ housing. & 73 \\
\hline Figure 21 (a). Prototypes created during the tolerance optimisation process of the lens housing. & 75 \\
\hline Figure 21 (b). & 75 \\
\hline Figure 21 (c). & 75 \\
\hline Figure 22 (a). Prototypes created during the tolerance optimisation process of the Neopixel Ring housing. & 77 \\
\hline Figure 22 (b). & 77 \\
\hline Figure 22 (c). & 77 \\
\hline Figure 23 (a). Prototypes created during the tolerance optimisation process of the camera housing. & 79 \\
\hline Figure 23(b). & 79 \\
\hline Figure 23 (c). & 79 \\
\hline Figure 24(a). Prototypes created during the tolerance optimisation process of the Raspberry Pi. & 81 \\
\hline Figure 24 (b). & 81 \\
\hline Figure 24 (c). & 81 \\
\hline Figure 25 (a). Exploded view of the initial prototype configuration. & 83 \\
\hline Figure 25 (b). Assembled Initial prototype. & 83 \\
\hline Figure 26. Ideation sketches based on VR headset precedents. & 91 \\
\hline Figure 27. Low fidelity headset prototype \& assorted straps. & 93 \\
\hline Figure 28. Ideation sketches based on binocular precedents. & 99 \\
\hline Figure 29. Gold-foam ergonomic experiments based on binocular precedent analysis. & 101 \\
\hline Figure 30. Ideation sketches based on camera precedents. & $107 \mathrm{Y}>\mathrm{C}$ \\
\hline
\end{tabular}




\begin{tabular}{|l|l|}
\hline Figure 31. Gold-foam ergonomic experiments based on camera precedents. & 109 \\
\hline Figure 32 (a). Low fidelity card prototype used to contain a raspberry Pl and a battery. & 111 \\
\hline $\begin{array}{l}\text { Figure 32 (b). Exploratory prototyping conducted by taping together a range of components to test different } \\
\text { configurations. }\end{array}$ & 111 \\
\hline Figure 33. Box-like utility prototypes made from foam. & 114 \\
\hline $\begin{array}{l}\text { Figure 34. Refined sketches based on the utility cannister prototypes and the ergonomic research } \\
\text { conducted thus far. }\end{array}$ & 115 \\
\hline Figure 35. Box-like utility prototype made from card. & 116 \\
\hline Figure 36. Digital render of the Openpupil device. & 118 \\
\hline Figure 37. Prototypes created during the development of the final eyepiece design. & 120 \\
\hline Figure 38. Prototypes created during the development of the final LED cap design. & 121 \\
\hline Figure 39. Prototypes created during the development of the final camera housing design & 122 \\
\hline Figure 40. Prototypes created during the development of the final battery housing design. & 123 \\
\hline Figure 41. Development of the ergonomic finger indent on the side of the device. & 124 \\
\hline Figure 42. Prototypes created during the development of the final body design. & 125 \\
\hline Figure 43. Partially disassembled final prototype. & 126 \\
\hline Figure 44. Partially disassembled final prototype & 127 \\
\hline Figure 45. Closeup image of the carry strap connected to the final prototype & 128 \\
\hline Figure 46. Closeup image of the ergonomic finger indent positioned on the side of the device. & 129 \\
\hline Figure 47. Final prototype in use. & 131 \\
\hline Figure 48. Exploded view of the Openpupil device displaying the layout of the internal components, and \\
how the device is configured.
\end{tabular} \mid \begin{tabular}{l}
\hline 33 \\
\hline Figure 49. Closeup image of the surface texture of the eyepiece.
\end{tabular}

Figure 52(c). A patient undergoing a pupil measurement test, while Doctor Gale examines the results from his computer.

Figure 52 (d). Openpupil device placed amongst other Opthalmologic tools.

Figure 53. Wellington free ambulance paramedic wearing the Openpupil device.

Figure 54 (a). The Openpupil device stored within an ambulance, ready for use.

Figure 54 (b). A patient being fitted with the openpupil device to test his pupil light reflex.

Figure 54 (c). A paramedic fitting a patient with the openpupil device to test the pupil light reflex.

Figure 54 (d). A paramedic monitors the pupil data of the patient

Figure 55. The Openpupil device stored in the teams gear bag awaiting use.

Figure 56 (a). The Openpupil device stored in the teams gear bag awaiting use.

Figure 56 (b). Player suspected of suffering a concussion prepares to undergo a pupil screening test.

Figure 56 (c). Player suspected of suffering a concussion undergoes a pupil screening test.

Figure 56 (d). Physiotherapist monitors the players test results from his mobile phone.

Figure 57. Anthropometric measurements used in the development of the pupilometer.

Figure 58. Color variations of the Openpupil device logo.

Figure 59 (a). Conceptual render of the Openpupil device made from a titanium material.

Figure 59 (b). Conceptual render of the Openpupil device made from a titanium material.
146 
List of tables

Table 1. The aims, objectives, methods and design tools used within this thesis.

Table 2. Services offered by Online 3D printing platforms.

Table 3. Table comparing the range of $3 D$ printing services, processes, and materials used to manufacture the eyecups.

Table 4. Table comparing the range of $3 D$ printing services, processes, and materials used to manufacture the Raspberry Pi housing

Table 5. Table comparing the range of $3 \mathrm{D}$ printing services, processes, and materials ability to manufacture the eyepiec

Table 6. Table comparing the range of $3 D$ printing services, processes, and materials used to manufacture the diffuser

Table 7. Table depicting the cost to purchase the non $3 D$ printable parts and component of the Openpupil device. Table 8. Table depicting the cost to print the Openpupil device using Shapewats SLS nylon.

Table 9. Additive manufacturing processes defined by the International Organisation for Standardisation (ISO)

Table 10. Table comparing the range of $3 \mathrm{D}$ printing services, processes, and materials used to manufacture the diffuser 60 62 64 135 135 156 158 


\section{References}

Adafruit Industries, Unique \& fun DIY electronic and kits. (n.d.). Retrieved November 5, 2018, from https://www.adafruit.com/

Alcock, C., Hudson, N., \& K. Chilana, P. (2016). Barriers to Using, Customizing, and Printing $3 D$ Designs on Thingiverse (pp. 195-199). hitps.//do. org/10.1145/2957276.2957301

Almquist T, Modrek B, Jacobs P, Lewis C, Lewis M, Liran A. (1989). U.S. Patent No. 5,174,931.

Amazon.com: Online Shopping for Electronics, Apparel, Computers, Books, DVDs \& more. (n.d.). Retrieved July 13, 2019, from https://web.archive. \& Services, 26(2), 76-79. doi:http://dx.do $\mathrm{com} /$

Arduino - Home. (n.d.). Retrieved July 13, 2019, Crump, S. (1992). U.S. Patent No. 5,121,329 from https://www.arduino.cc/

United States Patent and Trademark Office.

Attaran, M. (2017). The rise of 3-D printing: The Defense Distributed I. (n.d.). Retrieved December advantages of additive manufacturing over traditional 7,2018 , from https://defdist.org/

manufacturing. Business Hoizons, 60(5), 677-688. https://doi.org/10.1016/j.bushor.2017.05.011

Baumann, F. W. (2018). Thirty Thousand 3D Models from Thingiverse. Data; Basel, 3(1). http://dx.dol. org.helicon.vuw.ac.nz/10.3390/data3010005

Baden-Fuller, C. \& Haefliger, S. (2013). Business Models and Technological Innovation. Long Range Planning, 46(6), pp. 419-426. doi: 10.1016/].
Irp.2013.08.023

Bailes, H. J., \& Lucas, R. J. (2010). Melanopsin and inner retinal photoreception. Cellular and (10) org/10.1007/s00018-009-0155-7

elori, F. C., Webb, R. H., \& Sliney, D. H. (2007) Maximum permissible exposures for ocular safety (ANSI 2000), with emphasis on oph halmic devices. JOSA A, 24(5), 1250-1265. https://doi.org/10.1364/ OSAA.24.001250

Desrosier, J. (2011). Rapid Prototyping Reconsidered. The Journal of Continuing Higher (2) 63.2011.61488

de Vries, C., \& Parkinson, M. B. (2014). Limiting isproportionate disaccommodation in design for doi.org/10.1080/00140130.2013.853102 g/0.1080/00140139.2013.853102

Bauchner H, Golub RM, \& Fontanarosa PB. (2016). Downloadable files for 3D-printed guns to be made Data sharing: An ethical and scientic imperative. publicly accessible. (2018, July 24). Retrieved JAmA, 315: 12 (238-1240. he

Berman, B. (2012). 3-D printing: The new industrial defense-distributed/

evolution. Business Horizons, 55(2), 155-162. https://doi.org/10.1016/j.bushor.2011.11.003

Downton, P. (2003). Design research. Melbourne: RMIT Pub.

Binda, P., Pereverzeva, M., \& Murray, S. O.

(2013). Attention to Bright Surfaces Enhances the Enabling The Future. (n.d.). Retrieved November Pupillary Light Reflex. Journal of Neuroscience, 18, 2018, from http///enablingthefuture.org/ 2199-2204. https://doiorg/10.1523/ NEUROSCI.3440-12.2013
Ferreira, D., Duarte, T., Alves, J. L., \& Ferreira, I. GitHub - kaiwhata/OpenPupil: Open Source (2018). Development of low-cost customised hand pupilometer. (2019, July 13). Retrieved July 14, 2019, prostheses by additive manufacturing. Plastics, from https://web.archive.org/web/20190713164133/ Rubber and Composites, 47(1), 25-34. https://doi. https://github.com/kaiwhata/OpenPupil $\mathrm{org} / 10.1080 / 14658011.2017 .1413793$

Godin, D., \& Zahedi, M. (n.d.). Aspects of Research First Amendment - technology - Fifth Circuit through Design: A Literature Review, 14 declines to enjoin regulation of online publication of 3D-printing files - Defense Distributed V. Gross, B. C., Erkal, J. L., Lockwood, S. Y., Chen, C. United States Department of State. (2017, \& Spence, D. M. (2014). Evaluation of 3D Printing April). Harvard Law Review, 130(6), 1744+. and Its Potential Impact on Biotechnology and the Retrieved from http://ink.galegroup.com. Chemical Sciences. Analytical Chemistry, 86(7) helicon.vuw.ac.nz/apps/doc/A491136617/ 3240-3253. https://doi.org/10.1021/ac403397r AONE?u=vuw\&sid=AONE\&xid=e4ca7768

(2019, July 13). Retrieved July 13,2019 , from ., \& Kress, C. (2017). An economic https://web.archive.org/web/20190713003110/ analysis comparing the cost feasibility of replacing https://glia.org/

mection molling processes with emerging addilve manufacturing techniques. The International Jounal of Advanced Manufacturing Technology, 88(9), 2573-2579. https://doi.org/10.1007/s00170016-8968-7

Frayling, C. (1993). Research in Art and Design. Royal College of art Research Papers, 1(1), 1-5

Friedman, Ken. (2008). Research into, by and for design AU - Journal of Visual Art Practice, 7(2), 153-160. https://doi.org/10.1386/jvap.7.2.153_1

Gale, J., Eldridge, E., Pathmanathan, S., Polutea, K., Gouws, G., \& Fraser, S. (2017). Development of an open-source pupilometer for testing melanopsin responses. Investigative Ophthalmology \& Visual Science, 58(8), Investigative Ophth
Visual Science, 2017 Jun, Vol.58 (8).

Gaver, W. (2011). Making spaces: How design workbooks work. Retrieved July . ResearchGatehttps://doi. org/10.1145/1978942.197916

Global Home: UPS - United States. (2019, July 13). Retrieved July 13, 2019, from https://web.archive. org/web/201907/3003339/https://www.ups.com/ us/en/global.page

Grasshopper - algorithmic modeling for Rhino. 2019, July 13). Retrieved July 13, 2019, from

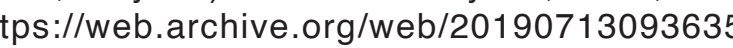
https://www.grasshopper3d.com/

anington, B., \& Martin, B. (2012). Universa methods of design: 100 ways to research

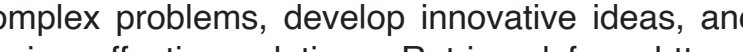
esign effective solutions. Retrieved from https:/ bookcentral.proquest.com

Henry, C. (1896). The Action of Light on the Iris, Demonstrated by a New Pupilometer. Nature, 53(1381), 568-569 Archive for Clinical and Experimental Ophthalmology $=$ Albrecht Von Graefes Archiv Fur Klinische Und Garneau, C. J., \& Parkinson, M. B. (2011). A Experimentelle Ophthalmologie, 253(10), 1831comparison of melhodogies for designing 1833. h. Fs./ddoi.org/10.1007/s00417-015-3017-z for human variability. Journal or Engineening lera, A., Floer

The Internet of things [Guest Editorial]. IEEE Gaver, W. (2011). Making spaces: How Wireless Communications, 17(6) 8-0. https:/doil work https://doi. org/10.1109/MWC.2010.5675772

org/10.1145/1978942.1979160

Isaacs, D. (2011). The hippocratic oath. Journal of Paediatrics and Child Health, 47(6), 321. 
Kim, T., \& Youn, J. (2013). Development of a CIRP, 33, 185-190. https://doi.org/10.1016/j. Smartphone-based Pupillometer. Journal of the procir.2015.06.034 Optical Society of Korea, 17(3), 249-254.

Michalski MH, \& Ross JS. (2014). The shape of Kogut, B., \& Metiu, A. (2001). Open-Source things to come: 3d printing in medicine. JAMA Software Development and Distributed Innovation. 312(21), 2213-2214. https://doi.org/10.1001 Oxford Review of Economic Policy, 17(2), 248-264. jama.2014.9542

https://doi.org/10.1093/oxrep/17.2.248

Krogh, P. G., Markussen, T., \& Bang, A. L. (2015) Niezen, G., Eslambolchilar, P., \& Thimbleby, Ways of Dritting - Five Methods of Experimentation devices. BMen-source hardware for medical in Research Through Design. In A. Chakrabarti org/10.1136/bmjinnov-2015-000080

(Ed.), ICoRD'15 - Research into Design across

Boundaries Volume 1 (pp. 39-50). Springer India. Open Source Hardware Association (OSHWA)

Kugler, L. (2018). The War over the Value of (2016). The Open Source Hardware (OSHW Personal Data. Commun. ACM, 61(2), 17-19. oshwa.org/definition/.

https://doi.org/10.1145/3171580

Pavlosky, A., Glauche, J., Chambers, S., Al-Alawi, Kühnle, H., \& Bitsch, G. (2015). Foundations \& M., Yanev, K., \& Loubani, T. (2018). Validation Principles of Distributed Manufacturing Elements of an effective, low cost, Free/open access of Manufacturing Networks, Cyber-Physical 3D-printed stethoscope. PLoS One; San Francisco, Production Systems and Smart Automation / by 13(3), e0193087. http://dx.doi.org.helicon.vuw. Hermann Kühnle, Günter Bitsch.

Kuniavsky, M. (2003). Observing the user experience Parsa-Parsi, R. W. (2017). The Revised Declaration : a practitioner's guide to user research. Retrieved from https://ebookcentral.proquest.com

Larson, M. D., \& Singh, V. (2016). Portable infrared pupillometry in critical care. Critical Care (London, England), 20(1), $161 . \quad$ https://doi.org/10.118 s13054-016-1349-7

of Geneva: A Modern-Day Physician's Pledge. JAMA, 318(20), 1971-1972. https://doi.org/10.1001/ jama.2017.16230

Pearce, J. M. (2017). Emerging Business Models for Open Source Hardware. Journal of Open Hardware 1(1), 2. https://doi.org/10.5334/joh.4

Mai, J., Zhang, L., Tao, F., \& Ren, L. (2016). Petrick, I. J., \& Simpson, T. W. (2013). 3D Printing Customized production based on distributed Disrupts Manufacturing: How Economies of One 3D printing services in cloud manufacturing. Create New Rules of Competition. ResearchInternational Journal of Advanced Manufacturing Technology Management, 56(6), 12-16. https://doi. Technology, 84(1-4), 71-83. https://doi.org/10.1007/ org/10.5437/08956308X5606193

\section{s00170-015-7871-y} from the from the world's largest online B2B marketplace- Manufacturing -An Overview. Materials Today: Alibaba.com. (2019, July 13). Retrieved Proceding, 5(2, Part 1), 3873-3882. https://do July 13, 2019, from https://web.archive.org/
web/20190713003455/https://www.alibaba.com/

Prakash, J. D. (2014). 3D Printing: An Industria Online 3D Printing Service I i.materialise. (2019, Revolution. Journal of Electronic Resources in July 13). Retrieved July 13, 2019, from htps:// Medical Librarles, 11(1), 39-45. hitps://doi.org/10. web. archive.org/web/
materialise.com/en

Matt, D. T., Rauch, E., \& Dallasega, P. (2015). Trends towards Distributed Manufacturing Systems and Modern Forms for their Design. Procedia
Prince, J. D. (2014). 3D Printing: An Industrial Revolution. [Table]. Reprinted from Journal of Wiklund, M., \& Wilcox, S. (2005). Designing usability Electronic Resources in Medical Libraries, 11(1), into medical products / Michael E. Wiklund, Stephen 39-45. https://doi.org/10.1080/15424065.2014.877 B. Wilcox ; foreword by Matthew B. Weinger. Boca 247

Raton: CRC Press.

Rayna, T., Striukova, L., \& Darlington, J. (2015). Teach, Learn, and Make with Raspberry Pi Co-creation and user innovation: The role of online Raspberry Pi. (n.d.). Retrieved July 13, 2019, from 3D printing platforms. Journal of Engineering and https://web.archive.org/web/20190713003622/ Technology Management, 37, 90-102. https://doi. https://www.raspberrypi.org/

org/10.1016/j.jengtecman.2015.07.002

Redwood, B., Schöffer, F., \& Garret, B. (2017). The 3D printing handbook (1st ed.).

Rhino 6 for Windows and Mac. (n.d.). Retrieved July 13, 2019, from https://web.archive.org web/20190713093320/https://www.rhino3d.com/

Ross, J. S., Lehman, R., \& Gross, C. P. (2012). The importance of clinical trial data sharing: toward more open science. Circulation. Cardiovascular Quality and Outcomes, 5(2), 238-240. https://doi. org/10.1161/CIRCOUTCOMES.112.965798

R, Eric, \& OLPH. (2015, May 1). Experts see revolutionary changes to war with $3 D$ printing.
Retrieved May 17, 2018, from http://www. timesofisrael.com/experts-see-revolutionarychanges-to-war-with-3d-printing/

Scientists design potentially life-saving 3D-printed stethoscope. (2019, July 13). Retrieved July $13, \quad 2019, \quad$ from https://web.archive.org/
web/20190713104550/https://newatlas.com/gliamodel-3d-printed-stethoscope/53811/

Smartphone Ophthalmoscope \& Smartphone retinal camera. (2019, July 13). Retrieved July 13, 2019 , from https/web.artiveb/20190713002634/ http://www.odocs-tech.com/

Shapeways - 3D Printing Service and Marketplace. (n.d). Retrieved May 17, 2018, from https://www. (n.d.). Retrieved

The world's leading software development platform Gittub. (2019, July 13). Retrieved July 13, 2019 from https.//web.archive.org/web/20190713000811 https://github.com/

Therapeutic Products Regulatory Scheme consultation I Ministry of Health NZ. (2019, July 14). Retrieved July 14, 2019, from https://web.archive. org/web/20190714085946/https://www.health.govt. $\mathrm{z} /$ publication/therapeutic-products-regulatorycheme-consultation

Tilley, A., \& Henry Dreyfuss Associates. (1993). The Measure of man and woman: Human factors in design / [compiled by] Alvin R. Tilley; Henry Dreyfuss Associates. New York]: Whitney Library of Design. Treatstock I Smart Manufacturing Platform. (2019 July 13). Retrieved July 13,2019 , from https://web. archive.org/web/20190713002153/https://www. eatstock.com/

isoScope Smartphone Ophthalmoscope \& Smartphone Retinal Camera. (2019, July 13) Retrieved July 13, 2019, from https://web.archive. org/web/20190713014920/http://www.odocs-tech /visoscope/\#

Yang, L., Shen, H., \& Wu, G. (2007). Racia Differences in Respirator Fit Testing: A Pilot Study Thether American Fit Panels are Representative ( Cheses. The Hygene, 51(4), 415-421. annhyg/mem005

Smartphone Ophthalmoscope \& Smartphone retinal Yuri Niyazov, Carl Vogel, Richard Price, Ben (n) http://www.odocs-tech.com/

Lund, David Judd, Adnan Akil, Max Shron. (2016) Open Access Meets Discoverability: Citations to Articles Posted to Academia edu. PLOS ONE,

Smith, P., \& Mortati, M. (2017). Commons people: 11(2), e0148257. https://doi.org/10.1371/journal. additive manufacturing enabled collaborative pone. 0148257

addive manufacturing (by esign). International

Journal of Ropid Manufacturing, $6(2 / 3), 197$. htps://

doi.org/10.1504/IJRAPIDM.2017.082159 
Zhang, J., Johnson, T. R., Patel, V. L., Paige, D. L., \& Kubose, T. (2003). Using usability heuristics to evaluate patient safety of medical devices. Journal of Biomedical Informatics, 36(1), 23-30.
org/10.1016/S1532-0464(03)00060-1

Zhuang, Z., Landsittel, D., Benson, S., Roberge, R., \& Shaffer, R. (2010). Facial anthropometric differences among gender, ethnicity, and age groups. The Annals of Occupational Hygiene, 54(4), 391-402. https://doi.org/10.1093/annhyg/meq007

3D CAD Design Software. (2019, July 13). Retrieved July 13, 2019, from https://web.archive. org/web/20190713093443/https://www.solidworks. com/3D Hubs: Local Manufacturing I 3D Printing
\& CNC Machining. (n.d.). Retrieved May 17, 2018, from https://www.3dhubs.com/

3D Printing Service I Shapeways. (2019, July 13) Retrieved July 13, 2019, from https://web.archive. org/web/20190713001530/https://www.shapeways. $\mathrm{com} /$ 